FELIPE WEIDLICH

Determinação do Impacto de Parâmetros Operacionais de Laminação a Quente no Processo de Degradação de Cilindros pelo Mecanismo de Fadiga Térmica 


\section{FELIPE WEIDLICH}

\section{Determinação do Impacto de Parâmetros Operacionais de Laminação a Quente no}

Processo de Degradação de Cilindros pelo Mecanismo de Fadiga Térmica

\section{Versão Corrigida}

(Versão original encontra-se na unidade que aloja o Programa de Pós-graduação)

Tese apresentada ao Programa de Pós-Graduação em Engenharia Mecânica PPGEM da Escola Politécnica da Universidade de São Paulo para a obtenção do título de Doutor em Ciências.

Área de Concentração: Projeto e Fabricação

Orientador: Prof. Dr. Roberto Martins Souza

São Paulo 
Autorizo a reprodução e divulgação total ou parcial deste trabalho, por qualquer meio convencional ou eletrônico, para fins de estudo e pesquisa, desde que citada a fonte.

Este exemplar foi revisado e corrigido em relação à versão original, sob responsabilidade única do autor e com a anuência de seu orientador.

São Paulo, de de

Assinatura do autor:

Assinatura do orientador:

Catalogação-na-publicação

Weidlich, Felipe

Determinação do Impacto de Parâmetros Operacionais de Laminação a Quente no Processo de Degradação de Cilindros pelo Mecanismo de Fadiga Térmica / F. Weidlich -- versão corr. -- São Paulo, 2019.

$112 \mathrm{p}$.

Tese (Doutorado) - Escola Politécnica da Universidade de São Paulo. Departamento de Engenharia Mecânica.

1.Laminação 2.Fadiga 3.Cilindro I.Universidade de São Paulo. Escola Politécnica. Departamento de Engenharia Mecânica II.t. 


\section{AGRADECIMENTOS}

Ao Prof. Dr. Eng. Roberto Martins Souza por acreditar no potencial do trabalho, por me dar a oportunidade de evoluir profissionalmente e pessoalmente. Exemplo de competência, dedicação e profissionalismo, impressiona sua capacidade de orientar e transferir, com maestria e humildade, seu enorme conhecimento. Meu muito obrigado novamente!

Ao Prof. Dr. Eng. Amilton Sinatora por ter sido a "porta de entrada" para o PPGEM quando no dia de 27 de fevereiro de 2013 respondeu prontamente minha solicitação de contato e então encaminhou-a ao Prof. Roberto.

Ao Prof. Dr. Eng. Mario Boccalini Jr. por possibilitar que o experimento fosse realizado nas instalações do IPT, por ser crítico nas suas observações sempre visando a melhoria do trabalho e também por ser um coautor do artigo que foi publicado no periódico The International Journal of Advanced Manufacturing Technology.

Aos colegas Dra. Enga Ana Paola Villalva Braga e MSc. Eng. Luiz Gustavo Del Biachi da Silva Lima pelo constante apoio, orientação e discussões ao longo destes anos. Também agradeço por terem sido coautores do artigo que foi publicado no periódico The International Journal of Advanced Manufacturing Technology.

A GERDAU por ser uma empresa fantástica que estimula e propicia o desenvolvimento contínuo dos seus profissionais. Me sinto muito orgulhoso e honrado por poder fazer parte desta equipe.

A minha esposa Vanessa e minhas filhas Martina e Rafaela por terem abdicado tempo ao meu lado em prol desta realização pessoal. Vocês são o motivo pelo qual isso tudo foi feito.

Aos meus irmãos Guilherme, Andre e Carlos por serem exemplos que me inspiram e também por serem meus parceiros nesta caminhada. 
A minha mãe Denise Dahlem Weidlich pelo exemplo de dedicação, coragem e perseverança que me guiam até hoje em todos meus desafios profissionais.

Ao meu pai, Eng. Luciano Weidlich por ser um profissional acima da média e o melhor pai do mundo. 


\section{RESUMO}

Este estudo apresenta uma abordagem para a avaliação do impacto de parâmetros operacionais de laminação a quente no processo de degradação da superfície do cilindro pelo mecanismo de fadiga térmica. Foi realizado um planejamento de experimentos (DOE) em um laminador piloto, localizado no Instituto de Pesquisas Tecnológicas de São Paulo (IPT), para avaliar a influência de três parâmetros de laminação a quente na temperatura superficial dos cilindros. São eles: temperatura do material, rotação dos cilindros e redução da altura do passe durante a laminação. $\mathrm{O}$ experimento permitiu a criação de um modelo para determinação da

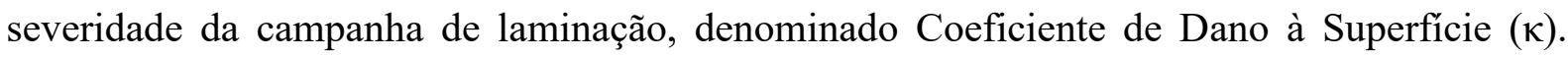
Foram calculadas a temperatura superficial e a profundidade da camada aquecida de vários cilindros de três laminadores industriais e do laminador experimental do IPT. Os dados foram correlacionados com três parâmetros operacionais de laminação a quente e com o Coeficiente de Dano à Superfície $(\kappa)$. Os resultados mostram uma melhor correlação com a temperatura superficial do cilindro do que com a profundidade da camada aquecida. A aplicação do Coeficiente de Dano à Superfície mostrou-se satisfatória como medida de severidade ao dano térmico. Este coeficiente foi então relacionado com o gradiente de deformação plástica que ocorre em cada ciclo térmico para os laminadores industriais, que foram confrontados com valores obtidos através do cálculo numérico, demonstrando coerência e uma possível tendência linear entre o Coeficiente de Dano à Superfície e a deformação plástica total.

Palavras chave: fadiga térmica, temperatura superficial, coeficiente de dano 


\begin{abstract}
This study analyzes the impact of operational parameters in the process of degradation of roll surface by thermal fatigue in rolling mill. A design of experiments (DOE) analysis was run at a reversible pilot-scale hot rolling mill at the Brazilian Institute for Technological Research (IPT), to evaluate the influence of hot rolling parameters on the roll surface temperature. The data were correlated with three operational hot rolling parameters: temperature of material, roll speed and the cross-section reduction during the rolling pass. The experiment allowed the development of a model to determine the severity of the rolling campaign, called Surface Damage Coefficient $(\kappa)$. The roll surface temperature and the heat-penetration depth for each stand, considering three industrial rolling mills and the reversible pilot-scale hot rolling mill at IPT were calculated. The data were correlated with the three hot rolling parameters and with the Surface Damage Coefficient $(\kappa)$. The results show a better correlation with the roll surface temperature than with the heat-penetration depth. The use of the Surface Damage Coefficient was satisfactory as a measure of severity to the thermal damage. A relationship between this coefficient and the total plastic strain of the roll material was established and it was also compared with numerical results using the Finite Element Method (FEM).
\end{abstract}

Keywords: thermal fatigue, surface temperature, damage coefficient 


\section{SUMÁRIO}

\section{LISTA DE FIGURAS}

\section{LISTA DE TABELAS}

LISTA DE SÍMBOLOS

1. INTRODUÇÃ

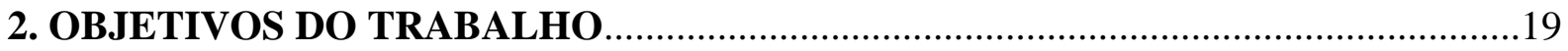

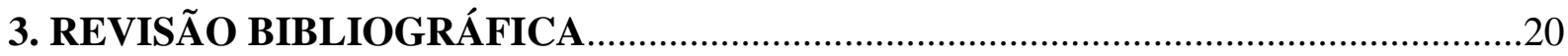

3.1. FORÇAS E RELAÇÕES GEOMÉTRICAS NA LAMINAÇÃO …...............................20

3.2. BALANÇO TÉRMICO DURANTE A LAMINAÇÃO A QUENTE .............................28

3.2.1. Fluxo de Calor no Cilindro Durante a Laminação ........................................................30

3.2.2. Coeficiente de Transferência de Calor na Interface Material-Cilindro...........................44

3.3. A FADIGA TÉRMICA EM CILINDROS DE LAMINAÇÃO .......................................50

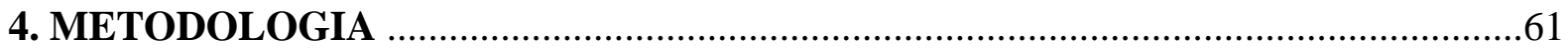

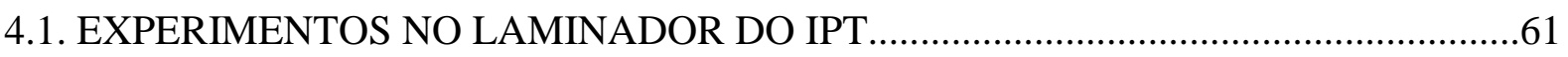

4.2. EXPERIMENTOS NOS LAMINADORES INDUSTRIAIS ........................................66

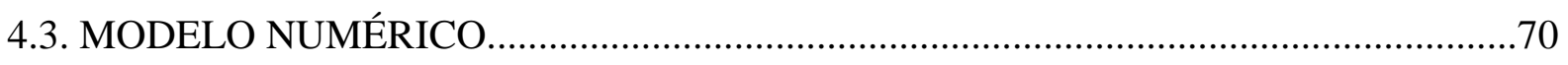

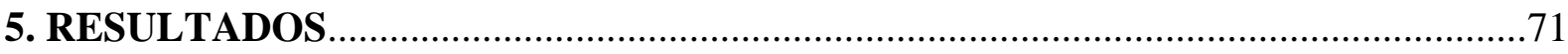

5.1. DETERMINAÇÃO DO MODELO PARA O LAMINDOR DO IPT...............................71

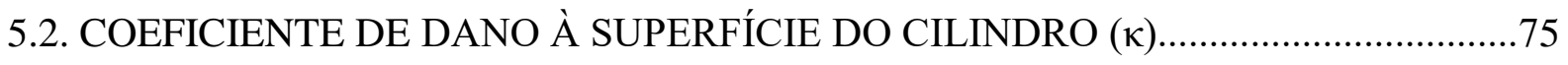

5.3. EQUAÇÃO QUE DESCREVE A CURVA CARACTERÍSTICA PARA OS

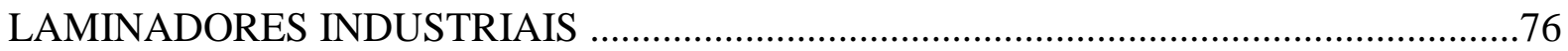

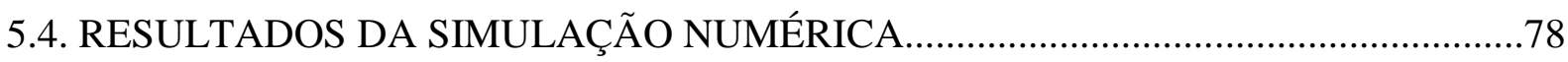

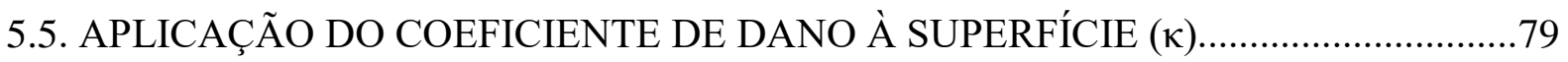

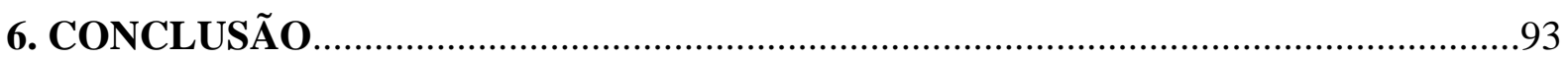

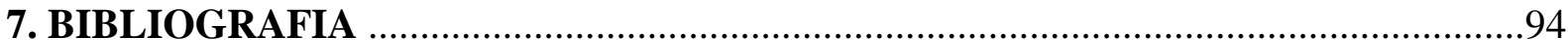

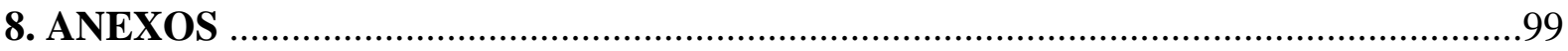




\section{LISTA DE FIGURAS}

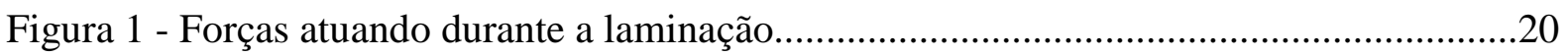

Figura 2 - Distribuição da pressão dos cilindros ao longo do arco de contato..........................22

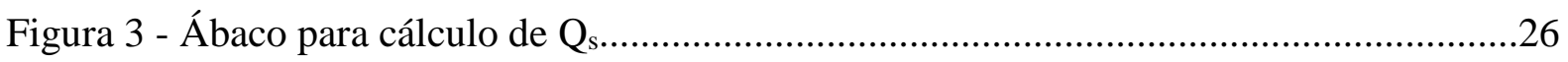

Figura 4 - Comparação gráfica entre a acurácia e precisão dos modelos de cálculo de carga..26

Figura 5 - Balanço térmico durante a laminação...................................................................29

Figura 6 - Esquema que mostra as entradas de calor no cilindro de trabalho...........................31

Figura 7 - Esquema que mostra as saídas de calor no cilindro de trabalho.............................31

Figura 8 - Distribuição interna de temperatura dentro do cilindro de trabalho..........................36

Figura 9 - Distribuição interna de temperatura dentro do cilindro de trabalho..........................37

Figura 10 - Efeito da redução em altura na temperatura superficial do cilindro e efeito da

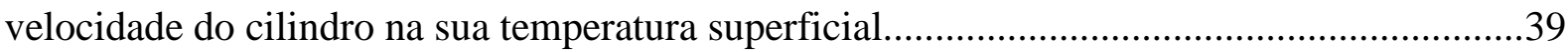

Figura 11 - Resposta térmica para um cilindro nas dez primeiras revoluções...........................40

Figura 12 - Esquema que mostra a zona térmica e sua espessura...........................................40

Figura 13. Diferença da temperatura normalizada vs. Coeficiente de proporcionalidade de espessura da fina camada superficial

Figura 14 - Relações entre os parâmetros de laminação e a profundidade da camada aquecida e temperatura superficial dos cilindros

Figura 15 - Relação entre o coeficiente de transferência de calor e a temperatura superficial do cilindro

Figura 16 - Variação do coeficiente de transferência de calor na região do arco de contato...45 Figura 17 - Relação entre o coeficiente de transferência de calor na interface e a pressão média de contato do cilindro.

Figura 18 - Influência da espessura da camada de óxido no coeficiente de transferência de calor no momento da mordida do material pelos cilindros

Figura 19 - Desenvolvimento de tensões térmicas compressivas na superfície do cilindro de laminação.

Figura 20 - Variação da temperatura do cilindro de laminação durante o primeiro ciclo/revolução.

Figura 21 - Desenvolvimento da histerese de tensão-deformação para a superfície de um cilindro de laminação a quente. 
Figura 22 - Tensões e deformações durante o ciclo térmico entre temperaturas T1 e T2 (T1 < $\mathrm{T} 2)$

Figura 23 - Efeito da temperatura máxima de aquecimento (amplitude do ciclo térmico) no tempo necessário para a nucleação de trincas por fadiga térmica.

Figura 24 - Deformações típicas para o material QRO90 durante o ciclo térmico com resfriamento em ar à temperatura ambiente para as temperaturas máximas de $600^{\circ} \mathrm{C}$ (a), $700^{\circ} \mathrm{C}$, (b) e $850^{\circ} \mathrm{C}(\mathrm{c})$ .58

Figura 25 - Relação entre velocidade dos cilindros de laminação e o dano plástico acumulado.

Figura 26 - Relação entre temperatura do material laminado e o dano plástico acumulado....59

Figura 27 - Laminador em escala piloto instalado no IPT. 61

Figura 28. Amostras utilizadas no experimento e diferença da qualidade superficial das amostras ensaiadas .62

Figura 29. Planejamento do experimento Full Factorial .64

Figura 30 - Perfil de temperatura durante o ciclo térmico .64

Figura 31 - Layout do laminador industrial \#1

Figura 32 - a) visão geral de uma gaiola de laminação do trem contínuo b) esquema que mostra o que é considerado como sendo o canal de laminação de um cilindro "mesa lisa"....66 Figura 33 - Layout do laminador industrial \#2.

Figura 34 - Layout do laminador industrial \#3.

Figura 35 - Descrição e detalhe da malha de elementos finitos dos modelos bidimensionais..70

Figura 36 - Gráfico de Pareto dos efeitos para a temperatura superficial do cilindro...... .73

Figura 37 - Gráfico de efeitos principais para a temperatura superficial do cilindro...............73

Figura 38 - Gráfico de interações para a temperatura superficial do cilindro. .74

Figura 39 - Comparação das curvas temperatura superficial do cilindro versus tempo de contato .77

Figura 40 - Gráficos tensão-deformação para os laminadores industriais.. 78

Figura 41 - Relação entre a temperatura do material $(\mathrm{Tm})$ e as respectivas respostas $(\delta$ e $\left.\mathrm{Tc}_{\mathrm{s}}\right)$.

Figura 42 - Relação entre a rotação dos cilindros de laminação (U) e as respectivas respostas $(\delta$ e Tcs $)$ .80

Figura 43 - Relação entre a redução em altura $(\Delta h)$ e as respectivas respostas ( $\delta$ e Tcs). 81 
Figura 44 - Relação do coeficiente de dano à superfície do cilindro $(\kappa)$ e a profundidade da camada aquecida.

Figura 45 - Relação do coeficiente de dano à superfície do cilindro $(\kappa)$ e a temperatura superficial do cilindro.

Figura 46 - Condição superficial dos canais de laminação das gaiolas \#1, \#3 e \#5 do laminador \#1. .84

Figura 47 - Evolução da superfície do cilindro da gaiola \#8 após a campanha de laminação do laminador \#2. .85

Figura 48 - Evolução da superfície do cilindro da gaiola \#6 após a campanha de laminação do laminador \#2.

Figura 49 - Superfície dos cilindros após as campanhas de laminação utilizando-se lingotes 134, 544 e 574 no laminador \#3

Figura 50 - Superfície do cilindro após as campanhas de laminação no laminador piloto do IPT. a) cilindro antes da laminação, b) após 4544 ciclos térmicos e c) após 6754 ciclos térmicos . .88

Figura 51 - Relação entre a deformação plástica total e o coeficiente de dano à superfície do cilindro. 


\section{LISTA DE TABELAS}

Tabela 1 - Experimento realizado no laminador piloto do IPT...........................................63

Tabela 2 - Informações sobre os diferentes tipos de lingotes utilizados na avaliação da gaiola

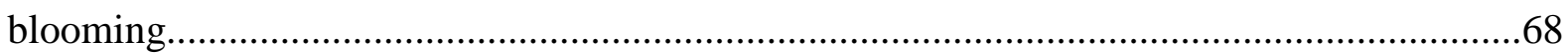

Tabela 3 - Laminadores e gaiolas estudadas com parâmetros de laminação calculados e temperatura do material medida pelo termômetro infravermelho.............................................69

Tabela 4 - Resultados do experimento realizado no laminador piloto do IPT.........................72

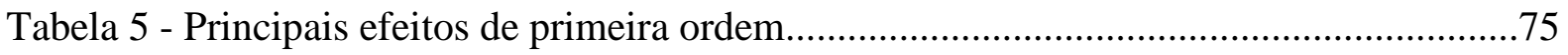

Tabela 6 - Equações das curvas características dos laminadores estudados............................78

Tabela 7 - Resultados calculados para os laminadores estudados.......................................79

Tabela 8 - Informações das campanhas de laminação avaliadas.............................................84

Tabela 9 - Kappa calculado para os 5 passes de laminação do estudo de Lima [40]................88 


\section{LISTA DE SÍMBOLOS}

$h_{o} \quad$ espessura inicial do material

$h_{f} \quad$ espessura final do material

$v_{o} \quad$ velocidade inicial do material

$v_{f} \quad$ velocidade final do material

$v_{c i l} \quad$ velocidade nominal dos cilindros

$v_{w} \quad$ velocidade do fluxo d'água

$v_{t} \quad$ velocidade tangencial

$\omega$ velocidade angular do cilindro

$b$ largura do material

$b_{0} \quad$ largura da barra antes de ser conformada pelos cilindros

$l_{0} \quad$ comprimento da barra antes de ser conformada pelos cilindros

$P$ força ou carga de laminação

$P_{r} \quad$ força ou carga de laminação

$F \quad$ força tangencial de atrito

p pressão específica

$L_{p} \quad$ arco de contato

$R \quad$ raio do cilindro de trabalho

$r \quad$ grau de redução do material

$\alpha \quad$ ângulo de contato

$\beta \quad$ ângulo do ponto neutro

$\theta \quad$ ângulo à algum ponto da superfície de contato

$\Delta h \quad$ redução em altura de laminação

$\mu \quad$ coeficiente de atrito

$v \quad$ coeficiente ou módulo de Poisson

E módulo de elasticidade

$Q \quad$ fator geométrico

$\sigma_{0}$ tensão de escoamento do material

$U$ rotação dos cilindros de laminação 
$t$ tempo de aplicação da deformação ou tempo de contato

$T c_{S} \quad$ temperatura da superfície do cilindro

$T c_{0} \quad$ temperatura a uma distância abaixo da superfície do cilindro (núcleo)

Tm temperatura do material que está sendo laminado

$\mathrm{Ta}$ temperatura ambiente

$T_{S}^{*} \quad$ temperatura que depende de propriedades físicas do material do cilindro

$T w \quad$ temperatura da água de refrigeração do cilindro

$h_{d} \quad$ coeficiente de transferência de calor na interface cilindro-material

$\lambda_{\text {cil }} \quad$ condutividade térmica do cilindro

$\lambda_{\text {mat }} \quad$ condutividade térmica do material

$\xi_{c i l} \quad$ difusividade térmica do cilindro

$\xi_{\text {mat }}$ difusividade térmica do material

$\rho_{\text {mat }}$ densidade do material

$\rho_{\text {cil }} \quad$ densidade do cilindro

$C p_{\text {mat }}$ calor específico do material

$C p_{c i l} \quad$ calor específico do cilindro

$m \quad$ massa específica do material laminado

$G \quad$ massa do material laminado

$\Delta T_{c i l}$ aumento de temperatura do cilindro devido à condução de calor pelo material

$\gamma \quad$ coeficiente de expansão térmica

$\gamma_{c i l} \quad$ coeficiente de expansão térmica do cilindro

$\varepsilon \quad$ deformação efetiva do material

$\varepsilon_{h} \quad$ deformação homogênea do material

$\dot{\varepsilon} \quad$ taxa de deformação do material

$\varepsilon_{e} \quad$ deformação elástica

$\varepsilon_{p} \quad$ deformação plástica

$\varepsilon_{t} \quad$ deformação total

$\Delta \varepsilon_{p} \quad$ amplitude de deformação plástica 


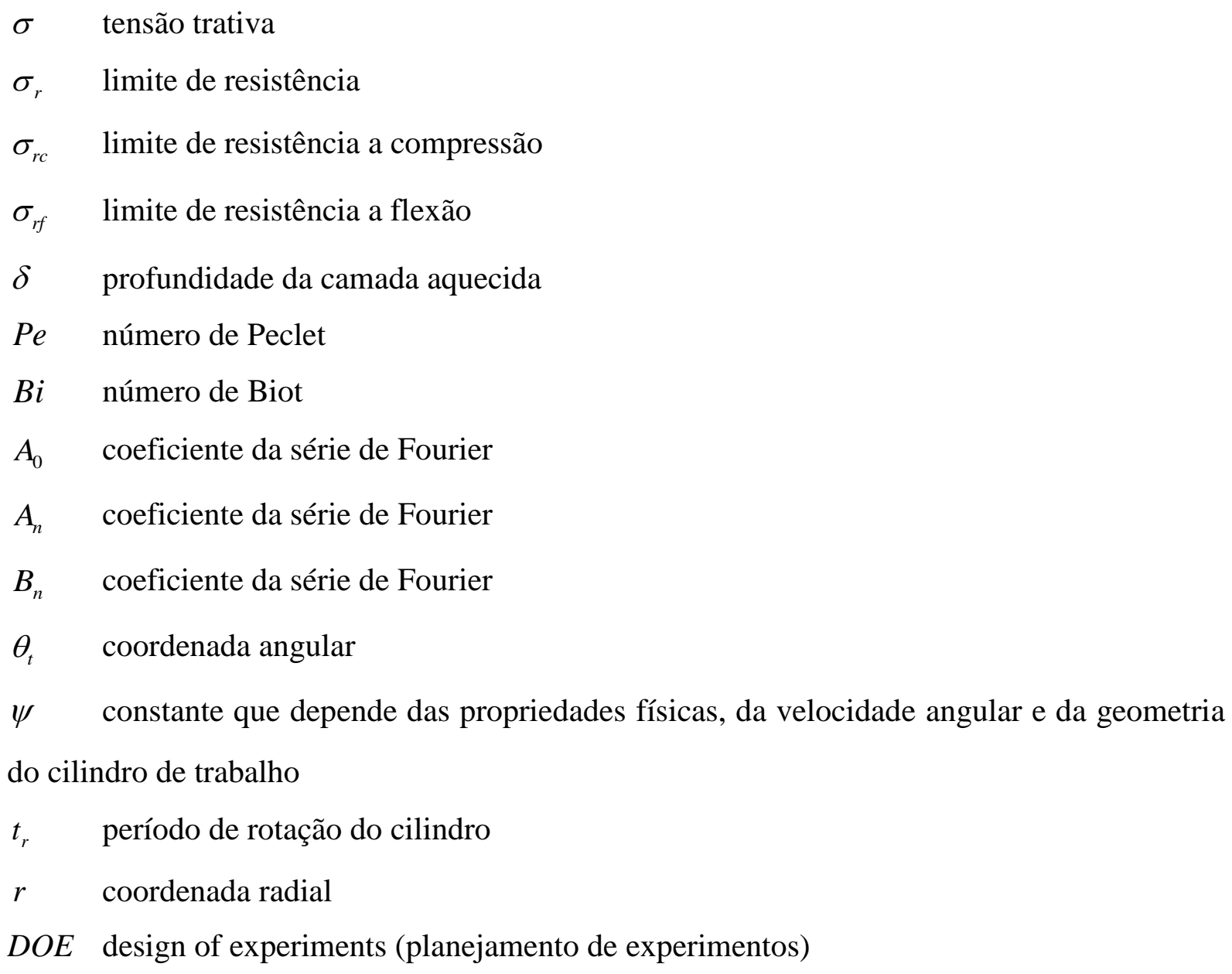




\section{INTRODUÇÃ̃}

O processo de laminação a quente possui grande importância no cenário siderúrgico mundial. Segundo o Instituto Aço Brasil, em 2016 a produção de aço bruto no Brasil foi de 31,3 milhões de toneladas e, deste total, 30,2 milhões de toneladas foram transformadas em produtos siderúrgicos [1]. A Associação Brasileira de Metalurgia, Materiais e Mineração (ABM) publicou no seu último Estudo Prospectivo do Setor Siderúrgico, em 2008, que da produção siderúrgica mundial, considerando os processos de fundição, lingotamento convencional e lingotamento contínuo, $92,8 \%$ foi posteriormente laminado a quente para diversas aplicações [2]. Vários são os itens que compõem o custo operacional de um laminador a quente: gases para o forno de reaquecimento, energia elétrica, máquinas e ferramentas, pessoas, etc. Estes custos podem variar de acordo com o projeto do laminador e com o seu respectivo regime de operação. Os cilindros de laminação podem representar até $10 \%$ do custo operacional [3].

O processo de laminação a quente envolve pressões e temperaturas elevadas. Vários tipos de aço são laminados com temperaturas próximas a $1100^{\circ} \mathrm{C}$ e pressões que podem atingir $300 \mathrm{MPa}$. Esta condição operacional produz tensões de magnitude suficiente para causar desgaste e a propagação de trincas no cilindro de laminação. A degradação da superfície do cilindro gradualmente afetará a qualidade superficial do material laminado, comprometendo sua fabricação. Este desgaste também diminuirá a vida útil do cilindro, sendo comum a prática de usinagem de sua superfície para correção dimensional e eliminação de trincas térmicas.

As condições térmicas num cilindro de laminação a quente são consideradas um problema complexo, devido ao grande número de interações que ocorrem em sua superfície durante o trabalho. O coeficiente de transferência de calor $\left(h_{d}\right)$ é de difícil determinação, uma vez que vários são os fatores que influenciam na troca de calor entre o material laminado e o cilindro de laminação. A dificuldade para a exata determinação do valor para o coeficiente de transferência de calor $\left(h_{d}\right)$ está na consideração dos fatores que serão avaliados e ou medidos. Benasciutti et al. [4] utilizaram valores entre 10 e $40 \mathrm{~kW} / \mathrm{m}^{2} \mathrm{~K}$ no seu modelo numérico. Já Phaniraj et al. [5] utilizaram valores entre 2 e $200 \mathrm{~kW} / \mathrm{m}^{2} \mathrm{~K}$ para a troca de calor no momento do agarre do material pelos cilindros. Zhou [6] aplicou valores entre 0 e $450 \mathrm{~kW} / \mathrm{m}^{2} \mathrm{~K}$ para o coeficiente de transferência de calor em seu modelo numérico. Wright [7] inicialmente 
utilizou em seu modelo numérico um valor de $24 \mathrm{~kW} / \mathrm{m}^{2} \mathrm{~K}$ para o coeficiente de transferência de calor durante o processo de laminação.

O coeficiente de transferência de calor é um parâmetro de extrema importância para a análise térmica dos cilindros de laminação. Existem, entretanto, várias abordagens diferentes que contemplam especificidades de cada estudo e simulação. Os laminadores são equipamentos que, em sua grande maioria, podem ser considerados projetos exclusivos que possuem características de processo únicas. Adiciona-se a este fato a necessidade da determinação do coeficiente de transferência de calor para cada uma das etapas onde existe troca de calor durante o processo de laminação. Por exemplo: radiação e convecção livre do material laminado com o ar após a saída do forno de reaquecimento, convecção forçada e condução no momento da descarepação do material laminado antes do primeiro passe de laminação, condução no momento do agarre do material laminado pelos cilindros, convecção forçada e condução no momento do resfriamento dos cilindros pelo sistema de refrigeração da gaiola de laminação e etc.

A superfície de um cilindro de laminação a quente está sujeita a efeitos combinados de três fenômenos mecânicos, que podem ser considerados separadamente. São eles: tensões térmicas devido à restrição à contração e expansão do material, tensões residuais produzidas durante a fabricação do cilindro e tensões mecânicas oriundas da conformação do material, ou seja, da redução de seção transversal. Durante o processo de laminação, ocorre grande alternância entre os estados de tração e compressão na superfície do cilindro. É possível mostrar por meio de simulação pelo método de elementos finitos (FEM) que as tensões atingem valores na ordem de 500 à $1000 \mathrm{MPa}$, oriundos da variação de temperatura na superfície do cilindro durante o processo de laminação [4]. Para os esforços mecânicos de conformação, que podem variar significativamente em função da geometria da seção transversal da barra, da taxa de redução do material e da temperatura de laminação, encontram-se tensões na ordem de 50 a $150 \mathrm{MPa}$ [8]. Uma das principais causas de sua degradação é a fadiga térmica, que, neste contexto, geralmente possui uma maior importância que a fadiga provocada pelos esforços mecânicos [7].

Atualmente, as grandes siderúrgicas utilizam controles empíricos de vida útil para os cilindros de laminação a quente, onde a única variável avaliada é a tonelagem produzida. Os cilindros de laminação possuem um processo de fabricação complexo e têm custo razoavelmente alto, mesmo para os padrões da siderurgia. É importante, dentro deste 
contexto, conhecer detalhadamente quais são as condições operacionais de laminação que potencializam o desgaste prematuro da superfície do cilindro, comprometendo, desta forma, sua utilização. Com este conhecimento pode ser possível a modificação das estratégias de usinagem dos cilindros, maximizando sua vida útil e reduzindo, desta forma, custos com a aquisição de novas peças. 


\section{OBJETIVOS DO TRABALHO}

Diversos autores $[4,6,7,8,9]$ apresentaram modelos que descrevem o comportamento térmico no cilindro utilizando-se o método de elementos finitos (FEM). Estes modelos são, entretanto, específicos e aplicados sob condições particulares, o que muitas vezes dificulta sua rápida aplicação no ambiente industrial.

O ciclo térmico equivalente ao aquecimento e posterior resfriamento da superfície do cilindro, durante a laminação a quente, pode ser responsável pela deformação plástica e consequente degradação da superfície do cilindro. Existem, entretanto, inúmeros fatores que influenciam este balanço térmico.

São objetivos gerais deste trabalho:

$\checkmark$ Tornar claro para o engenheiro de laminação quais são os principais influenciadores (parâmetros críticos) no comportamento térmico do cilindro de laminação;

$\checkmark$ Apresentar resultados dos cálculos para temperatura superficial dos cilindros $\left(\mathrm{Tc}_{\mathrm{s}}\right)$ e para espessura da camada aquecida $(\delta)$, obtidos através de observação em laminadores industriais, corroborando assim, com teorias já desenvolvidas;

$\checkmark$ Criar um modelo capaz de auxiliar o engenheiro de laminação na avaliação do impacto dos parâmetros operacionais de laminação a quente no processo de degradação da superfície do cilindro pelo mecanismo de fadiga térmica.

São objetivos específicos deste trabalho:

$\checkmark$ Determinar modelo matemático capaz de predizer a temperatura superficial dos cilindros do laminador do IPT, utilizando-se apenas os parâmetros de laminação, através de análise de regressão;

$\checkmark$ Determinar modelos matemáticos para estimativa da temperatura superficial dos cilindros para os laminadores industriais estudados; 


\section{REVISÃo BIBLIOGÁFICA}

\subsection{FORÇAS E RELAÇÕES GEOMÉTRICAS NA LAMINAÇÃO}

A laminação é um processo de conformação mecânica que consiste na passagem de um corpo sólido (peça) entre dois cilindros (ferramentas) que giram a mesma velocidade periférica, mas giram em sentidos contrários [10]. Desta forma, tendo o corpo da peça inicial uma dimensão maior do que a distância entre as superfícies laterais dos cilindros, ele sofre uma deformação plástica na passagem entre os cilindros que resulta na redução de sua secção transversal e no aumento do seu comprimento e largura [10]. A laminação é o processo de transformação mecânica mais utilizado na prática $[1,2]$, porque apresenta uma alta produtividade e um controle dimensional do produto acabado que pode ser bastante preciso. $\mathrm{Na}$ laminação, o material é submetido a elevadas tensões compressivas, resultantes da pressão dos cilindros, e a tensões superficiais de cisalhamento, resultantes do atrito entre os cilindros e o material [11]. A Figura 1 ilustra um número de relações importantes entre a geometria dos cilindros e as forças envolvidas na deformação por laminação.

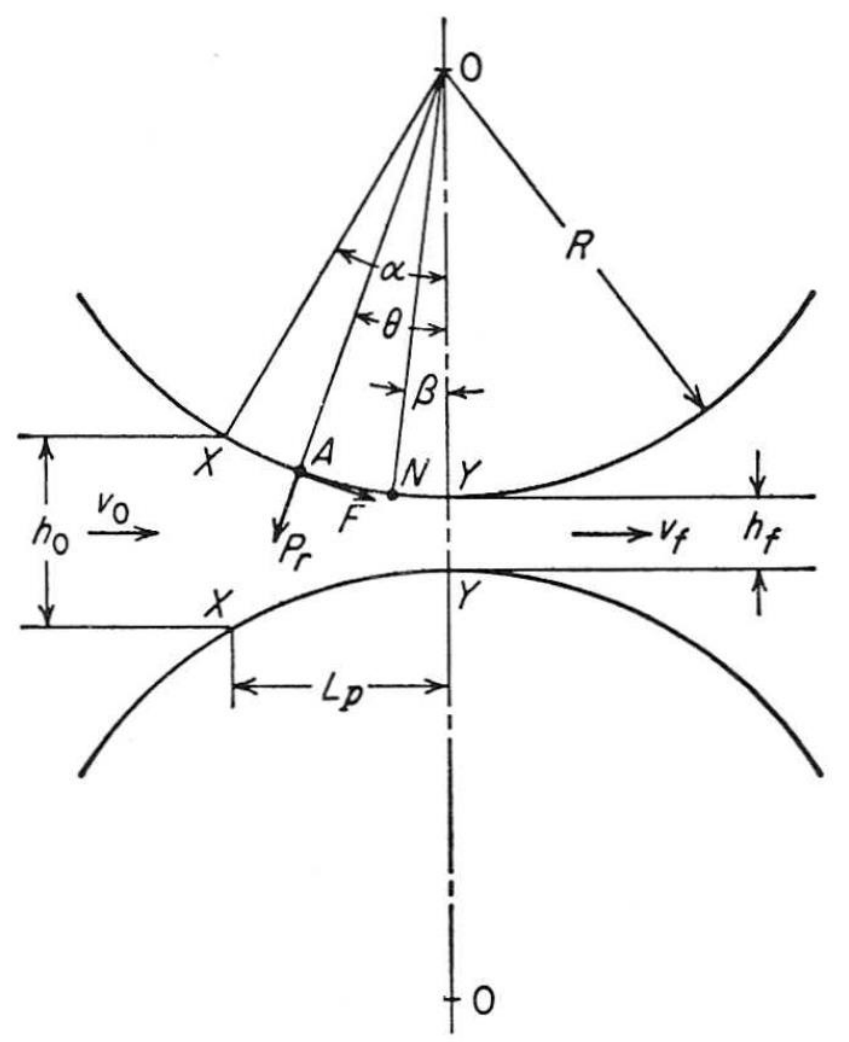

Figura 1. Forças atuando durante a laminação [11]. 
Uma chapa metálica com espessura ho entra no laminador no plano de entrada $\mathrm{XX}$ com uma velocidade $v_{0}$. Ela passa pela abertura do laminador e deixa o plano de saída YY com a espessura reduzida para $\mathrm{h}_{\mathrm{f}}$. Em uma primeira aproximação, não ocorre qualquer aumento na largura, de maneira que a compressão vertical do metal é transformada em um alongamento na direção de laminação. Considerando que o volume de um sólido permanece constante durante a deformação plástica [11] e uma vez que volumes iguais do metal devem passar em um dado ponto por unidade de tempo, pode-se escrever:

$$
b h_{o} v_{o}=b h v=b h_{f} v_{f}
$$

onde b é a largura da chapa e $v$ é a sua velocidade em qualquer espessura intermediária entre $\mathrm{h}_{0} \mathrm{e} \mathrm{h}_{\mathrm{f}}$. A fim de que cada elemento vertical na chapa não sofra distorção, a equação (1) indica que a velocidade de saída $v_{\mathrm{f}}$ deve ser maior que a velocidade de entrada $v_{0}$. Por isso, a velocidade da placa deve crescer continuamente da entrada para a saída. Somente em um ponto ao longo da superfície de contato entre o cilindro e a placa a velocidade superficial do cilindro $v_{\text {cil }}$ é igual à velocidade da placa. Esse ponto é conhecido como ponto neutro ou ponto sem deslizamento, sendo $\beta$ o ângulo do ponto neutro. Esse ponto está indicado na Figura 1 pela letra N. Em qualquer ponto ao longo da superfície de contato, tal como no ponto A, duas forças atuam no material, sendo $\theta$ o ângulo deste ponto. Essas forças são a força radial $P_{r}$ e a força tangencial de atrito F. Entre o plano de entrada e o ponto neutro, a placa se move mais lentamente que a superfície do cilindro, e a força de atrito atua na direção mostrada na Figura 1, de maneira que empurra o metal para os cilindros. Na região depois do ponto neutro até o plano de saída a placa se move mais rapidamente que a superfície do cilindro. A direção da força de atrito é agora reversa, de maneira que atua contrária à saída do material dos cilindros. A componente normal $P_{r}$ é conhecida como a carga de laminação P. A carga de laminação é a força com a qual os cilindros comprimem o material e, por ser também igual à força exercida pelo material na tentativa de forçar os cilindros a se afastarem, é frequentemente conhecida como força de separação. A pressão específica dos cilindros p é a carga de laminação dividida pela área de contato. A área de contato entre o material e os cilindros é igual ao produto da largura da placa b pelo comprimento projetado do arco de contato $\mathrm{L}_{\mathrm{p}}$ [11]. 


$$
L_{p}=\left[R\left(h_{o}-h_{f}\right)-\frac{\left(h_{o}-h_{f}\right)^{2}}{4}\right]^{1 / 2} \approx\left[R\left(h_{o}-h_{f}\right)\right]^{1 / 2}
$$

Desta forma, a pressão específica dos cilindros é dada por:

$$
p=\frac{P}{b L_{p}}
$$

A distribuição da pressão dos cilindros ao longo do arco de contato está indicada na Figura 2. A pressão atinge um máximo no ponto neutro. A área abaixo da curva é proporcional à carga de laminação que, para fins de cálculo, atua no centro de gravidade da distribuição de pressão. Por isso, a forma da distribuição de pressão é importante porque a localização da carga de laminação resultante, com respeito ao centro dos cilindros, determina o torque e a potência requerida para produzir a redução [11].

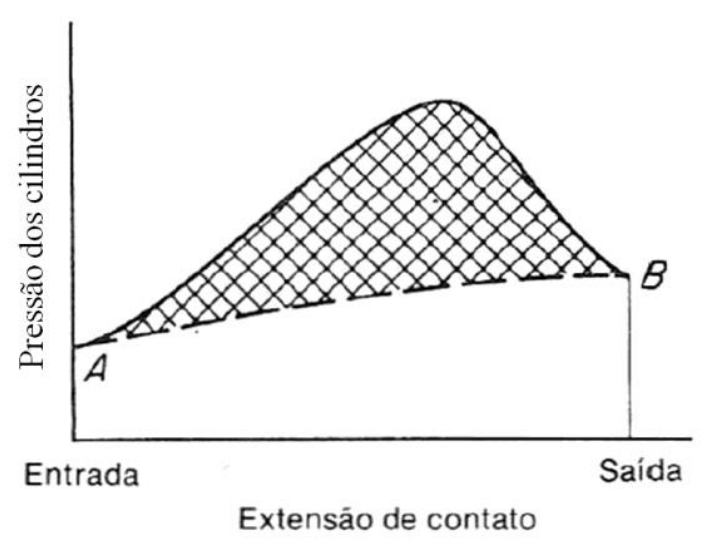

Figura 2. Distribuição da pressão dos cilindros ao longo do arco de contato [11].

A área hachurada na Figura 2 representa a força necessária para superar as forças de atrito entre o cilindro e o material, enquanto que a área abaixo da linha pontilhada $\mathrm{AB}$ representa a força necessária para deformar o material no plano de compressão homogêneo. $\mathrm{O}$ ângulo entre o plano de entrada e a linha de centro dos cilindros é chamado de ângulo de contato, ou ângulo de ataque $\alpha$. Referindo-se à Figura 1, a componente horizontal da força normal é $\left(\mathrm{P}_{\mathrm{r}} \operatorname{sen} \alpha\right)$, e a componente horizontal da força de atrito é (F $\left.\cos \alpha\right)$. Para a peça entrar na zona de agarre dos cilindros, a componente horizontal da força de atrito, que atua na 
direção da abertura dos cilindros, deve ser igual ou maior que a componente horizontal da força normal, que atua para o lado oposto da abertura dos cilindros. A condição limite para o material entrar entre os cilindros é

$$
\begin{aligned}
& F \cos \alpha=P_{r} \sin \alpha \\
& \frac{F}{P_{r}}=\frac{\sin \alpha}{\cos \alpha}=\tan \alpha
\end{aligned}
$$

como

$$
F=\mu P_{r}
$$

então

$$
\mu=\tan \alpha
$$

A peça não pode ser puxada pelos cilindros se a tangente do ângulo de contato for maior que o coeficiente de atrito. Se $\mu=0$, a laminação não pode ocorrer, mas conforme $\mu$ aumenta, placas cada vez mais grossas podem ser puxadas para a região de agarre dos cilindros [11]. Dieter [11] inicia suas definições com base na compressão homogênea de um disco plano e define o coeficiente de atrito coulombiano (atrito devido ao escorregamento na interface) em termos de tensões. De acordo com esta definição, o coeficiente de atrito cai à medida que a pressão aumenta. Isso se opõe à realidade e pode levar a interpretações errôneas dos valores tabeldos de $\mu$. Por outro lado, a definição do coeficiente de atrito como sendo a razão entre a resistência de cisalhamento na interface e a tensão cisalhante limite de escoamento tem sido crescentemente utilizada para descrever o atrito nos processos de conformação (especialmente nos processos que envolvem grandes deformações, como é o caso da laminação a quente).

Para as mesmas condições de atrito, um laminador com cilindros de grande diâmetro permitirá a laminação de placas mais grossas do que um laminador com cilindros de pequeno diâmetro. Esta diferença é devida aos comprimentos dos arcos de contato serem apreciavelmente diferentes, uma vez que o ângulo formado pelo centro dos cilindros e o plano de entrada será o mesmo em ambos os $\operatorname{casos}(\tan \alpha)$, conforme equação (2). Reportando à Figura 1, pode-se escrever a equação (2) como: 


$$
L_{p} \approx \sqrt{R \Delta h}
$$

onde $\Delta \mathrm{h}$ é a redução em altura na laminação. Das relações geométricas da Figura 1, pode-se obter:

$$
\tan \alpha=\frac{L_{p}}{R-\Delta h / 2} \approx \frac{\sqrt{R \Delta h}}{R-\Delta h / 2} \approx \sqrt{\frac{\Delta h}{R}}
$$

Conforme definido na equação (4), e considerando as condições para que seja possível o agarre do material pelos cilindros, é possível determinar que o coeficiente de atrito deva ser maior ou igual à tangente do ângulo de contato:

$$
\begin{gathered}
\mu \geq \tan \alpha=\sqrt{\Delta h / R} \\
(\Delta h)_{\max }=\mu^{2} R
\end{gathered}
$$

As forças geradas na laminação são transmitidas ao material para permitir sua deformação entre os cilindros. Sob essas condições de carregamento, existem dois tipos importantes de deformação elástica. Primeiro, os cilindros tendem a fletir, pois o material tende a separá-los e eles estão limitados nos seus extremos. Segundo, os cilindros deformamse na região onde eles fazem contato com o material, de maneira que o raio de curvatura aumenta de R para R'. A análise usualmente utilizada para avaliação deste fenômeno foi desenvolvida por Hitchcock [12], que representou a distribuição real de pressões com a deformação elástica dos cilindros por uma distribuição elíptica. De acordo com essa análise, o raio de curvatura aumenta de $\mathrm{R}$ para $\mathrm{R}$ ' seguindo a equação abaixo:

$$
R^{\prime}=R\left[1+\frac{C P}{b\left(h_{0}-h_{f}\right)}\right]
$$

onde

$$
C=\frac{16\left(1-v^{2}\right)}{\pi E}
$$


$v$ é o coeficiente de Poisson e E é o módulo de elasticidade do material do cilindro. A carga de laminação P pode então ser definida como:

$$
P=\frac{2}{\sqrt{3}} \sigma_{0}\left[\frac{1}{Q}\left(e^{Q}-1\right) b \sqrt{R \Delta h}\right]
$$

onde $\sigma_{0}$ é a tensão de escoamento do material na temperatura de laminação e $2 / \sqrt{3}$ tem sua origem no fato de que a laminação com o cilindro achatado é um estado plano de deformação, de maneira que a tensão de escoamento deve ser a tensão de escoamento no estado plano de deformações [11]. Alguns pesquisadores propuseram, com base na equação (9), diferentes interpretações para o fator geométrico Q e, consequentemente, equações diferentes para o cálculo da carga de laminação, modificando o que havia sido pioneiramente proposto por Ekelund [13] em 1933.

Ekelund [13]

$$
Q_{e}=1+\frac{1,6 \mu L_{p}-1,2 \Delta h}{h_{0}-h_{f}}
$$

Orowan-Pascoe [14]

$$
Q_{p}=\frac{1}{4}\left[\pi \sqrt{\frac{R}{h_{f}}\left(\frac{\Delta h}{h_{f}}\right)}\right]
$$

Sims [15] utiliza um ábaco para o cálculo de $\mathrm{Q}_{\mathrm{s}}$ conforme pode ser visto na Figura 3. 


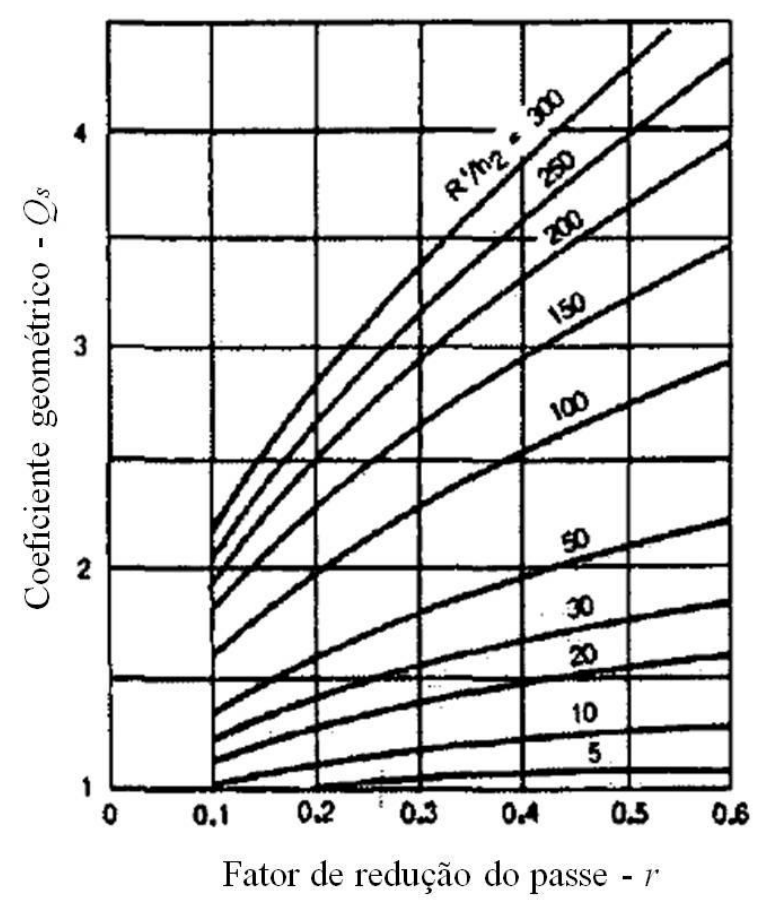

Figura 3. Ábaco para cálculo de $Q_{s}[15]$.

Avaliando-se a equação (9) pode-se concluir que os métodos para cálculo da força de laminação variam exclusivamente devido às diferentes formas de calcular o fator geométrico Q. Gorni et al. [16] fizeram um estudo comparativo de modelos para cálculo da carga de laminação e encontraram uma correlação razoável entre a carga real e o método de OrowanPascoe [14], conforme pode ser visto na Figura 4.

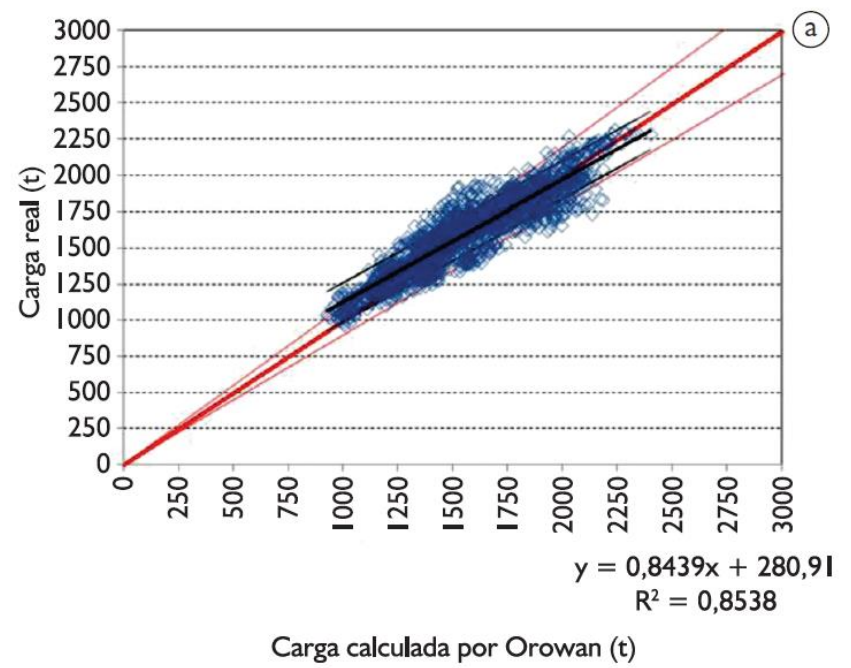

Figura 4. Comparação gráfica entre a acurácia e precisão dos modelos de cálculo de carga [16]. 
O tempo de aplicação da deformação é aproximadamente igual ao tempo necessário para que o cilindro se mova de um deslocamento angular $\alpha$, como mostrado na Figura 1, e também conhecido como ângulo de contato. Nota-se que o deslocamento angular $\alpha$ coincide com os pontos de entrada e saída do material [17]. Desta forma, o tempo pode ser equacionado por:

$$
t=\frac{\alpha}{2 \pi} \frac{60}{U}
$$

sendo $\alpha$ o ângulo de contato em radianos, definido na equação (4), e U é a rotação dos cilindros em rpm. A taxa de deformação do material $\dot{\varepsilon}$ pode ser definida como sendo a razão entre a deformação no passe de laminação E pelo tempo de aplicação da deformação t [17].

$$
\dot{\varepsilon}=\frac{d \varepsilon}{d t}
$$

Levando em consideração as espessuras de entrada e saída, a deformação efetiva do material $\varepsilon$ é a deformação homogênea $\varepsilon_{\mathrm{h}}$ multiplicada pelo critério de von Mises $(2 / \sqrt{3})$ [17]:

$$
\begin{gathered}
\varepsilon=\frac{2}{\sqrt{3}} \varepsilon_{h} \\
\varepsilon=\frac{2}{\sqrt{3}} \ln \left(\frac{h_{0}}{h_{f}}\right)
\end{gathered}
$$

Substituindo-se as equações (12) e (15) na equação (13), tem-se então a taxa de deformação efetiva do material durante o passe, dada por:

$$
\dot{\varepsilon}=\frac{\pi \sqrt{3} U}{45 \alpha} \ln \left(\frac{h_{0}}{h_{f}}\right)
$$




\subsection{BALANÇO TÉRMICO DURANTE A LAMINAÇÃO A QUENTE}

A previsão da temperatura do material que está sendo laminado é parte essencial na tecnologia de laminação. O uso de modelos matemáticos capazes de realizar tais previsões é desejável não somente para melhorar a eficiência da laminação (por exemplo, minimizar o número de passes em um laminador reversível), mas também para se atingir as propriedades mecânicas e as dimensões desejadas do produto final.

Em todas as etapas da laminação a quente, a temperatura do laminado varia com o tempo, o que caracteriza um problema transiente de transferência de calor [19]. O fato do material estar em movimento durante todo o processo torna este problema igualmente dinâmico. Estes aspectos reforçam a importância de se conhecer e dominar aspectos relacionados ao projeto do laminador e sua respectiva calibração (sequência de passes) para o produto laminado. Cabe salientar a influência das particularidades de cada laminador no cálculo e previsão da temperatura da peça laminada. As validações de modelos capazes de predizer estas temperaturas são feitas com medições experimentais e cálculos numéricos utilizando-se conceitos de transferência de calor.

Em muitos processos de laminação, a temperatura do cilindro de trabalho é controlada por sistemas de refrigeração nos quais água é projetada sobre a superfície do canal de laminação. Isso se torna necessário para manter a temperatura do cilindro dentro de uma faixa especificada, garantindo assim a sua operacionalidade [18].

Considerando-se que cada laminador possui um projeto específico, para cada passe do seu projeto de calibração, e para cada produto, existirá uma temperatura específica para o material em questão. Analogamente, para cada cilindro em cada passe de laminação, haverá uma temperatura superficial específica, que acarretará deformações elásticas e/ou plásticas e consequentemente limitará a vida da ferramenta à um determinado número de ciclos. Diante desta complexidade, é importante o conhecimento dos fenômenos térmicos que ocorrem durante o processo de laminação e que serão discutidos com mais detalhes nos capítulos subsequentes.

De forma geral o balanço térmico pode ser resumido pela Figura 5. 


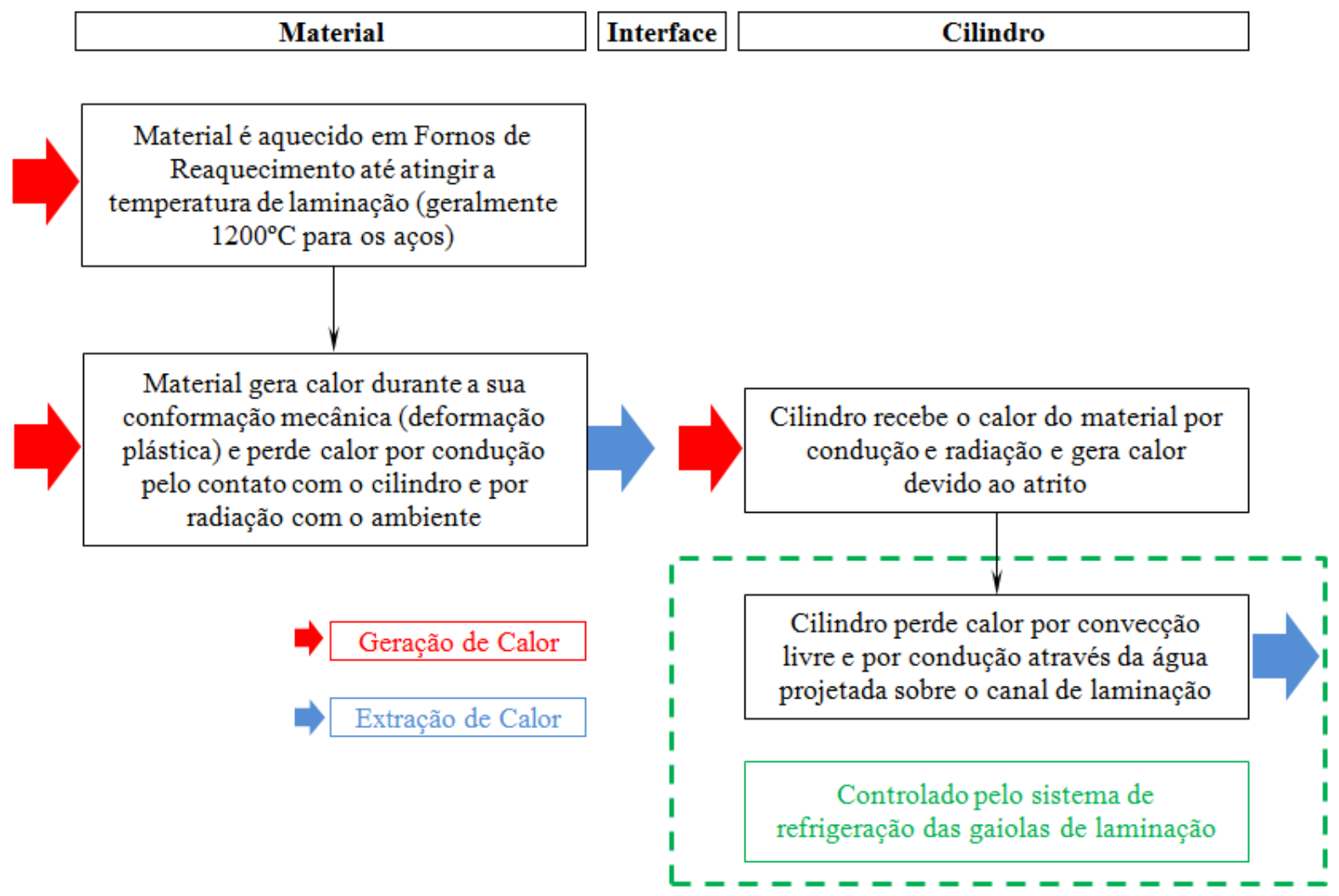

Figura 5. Balanço térmico durante a laminação.

A energia térmica gerada no interior do material inicia-se no momento de seu aquecimento em fornos de reaquecimento, que possuem geralmente um número de zonas que caracterizam regiões de pré-aquecimento, aquecimento e encharque. Posteriormente, ocorre um incremento desta energia térmica durante a sua conformação, que é proveniente, basicamente, de sua deformação plástica, pelo efeito do atrito no momento do agarre pelos cilindros de laminação e pela oxidação ou formação de carepa na superfície do material. $\mathrm{O}$ calor gerado durante a deformação plástica do material está diretamente relacionado à sua tensão de escoamento. Já o calor gerando pelo atrito no momento do agarre é função de parâmetros de laminação, como velocidade de saída do material, diâmetro dos cilindros e coeficiente de atrito. A oxidação superficial do material durante a laminação é uma reação exotérmica e a sua geração de calor depende de parâmetros tais como temperatura do material e espessura da camada de óxido (ou velocidade de formação de carepa).

A perda de calor do material laminado e consequentemente o ganho de calor pelos cilindros de laminação, durante o processo de laminação, ocorre: (i) pela troca de calor por condução entre o material e o cilindro de trabalho - momento no qual o cilindro recebe a maior parte da energia térmica do material; (ii) pela radiação, que também incrementa a 
quantidade de calor transferida para o cilindro; (iii) pela convecção livre (ar); (iv) pela água do sistema de refrigeração e (v) pela troca de calor por condução dentro do próprio material. Wright [7] apresentou, na revisão bibliográfica de sua tese de doutorado, vários modelos para simular a troca de calor entre o material laminado e os cilindros de laminação. Em todos estes modelos, foram consideradas as equações troca de calor por condução.

Outro aspecto que confirma a importância majoritária deste mecanismo de troca de calor em detrimentos a outros envolvidos na laminação a quente (troca de calor por radiação, convecção, convecção livre, etc), pode ser observado na Figura 24, onde fica visível o grande incremento da temperatura na superfície do cilindro durante o tempo de contato entre o material laminado e os cilindros de laminação.

Torna-se particularmente importante a quantificação da troca de calor por condução (explorada no item 3.2.1), pois este é o principal mecanismo responsável pelo aquecimento do cilindro. A troca de calor é fundamentalmente função de:

- Temperatura inicial do material laminado;

- Propriedades físicas do material utilizado para a fabricação do cilindro;

- Coeficiente de transferência de calor utilizado para caracterizar a interface materialcilindro (subcapítulo 3.2.2).

\subsubsection{Fluxo de Calor no Cilindro Durante a Laminação}

As entradas de calor no cilindro de trabalho podem ser vistas esquematicamente na Figura 6, que reforça que estes são devidas à radiação do material que passa pelos cilindros, à condução de calor do material através da camada de óxido, ao efeito do atrito ao longo do arco de contato da mordida dos cilindros e outras fontes [18]. 


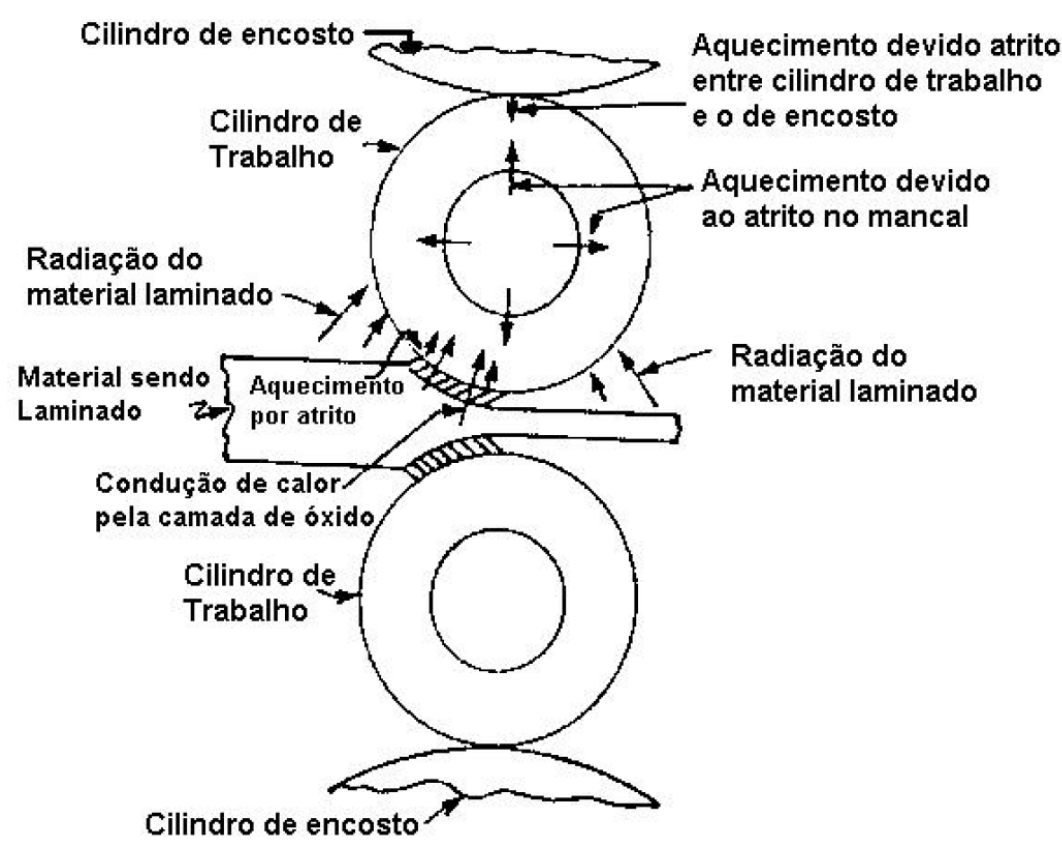

Figura 6. Esquema que mostra as entradas de calor no cilindro de trabalho. Adaptado de [18].

As saídas de calor do cilindro de trabalho podem ser vistas esquematicamente na Figura 7 e são devidas à convecção através do uso de fluido refrigerante (geralmente água); à convecção pelo ar; à radiação para as vizinhanças; ao contato com o cilindro de apoio (quando existir) e ao fluxo de calor na direção longitudinal para o munhão do cilindro [18].

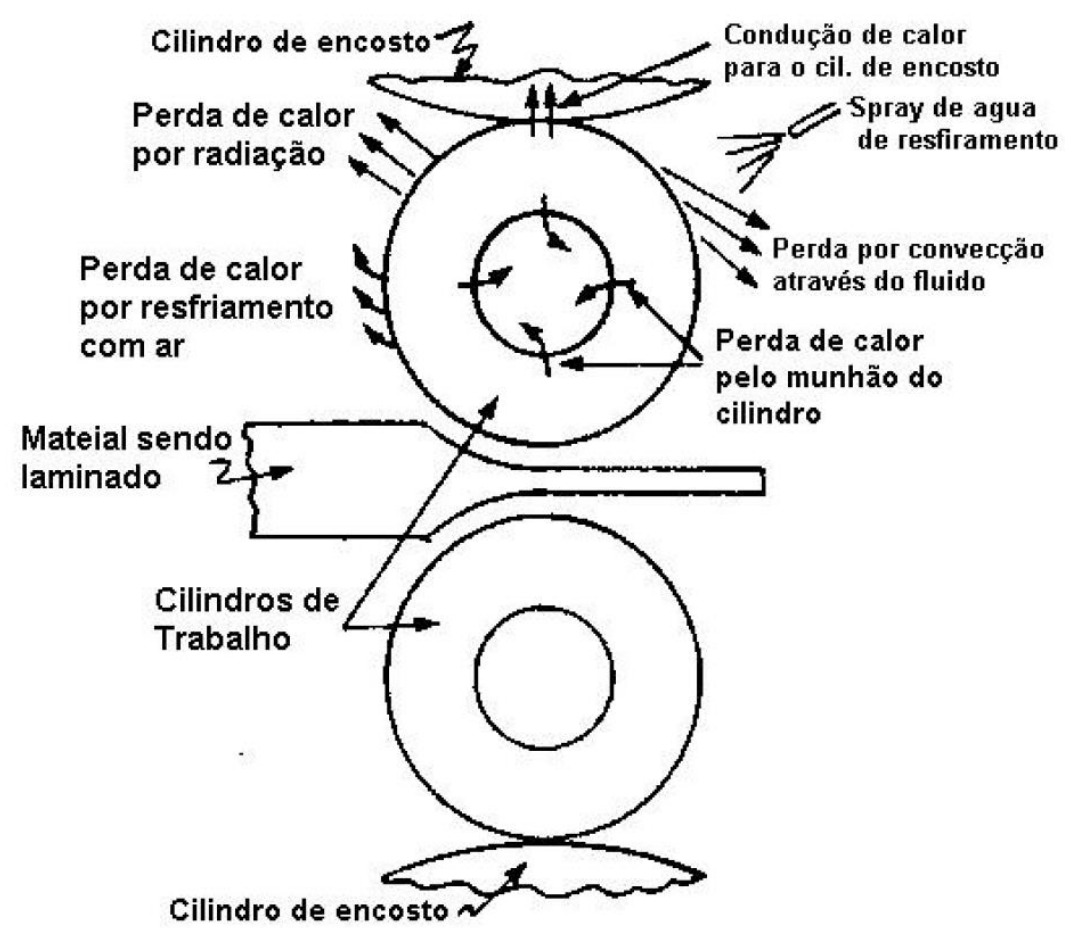

Figura 7. Esquema que mostra as saídas de calor no cilindro de trabalho. Adaptado de [18] 
Modelos matemáticos descrevem os fluxos de entrada e saída de calor do cilindro de trabalho de maneiras diversas e muito complexas. Basicamente, eles podem ser classificados em modelos uni ou bidimensionais [7]. Stevens et al. [22] desenvolveram equações capazes de predizer a temperatura superficial e subsuperficial do cilindro de trabalho durante o processo de laminação a quente. O modelo considera um fluxo térmico unidimensional entre dois corpos semi-infinitos, entre os quais é repentinamente colocada uma camada de outro material. Na superfície tem-se:

$$
T c_{S}=T c_{0}+\left(T m-T c_{0}\right)\left[\frac{h_{d} \sqrt{\xi_{c i l}}}{A \lambda_{c i l}}\right]\left\{1-e^{t A} e r f c A \sqrt{t}\right\}
$$

onde A é um coeficiente definido por:

$$
A=\frac{h_{d}}{\lambda_{\text {cil }} \lambda_{\text {mat }}}\left[\lambda_{\text {cil }} \sqrt{\xi_{\text {mat }}}+\lambda_{\text {mat }} \sqrt{\xi_{\text {cil }}}\right]
$$

Sendo que:

$T c_{S}$ é a temperatura da superfície do cilindro

$T c_{0}$ é a temperatura a uma distância abaixo da superfície do cilindro (núcleo)

$T m$ é a temperatura do material que está sendo laminado

$h_{d}$ é o coeficiente de transferência de calor na interface cilindro-material

$\lambda_{\text {cil }}$ é a condutividade térmica do cilindro

$\lambda_{\text {mat }}$ é a condutividade térmica do material que está sendo laminado

$\xi_{c i l}$ é a difusividade térmica do cilindro

$\xi_{\text {mat }}$ é a difusividade térmica do material que está sendo laminado

$t$ é o tempo de contato entre o cilindro e o material

Quando apenas a temperatura superficial do cilindro é necessária, pode-se fazer a seguinte simplificação [18]: 


$$
T c_{S}=T c_{0}+\left(T m-T c_{0}\right) h_{d} \sqrt{\frac{t}{\rho_{c i l} \lambda_{c i l}}}
$$

onde $\rho_{\text {cil }}$ é a densidade do cilindro de trabalho. Seredynsky [20] deduziu uma equação térmica que calcula a perda de temperatura devido à condução térmica do material para o cilindro de trabalho. Assume-se que a perda de calor pelo material é equivalente ao calor recebido pelo cilindro.

$$
\Delta T_{c i l}=60 h_{d} \sqrt{\frac{r}{h_{0} R}}\left(\frac{T m-T c_{0}}{(1-r) \pi \rho_{m a t} C p_{m a t} U}\right)
$$

onde:

$\Delta T_{c i l}$ é o aumento de temperatura do cilindro devido à condução de calor pelo material $h_{d}$ é o coeficiente de transferência de calor na interface cilindro-material $\rho_{\text {mat }}$ é densidade do material $C p_{\text {mat }}$ é o calor específico do material $U$ é a rotação dos cilindros de laminação $r$ é o grau de redução do material $h_{0}$ é a espessura inicial do material $R$ é o raio do cilindro de trabalho

Tm temperatura do material que está sendo laminado $T c_{0}$ é a temperatura a uma distância abaixo da superfície do cilindro (núcleo)

Hensel et al. [23] definiram uma equação para determinar as perdas de temperatura do material por condução (e consequentemente o ganho de temperatura pelo cilindro).

$$
\Delta T_{c i l}=\frac{2 k L p\left(T m-T c_{0}\right)}{v_{t} h_{f} m C p_{\text {mat }}}
$$

onde: 
$\Delta T_{c i l}$ é o aumento de temperatura do cilindro devido à condução de calor pelo material $k$ é o fator de condutibilidade térmica

$L_{p}$ é o arco de contato

$v_{t}$ é a velocidade tangencial dos cilindros

$h_{f}$ é a espessura final do material

$m$ é massa específica do material laminado

$C p_{\text {mat }}$ é o calor específico do material

Tm temperatura do material que está sendo laminado

$T c_{0}$ é a temperatura a uma distância abaixo da superfície do cilindro (núcleo)

Para o cálculo do fator de condutibilidade térmica, tem-se a equação (22):

$$
k=\frac{h_{d}}{2 \sqrt{t}}\left[e^{n^{2}}(1-\varphi(n))\right]-\left(\frac{1}{n}\right)+\left(\frac{2}{\sqrt{\pi}}\right)
$$

onde:

$h_{d}$ é o coeficiente de transferência de calor na interface cilindro-material

$t$ é o tempo de aplicação da deformação ou tempo de contato

$n$ é o argumento da função de Gauss

$\varphi(n)$ é a Função de Gauss

Para o cálculo do argumento da função de Gauss, tem-se:

$$
n=\left(\frac{2 \lambda_{\text {mat }}}{h_{d}}\right)\left(\frac{\sqrt{t}}{s}\right)
$$

onde:

$h_{d}$ é o coeficiente de transferência de calor na interface cilindro-material

$\lambda_{\text {mat }}$ é a condutividade térmica do material que está sendo laminado 
$t$ é o tempo de aplicação da deformação ou tempo de contato

$s$ é a espessura da camada de óxido do material laminado

Geleji [24] criou uma equação para o cálculo da troca térmica entre o material laminado e cilindro de laminação.

$$
\Delta T_{c i l}=\frac{2 L p b\left(T m-T c_{0}\right) t h_{d}}{G C p_{\text {mat }}}
$$

onde:

$\Delta T_{\text {cil }}$ é o aumento de temperatura do cilindro devido à condução de calor pelo material $L_{p}$ é o arco de contato

$b$ é a largura do material

$t$ é o tempo de aplicação da deformação ou tempo de contato

$h_{d}$ é o coeficiente de transferência de calor na interface cilindro-material

$G$ é a massa do material laminado

$C p_{\text {mat }}$ é o calor específico do material

Tm temperatura do material que está sendo laminado

$T c_{0}$ é a temperatura a uma distância abaixo da superfície do cilindro (núcleo)

Para o cálculo da massa da barra, tem-se:

$$
G=h_{0} b_{0} l_{0} m
$$

onde:

$h_{o}$ é a espessura inicial do material

$b_{0}$ é a largura da barra antes de ser conformada pelos cilindros

$l_{0}$ é o comprimento da barra antes de ser conformada pelos cilindros

$m$ é massa específica do material laminado 
Valores de $\mathrm{Tc}_{\mathrm{s}} \mathrm{e} T \mathrm{Tc}_{0}$ foram calculados por Williams et al. [25] para valores de $\mathrm{h}_{\mathrm{d}}$ entre 6,5 e $85 \mathrm{~kW} / \mathrm{m}^{2} \mathrm{~K}$ e para valores de $\mathrm{t}$ acima de 0,065 segundos. Os resultados podem ser vistos nas Figuras 8 e 9. Para os cálculos foi assumida a temperatura do cilindro de trabalho, no momento do agarre, como sendo $150^{\circ} \mathrm{C}$ (condição não considerada plenamente válida [18]). De fato, Williams et al. defenderam a tese de que a taxa do aumento de temperatura ao longo do cilindro (no sentido radial) não ultrapassa $20^{\circ} \mathrm{C} / \mathrm{cm}$. A equação (19) fornece a distribuição de temperaturas com um grau de acurácia de $\pm 5 \%$ [25]. Pela equação (19), observa-se que o valor da temperatura do cilindro não influencia de forma significativa o valor final da temperatura em sua superfície.

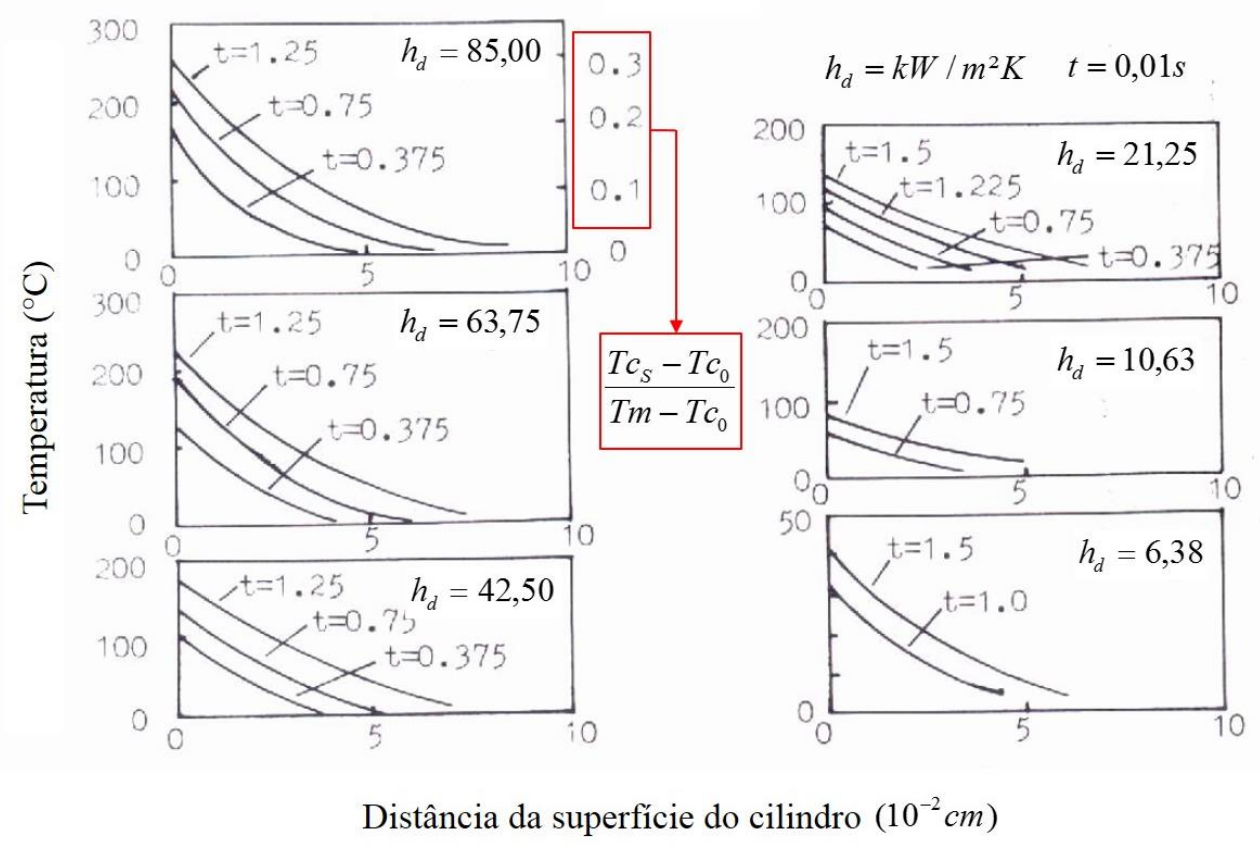

Figura 8. Distribuição interna de temperatura dentro do cilindro de trabalho. Adaptado de [25].

Uma observação importante que pode ser feita quando se analisa as Figuras 8 e 9 é que o tempo de contato no qual foram feitos os cálculos é muito pequeno. O maior tempo mostrado nos gráficos é de $1,25 \times 10^{-2}$ segundos. Valores praticados para laminadores industriais variam de aproximadamente $11,5 \times 10^{-2}$ a $0,5 \times 10^{-2}$ segundos, o que explica o fato de não terem sido observadas no gráfico, temperaturas superiores à $250{ }^{\circ} \mathrm{C}$. Entretanto, existem duas informações importantes que podem ser extraídas do estudo por Williams et al. [25]. Primeiro, o fato de que as mudanças significativas na temperatura superficial do cilindro são ocasionadas por mudanças no coeficiente de transferência de calor na interface cilindro- 
material. Segundo, a Figura 9 mostra que o momento em que se atinge a maior temperatura superficial no cilindro de trabalho é justamente o último momento em que existe o contato do cilindro com o material, confirmando, desta forma, a importância das relações de transferência de calor por condução.
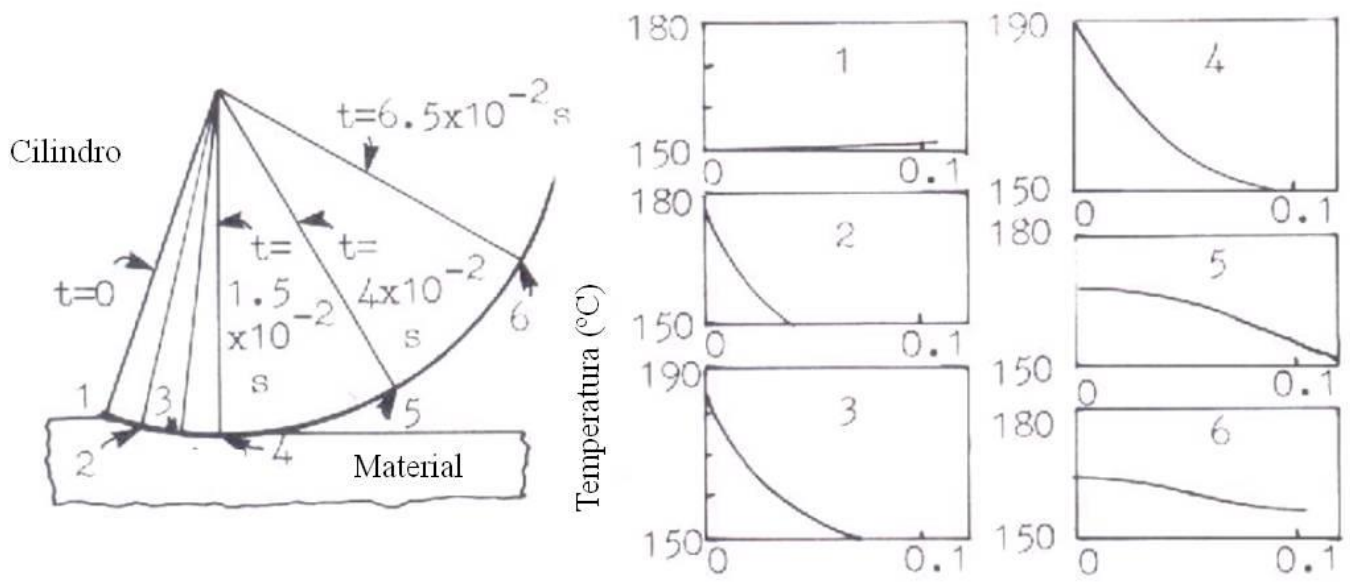

Distância da superficie do cilindro $(\mathrm{cm})$

Figura 9. Distribuição interna de temperatura dentro do cilindro de trabalho. Adaptado de [25].

As equações (17) e (19) consideram as propriedades físicas do cilindro de laminação e do material que sofre a conformação mecânica. Considera também dois importantes parâmetros de laminação, a temperatura do material e o tempo de contato entre o cilindro e o material durante sua conformação. O tempo de contato pode dar uma ideia da velocidade de laminação (velocidade com que giram os cilindros de laminação) ou redução em altura do passe de laminação (importante para a determinação do arco de contato). Entretanto, é muito difícil determinar a influência de um ou de outro na variável de resposta do modelo, que é a temperatura superficial do cilindro.

No trabalho de Corral et at [9] foi modelado o comportamento termo elástico de um cilindro de laminação. Foram consideradas as tensões e deformações causadas pela superposição dos efeitos térmicos e mecânicos. O modelo considera propriedades físicas do cilindro, além do comprimento da barra laminada e do intervalo de tempo entre barras. Esta foi uma iniciativa para a inclusão de parâmetros operacionais no cálculo da temperatura superficial de cilindros de laminação a quente. Estes parâmetros são inseridos na equação (26) de forma a determinar um perfil de temperatura mais coerente com o regime de operação do laminador. 


$$
T c_{S}=T a+T_{S}^{*} A_{0}+T_{S}^{*} \sum_{n=1}^{50} \frac{\exp (-\psi \sqrt{n})}{\sqrt{n}}\left[A_{n} \cos \left(n \theta_{t}-\psi \sqrt{n}\right)+B_{n} \sin \left(n \theta_{t}-\psi \sqrt{n}\right)\right]
$$

$$
\psi=\sqrt{\frac{\frac{2 \pi}{t_{r}}}{2 \xi_{c i l}} r}
$$

onde:

$T c_{S}$ é a temperatura da superfície do cilindro

$T a$ é a temperatura ambiente

$T_{S}^{*}$ é a temperatura que depende de propriedades físicas do material do cilindro

$A_{0}$ é um coeficiente da série de Fourier

$A_{n}$ é um coeficiente da série de Fourier

$B_{n}$ é um coeficiente da série de Fourier

$\theta_{t}$ é a coordenada angular

$\psi$ é uma constante que depende das propriedades físicas, da velocidade angular e da geometria do cilindro de trabalho

$t_{r}$ é o período de rotação do cilindro

$\xi_{\text {cil }}$ difusividade térmica do cilindro

$r$ é uma coordenada radial

A equação (27) mostra que quanto maior for a rotação do cilindro, menor será o incremento a ser feito no cálculo da temperatura de sua superfície. Para que esta condição possa fazer sentido, deve-se entender como período de rotação o tempo em que o cilindro está girando em vazio (sem carga). O modelo, entretanto, apresenta considerável complexidade matemática.

Serajzadeh [26] publicou um trabalho demonstrando a influência de parâmetros operacionais de laminação na temperatura superficial do cilindro de laminação à quente. Os resultados podem ser vistos na Figura 10 e mostram que a temperatura superficial do cilindro 
é diretamente proporcional ao percentual de redução da seção transversal durante o passe de laminação. Analogamente, pode-se verificar que a temperatura superficial do cilindro é inversamente proporcional à velocidade aplicada no momento da conformação do material.

Estes resultados podem ser fisicamente explicados, uma vez que maiores reduções acarretam um maior arco de contato entre o cilindro e o material, promovendo, desta forma, um maior tempo de contato, que consequentemente permitirá uma maior transferência de calor do material para o cilindro. $\mathrm{O}$ mesmo conceito é aplicado à velocidade, pois maiores velocidades propiciarão um menor tempo de contato.
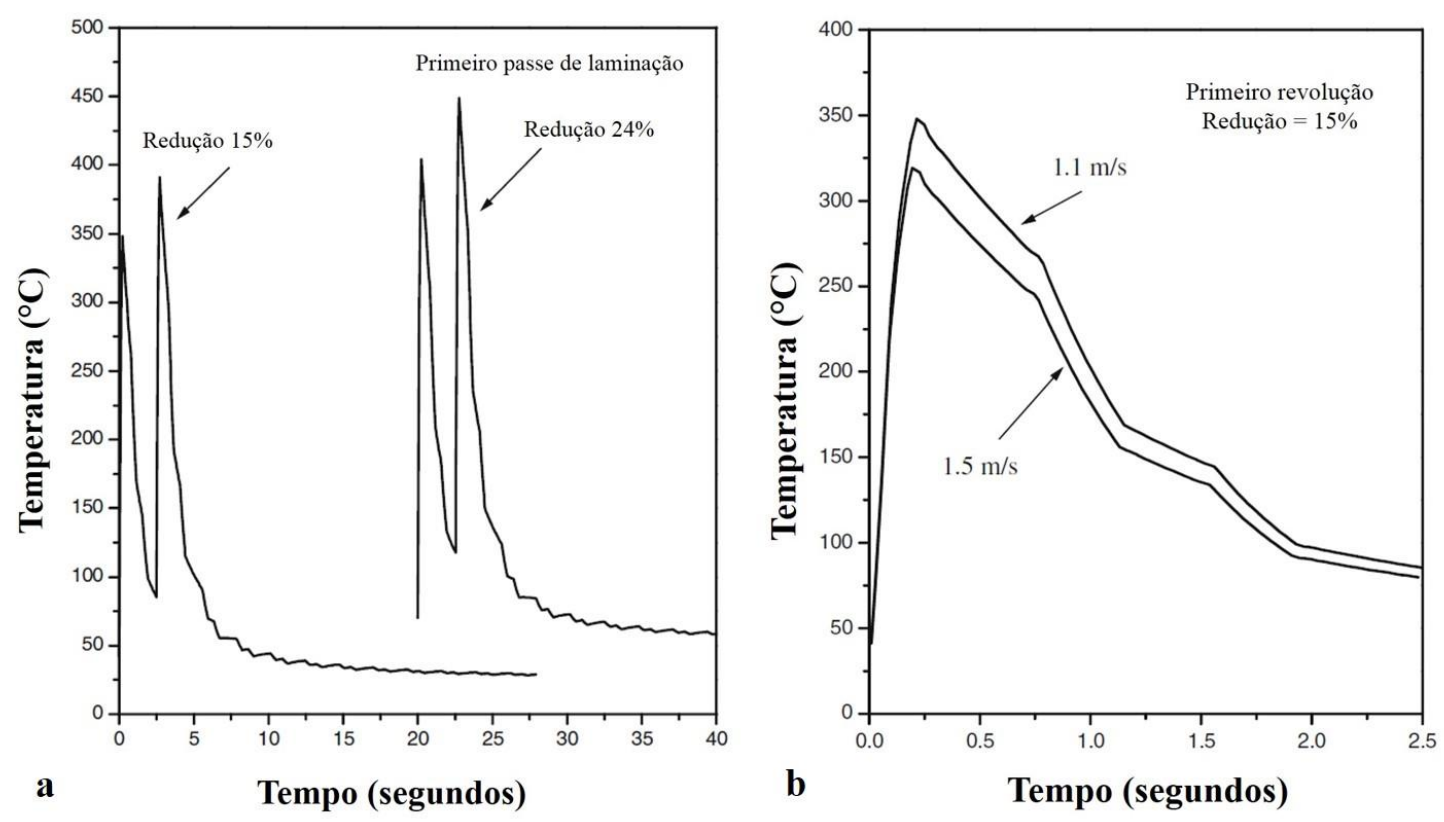

Figura 10. a) Efeito da redução em altura na temperatura superficial do cilindro b) Efeito da velocidade do cilindro na sua temperatura superficial. Adaptado de [26].

Dependendo da configuração do sistema de refrigeração, a distribuição de temperatura do cilindro pode atingir um estado cíclico permanente. Devadas [27] calculou a resposta térmica do cilindro para a primeira gaiola de laminação de um trem acabador para as primeiras 10 revoluções, na superfície do cilindro e a 1,5 e $10 \mathrm{~mm}$ de profundidade. Os resultados podem ser vistos na Figura 11, onde observa-se que o gradiente de temperatura é extremamente abrupto na superfície, especialmente no momento do agarre. A temperatura subsuperficial cresce gradativamente até a décima revolução e então permanece estável a partir deste ponto. A diferença de temperatura entre a superfície e o núcleo é extremamente elevada e a uma pequena profundidade $(1 \mathrm{~mm})$ atingiu um pico máximo de $120^{\circ} \mathrm{C}$, enquanto 
que na superfície o valor foi $400^{\circ} \mathrm{C}$. Verifica-se que as maiores variações se concentram em uma fina camada superficial do cilindro.

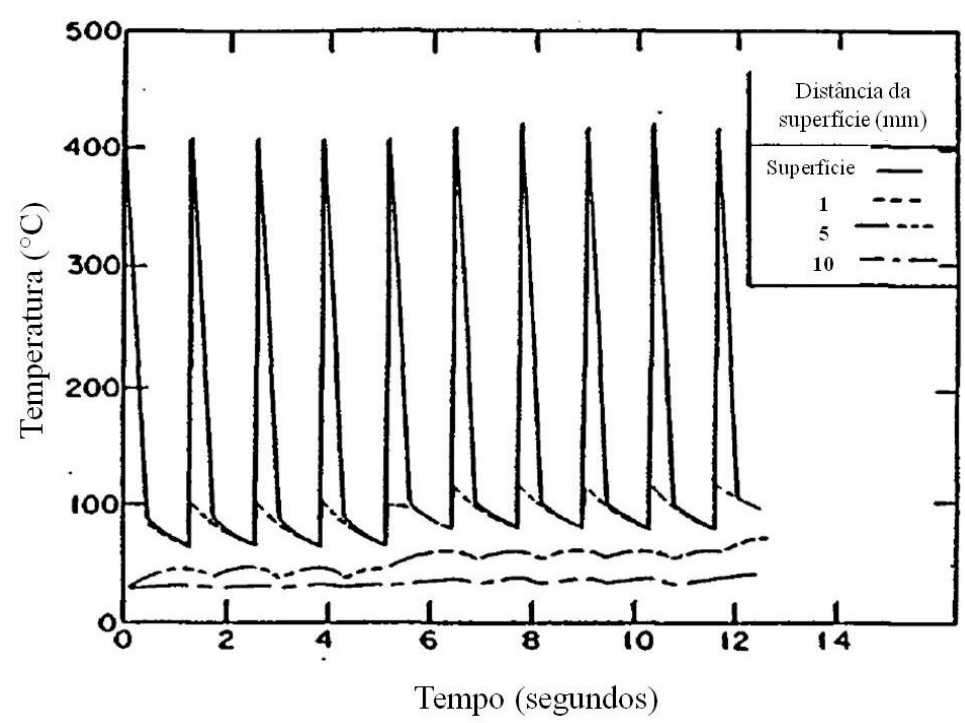

Figura 11. Resposta térmica para um cilindro nas dez primeiras revoluções. Adaptado de [27].

Confirma-se, portanto, que o gradiente de temperatura na direção radial do cilindro é muito íngreme, a pequenas profundidades da superfície. Ye [28] observou que para profundidades de $1 \mathrm{~mm}$ o pico de temperatura medido foi de $120^{\circ} \mathrm{C}$, bem menor do que os $400^{\circ} \mathrm{C}$ medidos na superfície do cilindro. Estas observações reforçam ainda mais a teoria de que as flutuações cíclicas de temperatura ocorrem em uma fina camada superficial do cilindro. Tseng [29] definiu a espessura de uma fina camada superficial $\delta$ como a profundidade abaixo da superfície do cilindro onde a diferença de temperatura no ciclo térmico durante a laminação é inferior à 1\% (Figura 12).

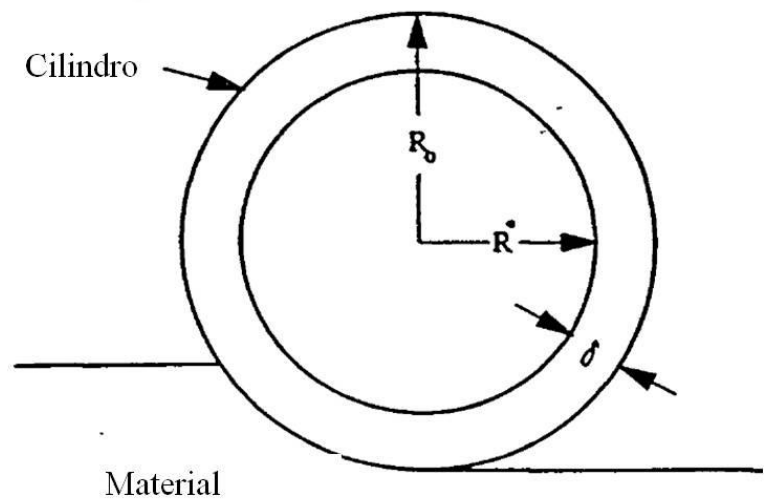

Figura 12. Esquema que mostra a zona térmica e sua espessura. Adaptado de [29]. 


$$
\delta=C R P e^{-1 / 2}
$$

onde $\mathrm{R}$ é o raio do cilindro de trabalho e $\mathrm{C}$ é o coeficiente de proporcionalidade de espessura da fina camada superficial, igual à 7 quando $\mathrm{Pe}=10^{5}$ e $\mathrm{Bi}=10^{2}$. Pe é o número de Peclet e $\mathrm{Bi}$ é o número de Biot, definidos por:

$$
\begin{gathered}
P e=R^{2} \omega \xi_{c i l}{ }^{-1} \\
B i=\frac{h_{d} L_{c}}{\lambda_{c i l}}
\end{gathered}
$$

onde:

$\omega$ é a velocidade angular do cilindro

$\xi_{c i l}$ é a difusividade térmica do cilindro

$h_{d}$ é o coeficiente de transferência de calor na interface cilindro-material

$\lambda_{\text {cil }}$ é a condutividade térmica do cilindro

$L_{c}$ é o comprimento característico definido como o volume do cilindro pela área da superfície de contato $\left(L_{c}=V_{\text {sólido }} / A_{\text {sup erficie }}\right)$

O número de Peclet compara a velocidade angular dos cilindros de laminação com suas características térmicas e geométricas em uma razão normalizada, enquanto o número de Biot quantifica a razão relativa dos fluxos térmicos convectivo e condutivo [4]. Tseng [29] utilizou a curva da Figura 13, que relaciona a diferença de temperatura normalizada entre superfície e núcleo do cilindro, com o coeficiente de proporcionalidade de espessura da fina camada superficial (C), considerando-se $\mathrm{Pe}=10^{5}$ e $\mathrm{Bi}=10^{2}$. Pode-se observar que para $1 \%$ de diferença de temperatura obtém-se um coeficiente igual à 7. Existe, entretanto, uma vulnerabilidade na teoria de Tseng, uma vez que Bi é influenciado pelo coeficiente de transferência de calor $\left(h_{d}\right)$ e pelo comprimento característico $\left(L_{c}\right)$. Se o sistema de refrigeração for modificado ou se o arco de contato for alterado, alterações no número de Biot são 
esperadas e modificariam a curva da Figura 13, acarretando, desta forma, modificações no valor do coeficiente C. Neste trabalho os valores de Bi variaram entre 60 e 130, mantendo assim uma certa coerência com a ordem de grandeza proposta por Tseng $\left(\mathrm{Bi}=10^{2}\right)$. Para estas variações utilizou-se uma proporcionalidade linear para o coeficiente $\mathrm{C}$.

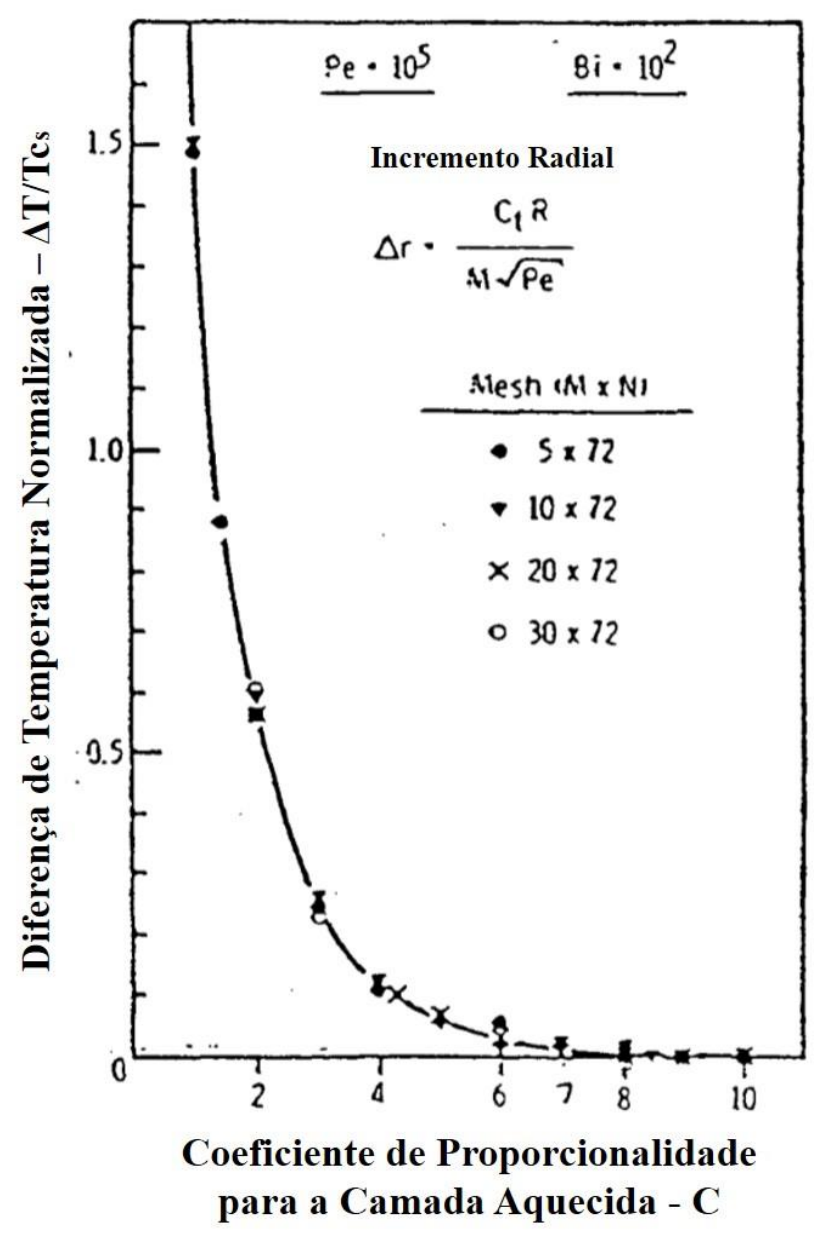

Figura 13. Diferença da temperatura normalizada vs. Coeficiente de proporcionalidade de espessura da fina camada superficial. Adaptado de [29].

Ryu et al. [30] propuseram um parâmetro para representar o dano causado pela fadiga térmica em cilindros de laminação a quente. Este parâmetro considera os efeitos da temperatura superficial do cilindro e a respectiva camada superficial aquecida como base para o modelo de dano. Foram laminados três tipos de material com diferentes reduções, velocidades e temperaturas do material. Os resultados podem ser vistos na Figura 14. É possível verificar as relações entre a profundidade da camada aquecida e temperatura 
superficial do cilindro com a) e b) temperatura do material, c) e d) rotação do cilindro e e) e f) redução da seção transversal, respectivamente.
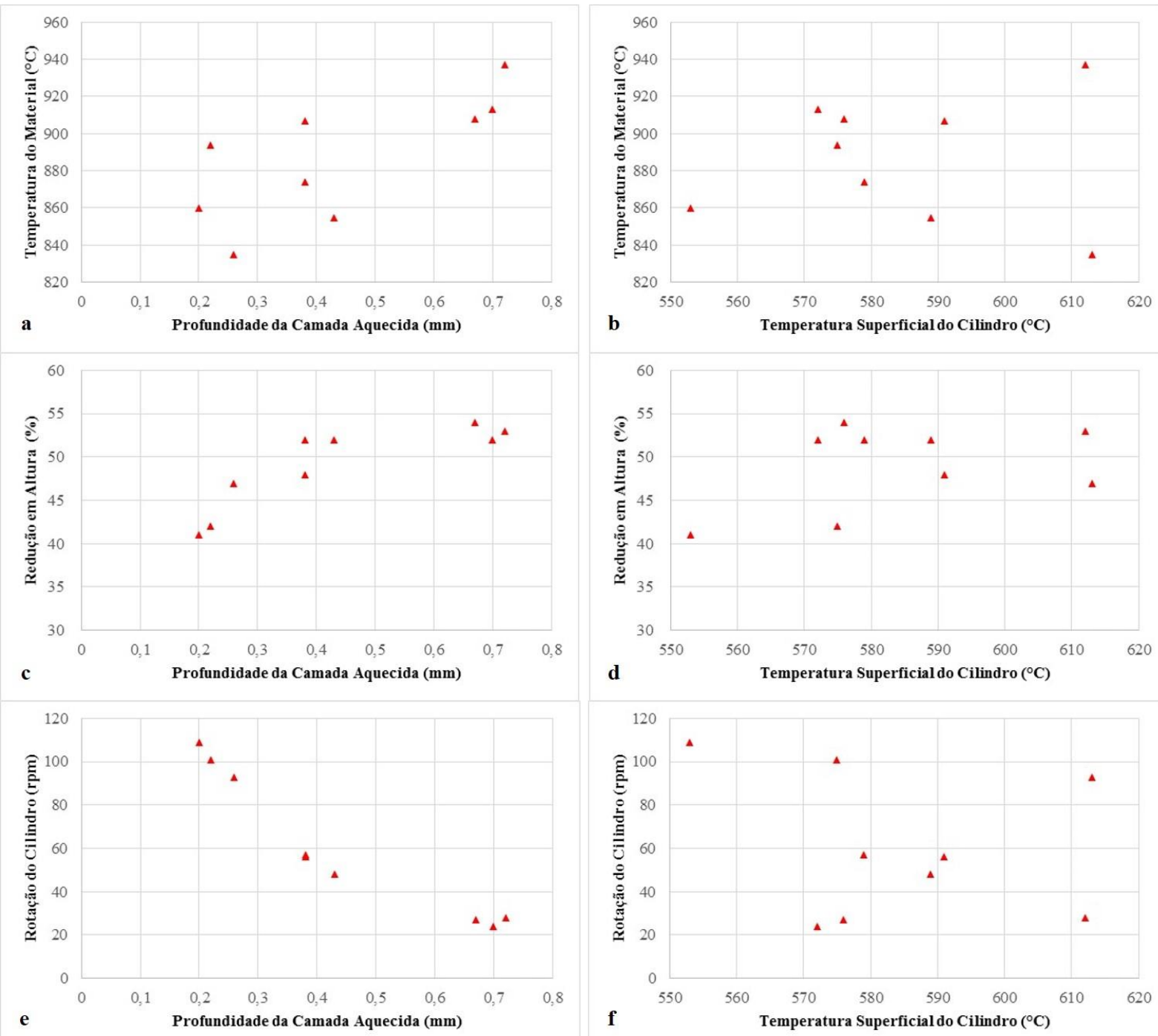

Figura 14. Relações entre os parâmetros de laminação e a profundidade da camada aquecida e temperatura superficial dos cilindros. Adaptado de [30].

Embora seja possível avaliar as relações entre os parâmetros de laminação (redução, rotação do cilindro e temperatura do material) com a respectiva profundidade da camada aquecida, o trabalho de Ryu et al. [30] não trouxe informações sobre as possíveis interações entre os parâmetros e sua significância para a variável reposta analisada. 


\subsubsection{Coeficiente de Transferência de Calor na Interface Material-Cilindro}

Serajzadeh et al. [34] demonstraram a influência do coeficiente de transferência de calor na interface cilindro-material na temperatura superficial dos cilindros de laminação. A Figura 15 mostra que $22 \%$ de incremento no $h_{d}$ é capaz de gerar, no momento do agarre, um aumento de $26 \%$ na respectiva temperatura superficial do cilindro. Neste estudo foi utilizado o método de elementos finitos para um modelo bi-dimensional que tinha como objetivo predizer a distribuição de temperatura do cilindro quando eram modificados parâmetros de laminação.

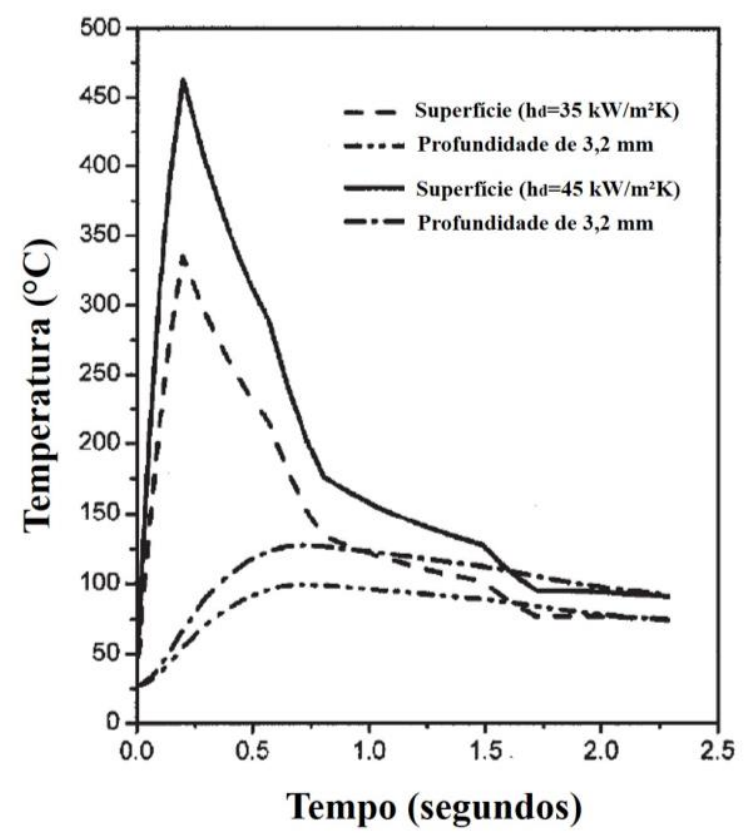

Figura 15. Relações entre o coeficiente de transferência de calor e a temperatura superficial do cilindro.

Adaptado de [34].

Devadas [27] determinou, em sua tese de doutorado, o coeficiente de transferência de calor da região do arco de contato (região de agarre) por meio de medições de temperatura feitas em um cilindro de laminação, conforme pode ser visto na Figura 16. Pode-se verificar que o coeficiente de transferência de calor aumenta rapidamente no estágio inicial da mordida do material pelos cilindros e se mantém constante durante o restante da região de contato. Este aumento do coeficiente de transferência de calor é atribuído ao aumento da pressão de contato entre os cilindros e o material. Devadas [27] também analisou a influência de alguns parâmetros de laminação no coeficiente de transferência de calor. Em seu trabalho houve a 
indicação de que maiores reduções em altura durante o passe de laminação ocasionam maiores valores para $\mathrm{h}_{\mathrm{d}}$, corroborando, desta forma, o que foi posteriormente publicado por $\mathrm{Li}$ et al. [35] e Serajzadeh [26]. A explicação proposta por Desvadas para explicar este fenômeno, entretanto, baseou-se no entendimento de que maiores pressões de contato favorecem a troca térmica entre o material laminado e os cilindros. Seu trabalho também apresenta a informação de que maiores velocidades de laminação acarretam maior valores para o coeficiente de transferência de calor $\left(h_{d}\right)$. Esta constatação, entretanto, difere do que foi apresentado por Serajzadeh [26] e pelo que será exposto neste trabalho. A explicação de Devadas para sustentar esta afirmação, baseou-se no fato de que maiores velocidades de laminação causariam maiores pressões iniciais de contato entre o material laminado e os cilindros e consequentemente, deformações mais rápidas do material laminado.

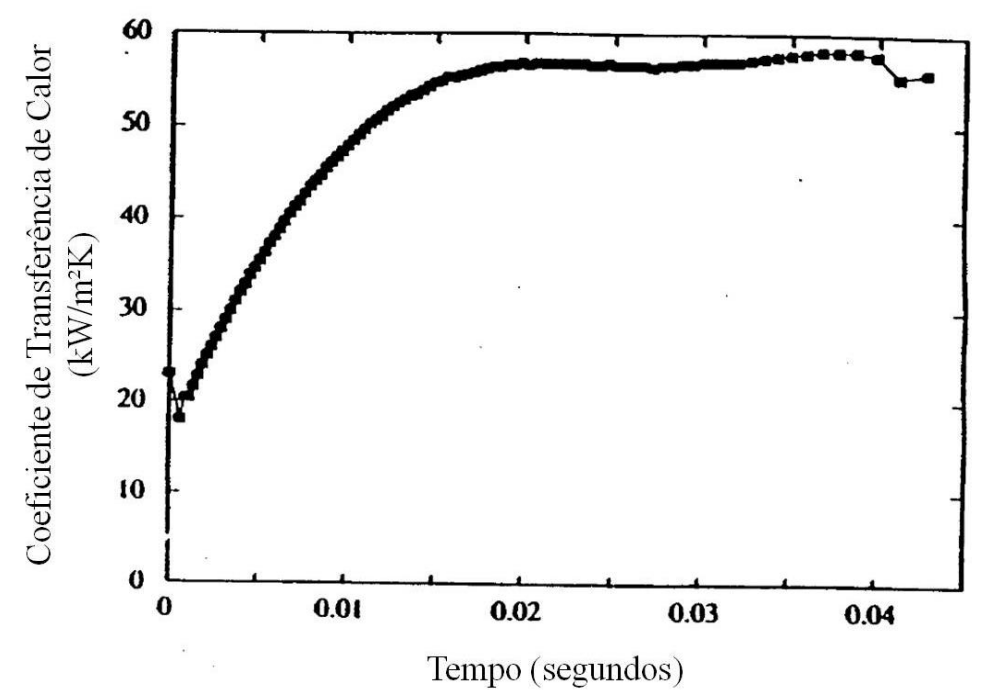

Figura 16. Variação do coeficiente de transferência de calor na região do arco de contato. Adaptado de [27].

Em 2003, Zhou [6] propôs um modelo integrado capaz de reproduzir o comportamento do material durante a laminação. Tal modelo nada tem a ver com a previsão de vida em fadiga para cilindros de laminação a quente, mas sim com o comportamento mecânico e térmico da interface cilindro-material na tentativa de estimar as propriedades mecânicas do produto final de laminação. O trabalho de Zhou [6], entretanto, explora a relação entre a pressão de contato do cilindro sob o material deformado e o respectivo coeficiente de transferência de calor nesta interface. Com a análise, o autor encontrou, por 
meio de simulação, valores próximos aos publicados por Devadas et al. [31] e Jin et al. [32] para pressões de contato até $480 \mathrm{MPa}$. Para pressões maiores que $480 \mathrm{MPa}$, Zhou [6] concorda com o que foi estabelecido por Pawelski [30], isto é, os valores para o coeficiente de transferência de calor $\left(h_{d}\right)$ estabilizam na faixa de $300 \mathrm{~kW} / \mathrm{m}^{2} \mathrm{~K}$. A Figura 17 permite estabelecer uma relação direta e proporcional entre o coeficiente de transferência de calor e a pressão média de contato do cilindro [32].

$$
h_{d}=0,6965 P_{r}-34,396
$$

onde $h_{d}$ é o coeficiente de transferência de calor na interface cilindro-material, dado em $\mathrm{kW} / \mathrm{m}^{2} \mathrm{~K}$, e $\mathrm{P}_{\mathrm{r}}$ é a pressão média de contato ou carga de laminação em MPa. Cabe salientar que tal equação torna-se válida apenas para pressões de contato entre 50 e $480 \mathrm{MPa}$.

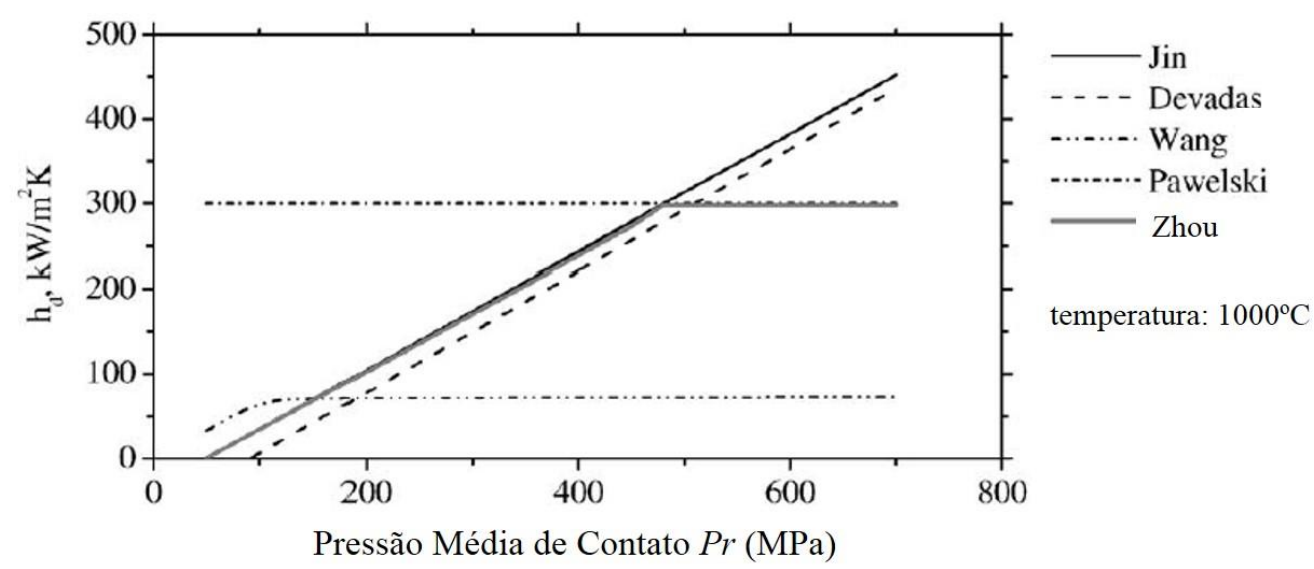

Figura 17. Relação entre o coeficiente de transferência de calor na interface e a pressão média de contato do cilindro. Adaptado de [6].

Hadly et al. [33] propuseram uma relação envolvendo propriedades físicas do cilindro e do material laminado, além de utilizar a tensão de escoamento do material laminado $\left(\sigma_{0}\right)$ e a pressão dos cilindros de laminação $\left(\mathrm{P}_{\mathrm{r}}\right)$, conforme descrito na Equação 32.

$$
h_{d}=\frac{\bar{k}}{c_{1}}\left(\frac{P_{r}}{\sigma_{0}}\right)^{1,7}
$$

onde $\bar{k}$ é um coeficiente definido por: 


$$
\bar{k}=\frac{\lambda_{c i l} \lambda_{\text {mat }}}{\lambda_{c i l}+\lambda_{\text {mat }}}
$$

e $\mathrm{c}_{1}$ é uma constante igual à $0,035 \mathrm{~mm}$ para aços C-Mn [33]. Como pode ser visto na Equação (32), existe uma relação entre o coeficiente de transferência de calor $\left(h_{d}\right)$ e a pressão média de contato dos cilindros ou carga de laminação $\left(\mathrm{P}_{\mathrm{r}}\right)$. Um maior coeficiente de transferência de calor interfacial acarreta uma maior zona termicamente afetada e, portanto, uma menor vida em fadiga da superfície do cilindro. O coeficiente de transferência de calor é uma função das condições de laminação, como a velocidade de laminação, a redução de espessura e a temperatura do material, pois estes parâmetros afetam diretamente a carga de laminação.

As interações térmicas que ocorrem entre o material e o cilindro durante o processo de laminação são influenciadas pela presença de uma fina camada de óxido. Li et al. [35] demonstraram a influência da camada de óxido no coeficiente de transferência de calor da interface cilindro-material (Figura 18). Ou autores confirmam, de forma indireta, a relação proporcional da redução da seção transversal do material com o coeficiente de transferência de calor.

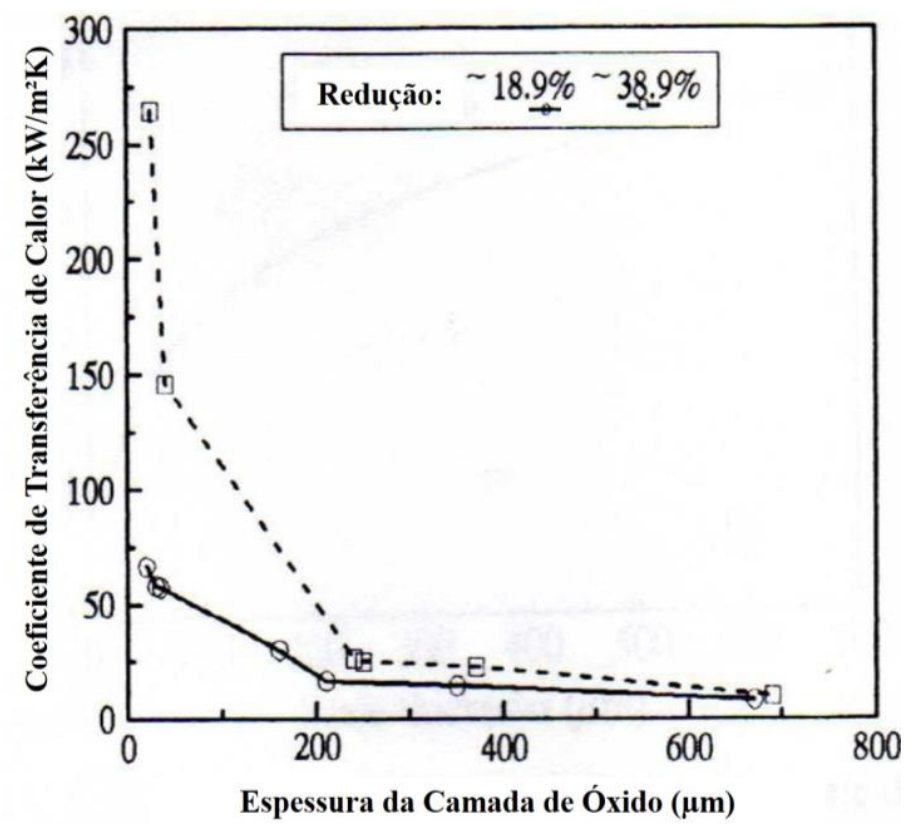

Figura 18. Influência da espessura da camada de óxido no coeficiente de transferência de calor no momento da mordida do material pelos cilindros. Adaptado de [35]. 
Krzyanowski et al. [36] desenvolveram um modelo utilizando o método de elementos finitos para simular o coeficiente de transferência de calor considerando-se condições de oxidação na interface cilindro-material e, consequentemente, sua influência na determinação do balanço térmico de laminação. Os resultados permitem, de forma bastante generalizada, propor duas equações que governam a influência da camada de óxido no coeficiente de transferência de calor.

Para uma camada de óxido com $0,10 \mathrm{~mm}$ de espessura:

$$
h_{d}=0,280 \Delta h^{2}-11,00 \Delta h-130
$$

Para uma camada de óxido com $0,03 \mathrm{~mm}$ de espessura:

$$
h_{d}=0,235 \Delta h^{2}+18,95 \Delta h-229
$$

Stevens et al. [22] e Tseng [29] trouxeram contribuições importantes na medida que tornaram possível prever, de forma bastante assertiva, a temperatura superficial e a profundidade da camada aquecida, e, por consequência, o dano térmico na superfície do cilindro. É possível verificar que o coeficiente de transferência de calor $\left(h_{d}\right)$ possui grande influência em ambas teorias e que as equações desenvolvidas pelos autores também consideram propriedades físicas do cilindro e do material laminado, como por exemplo, a condutividade e difusividade térmica destes materiais. Estas propriedades físicas, entretanto, não diferem muito em valor quando são modificados os materiais utilizados para a fabricação do cilindro e para a laminação. Suas variações impactam menos a temperatura superficial do cilindro e, consequentemente, sua respectiva profundidade da camada aquecida.

O mecanismo de transferência de calor na interface cilindro-material é fortemente influenciado pelo sistema de refrigeração dos cilindros de laminação. O objetivo deste sistema é basicamente garantir que a temperatura na superfície do cilindro permaneça sob controle, em um patamar que maximize a utilização da ferramenta no processo de conformação do material. Para evitar danos aos cilindros e preservar suas propriedades mecânicas, é necessário um sistema de refrigeração que resfriará a superfície do cilindro logo após o contato com o produto laminado. Sistemas de refrigeração com bocais e sprays são 
largamente utilizados em laminadores, com o objetivo de tornar eficiente a retirada de calor do cilindro.

Vários destes parâmetros influenciam diretamente o coeficiente de transferência de calor $\left(h_{d}\right)$ e consequentemente a quantidade de energia envolvida no processo de conformação. Mesmo considerando-se a facilidade de aplicar as equações (19) e (28) propostas por Stevens et al. [22] e Tseng [29], respectivamente, ainda é muito difícil determinar com exatidão qual é o coeficiente de transferência de calor envolvido na interface de contato entre o cilindro de laminação e o material durante a conformação.

Existem diversos trabalhos [30, 31, 32, 33, 35 e 36] que apresentam relações diretas de variáveis do processo de laminação a quente com o coeficiente de transferência de calor. Há, entretanto, que se considerar que estas análises foram feitas sob condições muito específicas e de forma individual, ou seja, não observaram possíveis correlações entre os demais parâmetros de processo. Pode-se afirmar, desta forma, que a determinação de um coeficiente de transferência de calor que represente completamente todas as variações possíveis durante o processo de laminação a quente é, ainda hoje, uma tarefa complexa.

Os parâmetros operacionais são variáveis importantes que determinam a quantidade de calor que o cilindro recebe do material, bem como definem a magnitude do coeficiente de transferência de calor na interface cilindro-material. As tensões térmicas geradas pelos sucessivos aquecimentos e resfriamentos da fina camada superficial do cilindro são determinantes para a previsão de sua vida em fadiga. 


\subsection{A FADIGA TÉRMICA EM CILINDROS DE LAMINAÇÃO}

Os materiais metálicos, quando submetidos a tensões flutuantes ou repetitivas, isto é, sob a ação de esforços cíclicos, rompem-se a tensões muito inferiores àquelas determinadas nos ensaios quase-estáticos de tração, compressão ou torção. A ruptura que ocorre nessas condições dinâmicas de aplicação de esforços é conhecida como ruptura por fadiga. [37].

A fadiga é um processo de degradação das propriedades mecânicas de um material que se caracteriza pelo crescimento lento de uma ou mais trincas sob a ação de carregamento dinâmico, levando eventualmente à fratura [38].

Os primeiros estudos sobre o comportamento de materiais metálicos e esforços alternados e repetitivos foram feitos por August Wöhler, na década de 1850. Importantes informações foram obtidas nestes estudos, entre elas a apresentação dos resultados do ensaio em um gráfico que correlaciona a tensão em função do número de ciclos até a fratura. Entre os principais fatores para que ocorra a falha por fadiga nos materiais, podem ser citados: a existência de tensões cíclicas ou flutuantes e o número de ciclos de aplicação da tensão suficientemente alto para que ocorram a nucleação e a propagação de uma trinca.

A atenção da engenharia a assuntos relacionados à fadiga passou a se voltar, em meados do século XX, também para fenômenos como a fadiga termomecânica, a fadiga térmica e a fadiga-fluência. Esses fenômenos têm dois aspectos em comum: a) a redução do limite de escoamento com a temperatura faz com que a deformação plástica passe a ter um papel importante no fenômeno da fadiga e b) os esforços são caracterizados pela imposição de um ciclo de deformações ao material, e não de um ciclo de carregamento [38]. Esta situação particular é conhecida como fadiga sob controle de deformação e neste tipo de problema um ciclo de deformação é aplicado e a fadiga se estabelece, portanto, em condições de tensão variável. A fadiga sob controle de deformação é caracterizada por altas amplitudes de tensão (por volta ou acima do limite de escoamento) e baixo número de ciclos para a ruptura [38]. A superfície dos cilindros de laminação a quente está sujeita à fadiga térmica.

De maneira mais abrangente, a degradação de um cilindro de laminação ocorre basicamente devido a quatro modos de desgaste: abrasão, adesão, oxidação e fadiga térmica e mecânica [39, 40]. Este trabalho tem como objetivo estudar apenas a fadiga térmica como modo de desgaste em cilindros de laminação a quente. A fadiga térmica resulta, geralmente, no surgimento de uma malha de trincas térmica comumente conhecida como firecracking. 
A ocorrência de fadiga térmica segundo a hipótese de baixo ciclo está diretamente relacionada à amplitude das temperaturas a que o material é submetido e, consequentemente, às deformações de origem térmica associadas [41].

A fadiga térmica na superfície de cilindros de laminação a quente foi discutida em 1971 por Stevens et al. [22]. A principal explicação para a ocorrência da fadiga térmica em cilindros está relacionada ao acúmulo de deformações plásticas resultantes dos estados de tração e compressão durante os ciclos tensão-deformação que ocorrem a cada revolução do cilindro em contato com o material laminado. Considerando um elemento da superfície do cilindro de laminação que entra em contato com o material durante o primeiro ciclo de conformação (Figura 19a), é possível afirmar que sua temperatura irá aumentar e que, consequentemente, este elemento tenderá a se expandir (Figura 19b). Entretanto, sua expansão é impedida pelo restante do corpo do cilindro, que permanece com uma temperatura menor. Esta condição resulta no desenvolvimento de tensões compressivas na superfície do cilindro na direção circunferencial (Figura 19c). Estes eventos têm curta duração (Figura 15) e costumam ser muito intensos.

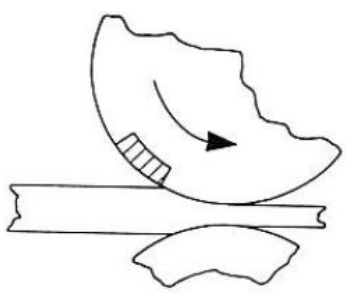

(a)

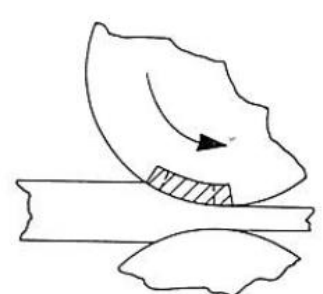

(b)

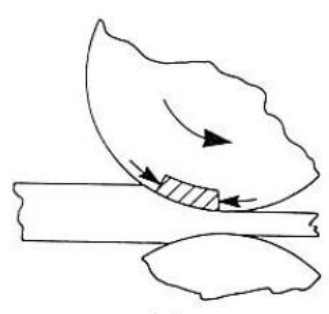

(c)

Figura 19. Desenvolvimento de tensões térmicas compressivas na superfície do cilindro de laminação [22]

Dependendo da diferença de temperatura entre a superfície e o restante do cilindro, esta tensão pode ser suficientemente severa para causar escoamento do material na superfície do cilindro [22]. A variação da temperatura do cilindro durante o primeiro ciclo ou revolução pode ser vista na Figura 20, que permite observar detalhadamente os efeitos da variação de temperatura, isto é, a diferença entre temperatura máxima e mínima. O pequeno aumento de temperatura entre os pontos 1 e 2 do cilindro deve-se à transferência de calor por radiação devido à aproximação do material antes do contato. $\mathrm{O}$ aumento abrupto de temperatura entre os pontos 2 e 3 ocorre com o contato do material laminado com o cilindro, no início do processo de conformação plástica. Entre os pontos 3 e 4 a superfície do cilindro não toca mais 
no material e a temperatura diminui devido à transferência de calor por condução da superfície para as camadas subsuperficiais do cilindro. No ponto 4 o sistema de refrigeração atinge a superfície aquecida e, devido à ebulição da água quando em contato com o cilindro, ocorre uma variação significativa da temperatura. Entre os pontos 4 e 5 a temperatura da superfície cai mais rapidamente, atingindo um valor mínimo abaixo dos jatos d'água. Após esta região a temperatura volta a aumentar devido à condução de calor entre as camadas subsuperficiais e superficiais do cilindro.

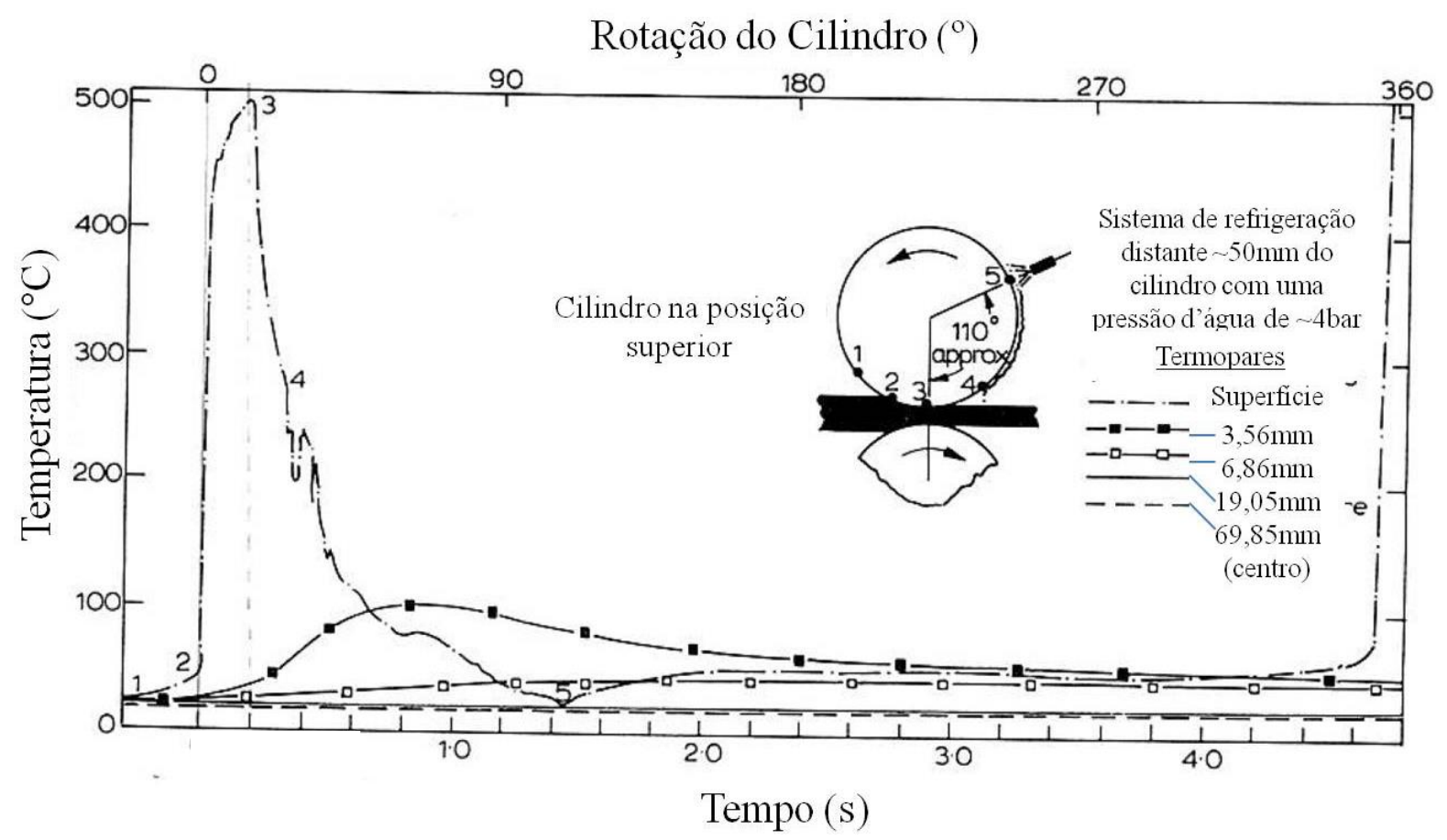

Figura 20. Variação da temperatura do cilindro de laminação durante o primeiro ciclo/revolução. Adaptado de [22].

Os efeitos das tensões induzidas termicamente podem ser analisados por meio de um diagrama tensão-deformação (Figura 21). Este diagrama representa um ciclo de temperatura entre $20^{\circ}$ e $450^{\circ} \mathrm{C}$ na superfície do cilindro no início do processo de laminação, ou seja, quando são então conformadas as primeiras peças. Como a superfície do cilindro entra em contato com o material no primeiro ciclo ou revolução do cilindro, as tensões compressivas aumentam conforme é elevada a temperatura. Inicialmente, a superfície do cilindro deforma elasticamente ao longo de 0A. Entretanto, quando a temperatura superficial atinge $370^{\circ} \mathrm{C}$, a tensão de escoamento é alcançada e a superfície inicia a deformação plástica, ao longo de AB. Nesta região, um aumento da temperatura resulta em um aumento da deformação, mas uma 
redução na tensão. A tensão compressiva em qualquer temperatura a partir deste ponto será a tensão de escoamento naquela mesma temperatura.

Quando a temperatura atinge $450^{\circ} \mathrm{C}$, a superfície do cilindro não toca mais o material e inicia-se o estágio de resfriamento, com a tensão de compressão sendo reduzida elasticamente ao longo de BC. Devido à deformação plástica anterior, as tensões se tornam trativas neste momento.

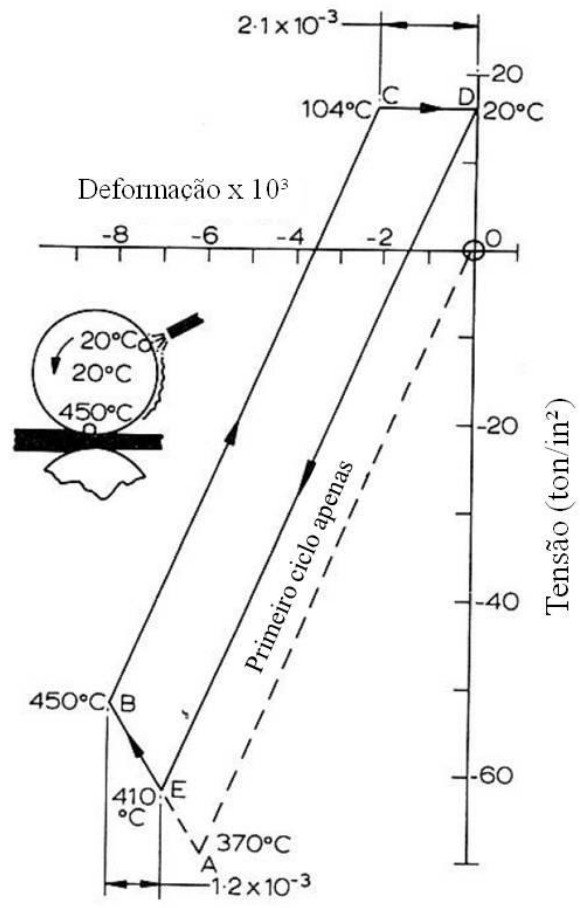

Deformação plásticas/ciclo $(\varepsilon \mathrm{P}=0,0033)$

Figura 21. Desenvolvimento da histerese de tensão-deformação para a superfície de um cilindro de laminação a quente. Adaptado de [22].

Quando a superfície atinge a temperatura de $104^{\circ} \mathrm{C}$, no ponto $\mathrm{C}$, a tensão de escoamento em tração é alcançada e a deformação plástica agora acontece em tração ao longo de $\mathrm{CD}$ até que a superfície atinja $20^{\circ} \mathrm{C}$, sua temperatura inicial. $\mathrm{Na}$ próxima revolução do cilindro, a superfície é aquecida novamente pelo contato com o material e deforma elasticamente ao longo de DE e então segue o início do ciclo, com EB. No resfriamento, a deformação da superfície segue o ciclo prévio BC, CD. Assim, a histerese do ciclo é estabelecida, onde o material da superfície do cilindro deforma com subsequentes ciclos e 
revoluções. O resultado é a fadiga térmica que geralmente produz uma fina malha de trincas na superfície do cilindro.

O desenvolvimento do diagrama tensão-deformação representado na Figura 21 foi feito utilizando o procedimento de cálculo de Northcott e Baron, apresentado em 1956 [46]. Em 1979, Malm e Norströn [47] consideraram o mesmo conceito para traçar as curvas da Figura 22, que mostra esquematicamente as tensões e deformações causadas pelo ciclo térmico. Como pode ser visto, existem basicamente duas deformações elásticas envolvidas, uma na temperatura mínima e outra na temperatura máxima. Partindo do ponto $\mathrm{T}_{1}$, o material está em uma condição livre de tensões (ponto 0 na Figura 22). Ao primeiro aquecimento, partindo de $\mathrm{T}_{1}$ para $\mathrm{T}_{2}$, o caminho é definido como $0 \rightarrow \mathrm{A} \rightarrow \mathrm{B}$. No ponto $\mathrm{A}$, a tensão termicamente induzida ultrapassa o limite de escoamento do material e segue a curva até o ponto B. A deformação plástica compressiva que ocorre no primeiro aquecimento é denominada $\varepsilon \mathrm{p}_{0}$. No resfriamento subsequente, de $\mathrm{T}_{2}$ para $\mathrm{T}_{1}$, o que implica o caminho de tensão/deformação $\mathrm{B} \rightarrow \mathrm{C} \rightarrow \mathrm{D}$, a deformação plástica trativa é então denominada $\mathrm{Ep}$.

\section{Considerando-se que:}

a) Prevalece o caso particular do estado plano de tensões, ou seja, o corpo é fixado em um plano, mas é livre para expandir na direção perpendicular a este;

b) O material é considerado isotrópico (propriedades mecânicas e térmicas são as mesmas em todas as direções) e com um comportamento elasto-plástico ideal (não existe encruamento);

c) Todo corpo passa de uma temperatura para outra instantaneamente, ou seja, não há gradiente térmico ao longo do corpo nas temperaturas consideradas. 


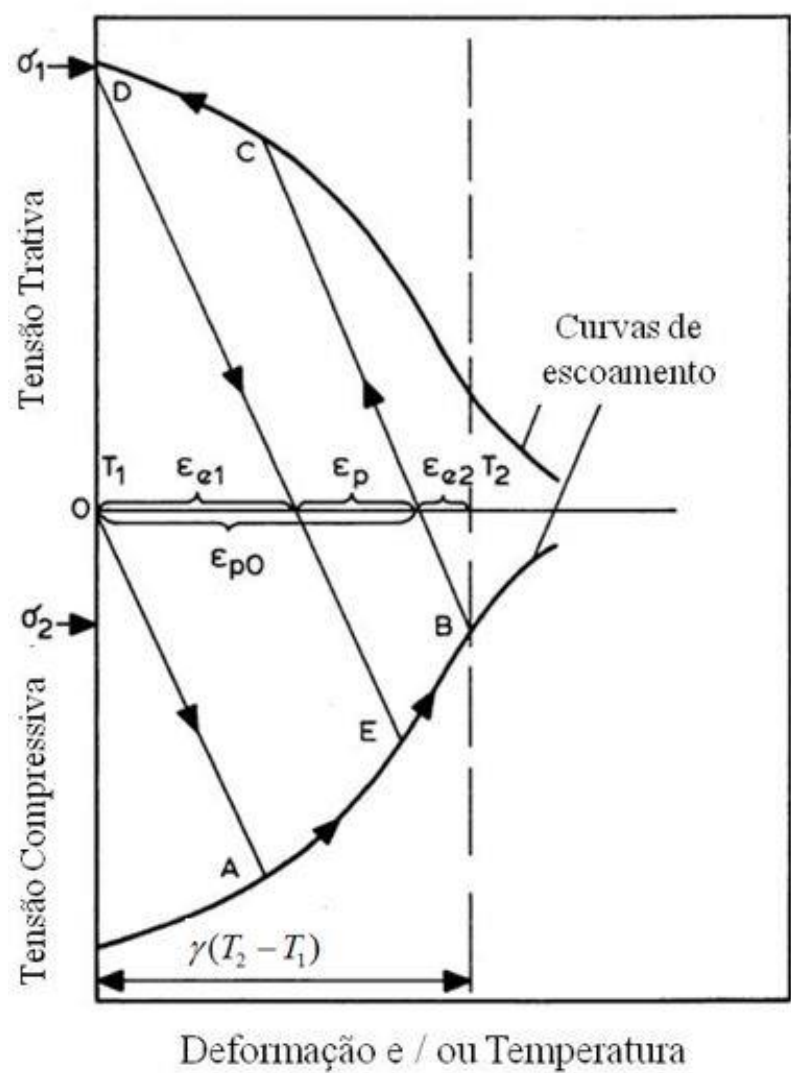

Figura 22. Tensões e deformações durante o ciclo térmico entre temperaturas $\mathrm{T}_{1}$ e $\mathrm{T}_{2}\left(\mathrm{~T}_{1}<\mathrm{T}_{2}\right)$. Adaptado de [47].

quando a temperatura da superfície aumenta, ocorre o aumento das deformações elásticas, em iguais proporções, nos sentidos axial e circunferencial do cilindro. Em cada direção do plano, a deformação total do corpo causada por expansão ou contração decorrentes da variação cíclica de temperatura entre uma temperatura menor $\mathrm{T}_{1}$ e uma temperatura maior $\mathrm{T}_{2}$ será:

$$
\varepsilon_{t}=\gamma\left(T_{2}-T_{1}\right)
$$

onde $\gamma$ é o coeficiente de expansão térmica do material. Entretanto, de acordo com a condição (a), o corpo está fixado em um plano; então, para cada direção daquele plano, Et deverá ser compensada pela deformação elástica, Ee, e, se necessário, deformação plástica, Ep. Para cada direção deste plano, a seguinte condição é válida [47]:

$$
\varepsilon_{t}=\varepsilon_{e}+\varepsilon_{p}
$$


Aplicando a Lei de Hooke para um estado plano de tensões e, considerando apenas uma direção deste plano, as deformações elásticas desenvolvidas nas temperaturas mínima, $\mathcal{E e}_{1}$, e máxima, $\mathcal{E e}_{2}$, são:

$$
\begin{gathered}
\varepsilon_{e 1}=\frac{\left(1-v_{1}\right)}{E_{1}} \sigma_{1} \\
\varepsilon_{e 2}=\frac{\left(1-v_{2}\right)}{E_{2}} \sigma_{2}
\end{gathered}
$$

onde $\sigma$ é o limite de escoamento do material do corpo, E é o módulo de elasticidade do material do corpo $v$ é o coeficiente de Poisson do material do corpo e os índices 1 e 2 referemse às temperaturas mínima e máxima, respectivamente. Nas regiões de deformação plástica, a tensão a qualquer temperatura é assumida igual à tensão de escoamento a esta temperatura. A deformação plástica compressiva que ocorre no primeiro aquecimento, $\varepsilon \mathrm{p}_{0}$ é obtida a partir das equações (36) e (38):

$$
\begin{gathered}
\varepsilon_{p 0}=\varepsilon_{t}-\varepsilon_{e 2} \\
\varepsilon_{p 0}=\gamma\left(T_{2}-T_{1}\right)-\frac{\left(1-v_{2}\right)}{E_{2}} \sigma_{2}
\end{gathered}
$$

No resfriamento subsequente, de $\mathrm{T}_{2}$ para $\mathrm{T}_{1}$, a deformação plástica trativa, $\varepsilon p$, é dada pela equação:

$$
\varepsilon_{p}=\gamma_{c i l}\left(T_{2}-T_{1}\right)-\frac{\left(1-v_{2}\right)}{E_{2}} \sigma_{2}-\frac{\left(1-v_{1}\right)}{E_{1}} \sigma_{1}
$$

No próximo ciclo de aquecimento $\mathrm{D} \rightarrow \mathrm{E} \rightarrow \mathrm{B}$ a deformação plástica compressiva será igual a Ep. O primeiro ciclo térmico é único, composto pela deformação plástica compressiva dada pela equação (40) e pela deformação plástica trativa dada peça equação (41). Os demais 
ciclos são idênticos, em que as deformações plásticas compressivas e trativas são iguais e dadas pela equação (41) [47].

As malhas de trinca são formadas devido à fadiga térmica do material do cilindro em cada ciclo/revolução. Este mesmo mecanismo de degradação foi descrito por outros pesquisadores [28, 40, 42, 43]. Le Roux et al. [44] realizaram experimentos com amostras de aço AISI H11 e avaliaram a influência de diferentes amplitudes térmicas e taxas de aquecimento na nucleação e densidade superficial das trincas de fadiga térmica. Os resultados mostram que a amplitude do ciclo térmico influencia de forma significativa o número de ciclos necessários para a nucleação de trincas na superfície das amostras (Figura 23). Isso explica a importância de conhecer a temperatura superficial do cilindro para poder dimensionar o dano que este estará sujeito durante as campanhas de laminação.

O número de ciclos para o surgimento da malha de trincas térmicas ou a quantidade de toneladas produzidas aumenta com a diminuição da deformação plástica por ciclo. A deformação plástica pode ser muito influenciada pelo gradiente de temperatura (entre $\mathrm{T}_{\min } \mathrm{e}$ $\left.\mathrm{T}_{\max }\right)$. A temperatura máxima ocorre no momento do agarre do material pelos cilindros e está diretamente relacionada às condições de agarre. A temperatura mínima pode ocorrer na zona de resfriamento do cilindro e é fortemente dependente das condições de resfriamento [21].

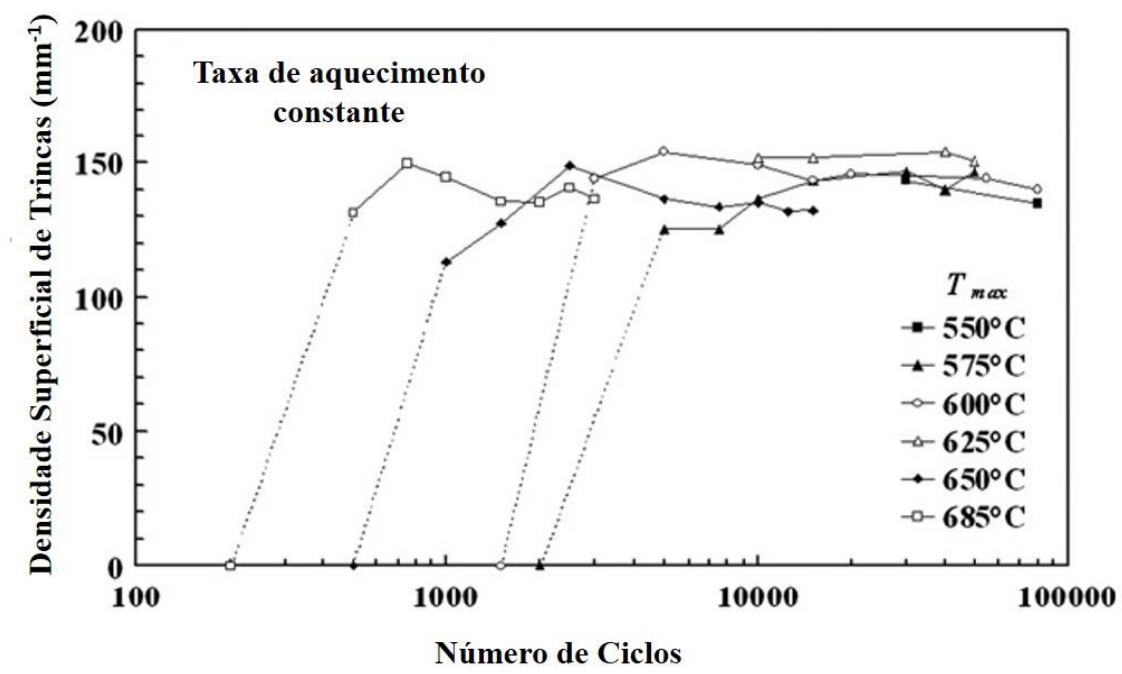

Figura 23. Efeito da temperatura máxima de aquecimento (amplitude do ciclo térmico) no tempo necessário para a nucleação de trincas por fadiga térmica. Adaptado de [44].

Recentemente, outros pesquisadores confirmaram a teoria de que a temperatura máxima de cada ciclo térmico está diretamente relacionada com o grau de deformação 
plástica da superfície, sendo, desta forma, determinante para a previsão de vida em fadiga, como pode ser visto na Figura 24 [43, 45]. A redução das temperaturas mínima e máxima em cada ciclo leva a mudanças nas tensões limites de escoamento a compressão e a tração, resultando em alterações na amplitude de deformação plástica a cada ciclo [41].
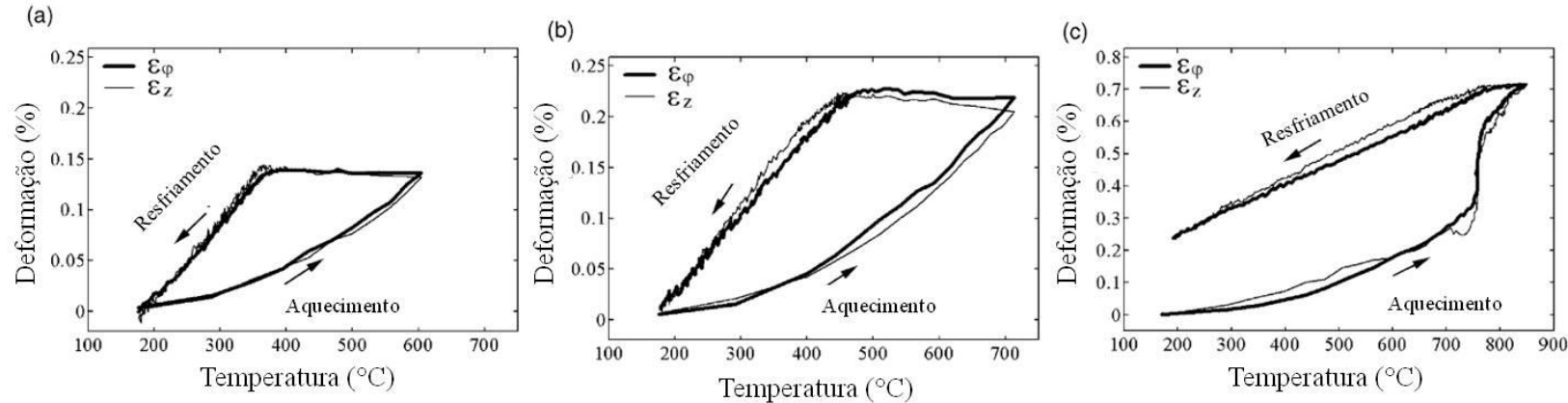

Figura 24. Deformações típicas para o material QRO90 durante o ciclo térmico com resfriamento em ar à temperatura ambiente para as temperaturas máximas de $600^{\circ} \mathrm{C}$ (a), $700^{\circ} \mathrm{C}$, (b) e $850^{\circ} \mathrm{C}$ (c) [45]

Conforme demonstrado nos itens 3.2.1 e 3.2.2, os parâmetros de laminação exercem grande influência na determinação da temperatura máxima superficial do cilindro. Sabe-se, também, que $\mathrm{T}_{\max }$ determina o início da nucleação das trincas térmicas [44, 45]. É de se esperar, portanto, que os parâmetros de laminação influenciem também a magnitude de deformação plástica envolvida em cada ciclo térmico, ou seja, em cada rotação dos cilindros de laminação durante a conformação do material. Dünckelmeyer et al. [48] constataram que menores velocidades de laminação e, consequentemente, maiores tempos de contato, permitirão uma maior transferência de calor para a superfície do cilindro, causando, desta forma, um maior dano acumulado devido a deformações plásticas (Figura 25).

Dünckelmeyer et al. [48] também confirmaram a ideia de que produtos laminados com temperaturas maiores causarão maiores danos acumulados por deformações plásticas, conforme pode ser visto na Figura 26. 


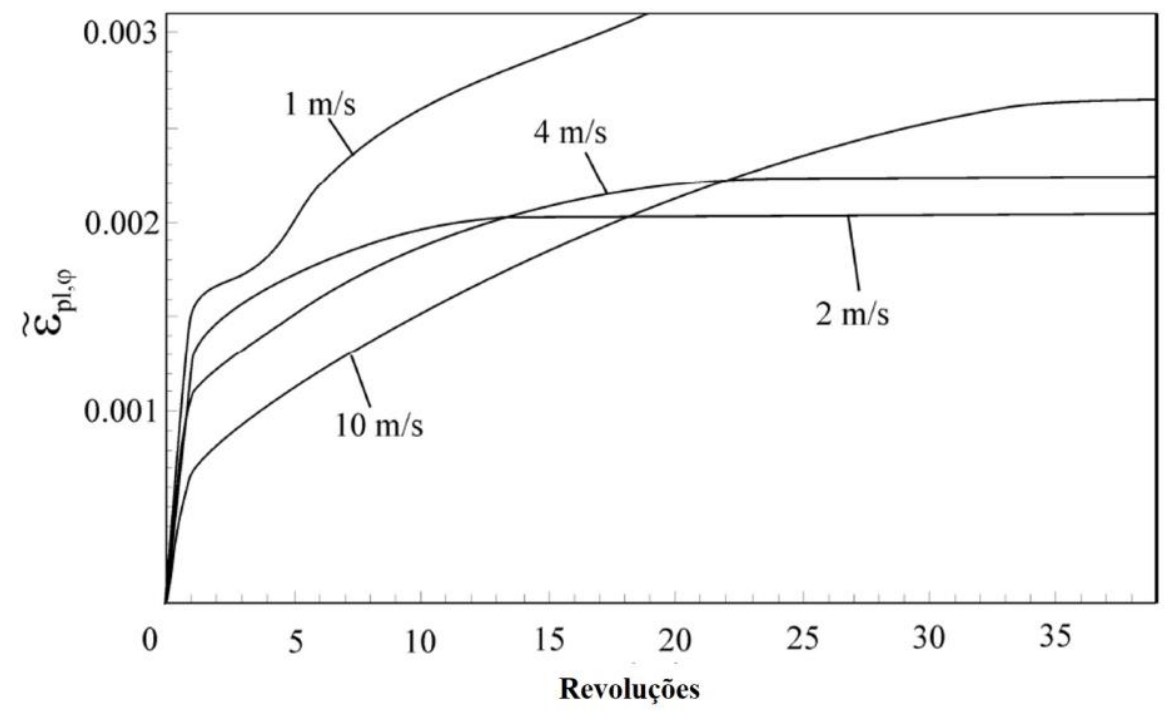

Figura 25. Relação entre velocidade dos cilindros de laminação e o dano plástico acumulado. Adaptado de [48].

A análise do dano térmico em cilindros de laminação a quente possui, fundamentalmente, duas abordagens distintas. Uma delas trata da estimativa da temperatura superficial do cilindro enquanto a outra aborda o conceito de profundidade da camada aquecida como forma de medir a severidade do dano térmico. Ambas abordagens consideram as propriedades físicas do cilindro, bem como pelo menos um parâmetro do processo de laminação.

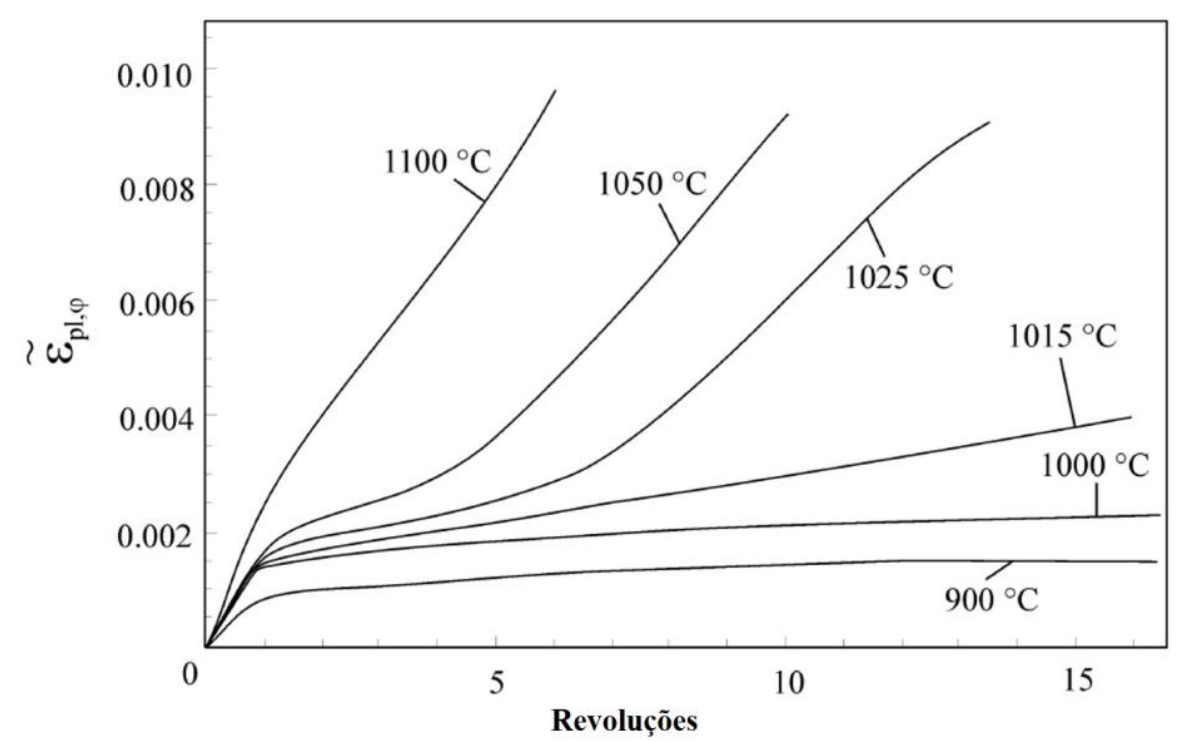

Figura 26. Relação entre temperatura do material laminado e o dano plástico acumulado. Adaptado de [48]. 
A equação (17) de Stevens et al. [22], amplamente utilizada na literatura, permite a determinação da temperatura superficial do cilindro e aborda tanto as propriedades físicas do material laminado e do cilindro, como também utiliza como parâmetro de processo a temperatura de laminação. Existe, entretanto, indicação indireta de outros parâmetros de processo como velocidade de laminação e redução da seção transversal do material, expressos através do tempo de contato entre o produto laminado e o cilindro de trabalho. A equação (12) mostra que o tempo de contato é uma função da velocidade de laminação e do ângulo de contato $(\alpha)$, que por sua vez está diretamente ligado à redução em altura do passe de laminação. A equação de Stevens et al. [22] sinaliza, desta forma, a existência de três parâmetros importantes do processo de laminação a quente: temperatura do material, velocidade de laminação e redução da seção transversal durante a conformação do material.

A equação (28) proposta por Tseng [29] permite a determinação da profundidade da camada aquecida do cilindro de laminação e utiliza propriedades físicas do cilindro, bem como a velocidade de laminação. Diferentemente de Stevens et al., esta abordagem ignora outros parâmetros de processo como temperatura do material e o tempo de contato entre o material e o cilindro, deixando que estes sejam representados de forma indireta por intermédio do coeficiente de transferência de calor $\left(h_{d}\right)$.

Em ambas abordagens, o coeficiente de transferência de calor $\left(h_{d}\right)$ possui grande significância e variações de seu valor causam grande impacto no cálculo da temperatura superficial do cilindro e na profundidade da camada aquecida. As propriedades físicas dos materiais utilizados na fabricação de cilindros de laminação a quente apresentam pequena variação e, matematicamente, exercem menor influência no resultado final de $\mathrm{Tc}_{\mathrm{s}}$ e $\delta$.

O coeficiente de transferência de calor na interface material-cilindro engloba inúmeras interações de variáveis não abordadas diretamente pelas teorias de Stevens et al. [22] e Tseng [29], como por exemplo, variações do arranjo do sistema de refrigeração da superfície do cilindro, forças de laminação, camada de óxido na superfície do cilindro, etc. Muitas vezes, esta constatação torna complexa a utilização destas abordagens para determinação do dano térmico durante as campanhas de laminação. A utilização de um modelo mais simples, que não necessite a utilização do coeficiente de transferência de calor, mas que aborde os principais parâmetros do processo de laminação a quente, pode se tornar uma importante ferramenta de trabalho para o engenheiro de laminação. 


\section{METODOLOGIA}

\subsection{EXPERIMENTOS NO LAMINADOR DO IPT}

Um laminador em escala piloto, do tipo reversível, mostrado na Figura 27, está instalado no Instituto de Pesquisas Tecnológicas (IPT) para realização de campanhas experimentais de laminação a quente. $\mathrm{O}$ equipamento foi automatizado para executar 5 passes de laminação por barra, podendo-se variar parâmetros de laminação. Importante salientar que neste experimento foi utilizado apenas o primeiro passe de laminação. A gaiola de laminação foi montada com cilindros fabricados em aço AISI H13, temperado e revenido para dar uma dureza de aproximadamente 46 Rockwell C. Em um dos cilindros foram instalados termopares para permitir a medição de temperatura na superfície e subsuperfície do cilindro [50].

Um sistema de refrigeração foi projetado para os cilindros superior e inferior, com o objetivo de replicar a condição de operação de um laminador industrial. Foram instalados 12 bocais de refrigeração (6 por cilindro) que projetam água à temperatura ambiente. Durante a operação do laminador, um sistema automatizado aciona apenas os bocais instalados no lado de saída do material do arco de contato, tanto para o cilindro inferior quanto para o superior.
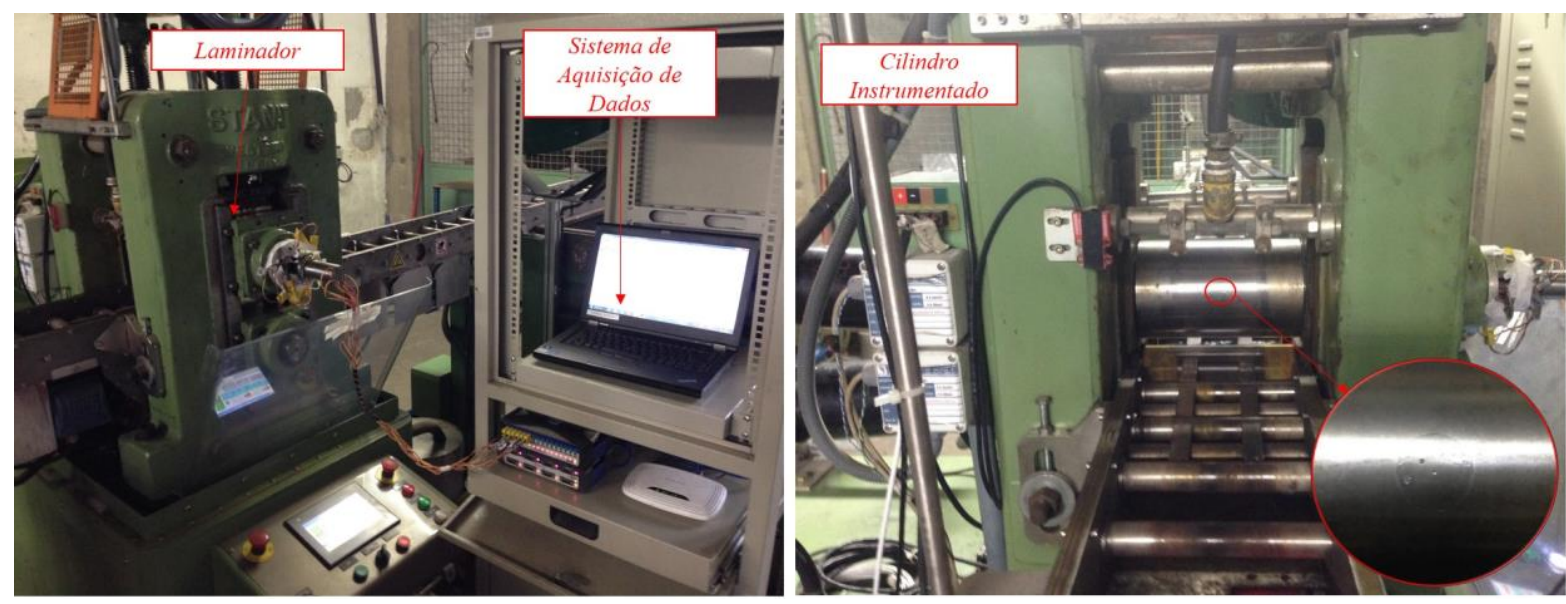

Figura 27. Laminador em escala piloto instalado no IPT

Placas de aço AISI 1045 foram laminadas no equipamento. Antes da conformação, as chapas foram aquecidas em um forno de indução, montado a aproximadamente 1,5 metros dos cilindros, chegando a temperaturas de saída do forno da ordem de $1400{ }^{\circ} \mathrm{C}$. Contudo, a 
distribuição de temperaturas não era uniforme, com as extremidades das chapas finalizando o aquecimento a aproximadamente $1000{ }^{\circ} \mathrm{C}$ [41]. A Figura 28 mostra as amostras utilizadas no experimento e também as diferentes superfícies do material ensaiadas.

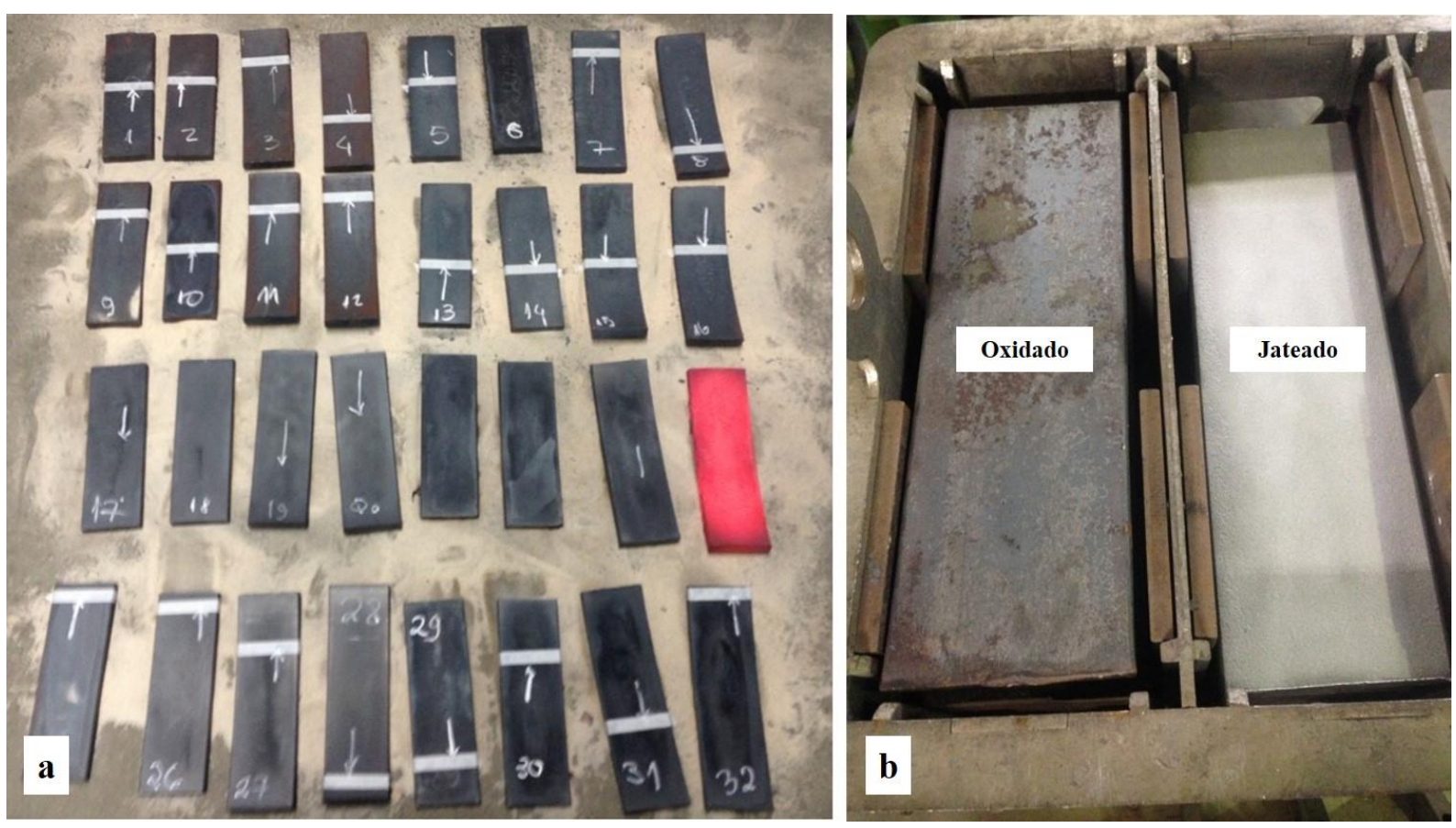

Figura 28. a) Amostras utilizadas no experimento e b) diferença da qualidade superficial das amostras ensaiadas

Além de fazer uma avaliação da campanha de laminação para o laminador piloto do IPT, também foi realizado um estudo para determinar a influência de cada parâmetro de laminação na temperatura superficial dos cilindros. Para tanto, foi realizado um planejamento de experimentos (DOE). Em um DOE, vários fatores são controlados, e seus efeitos sobre algumas respostas são investigados em dois ou mais níveis [49]. Os experimentos fatoriais permitem avaliar o efeito de cada fator de forma individualizada e também a interação entre estes fatores. Um software estatístico chamado Minitab, versão 17.0, foi utilizado para analisar os dados do experimento.

As placas foram testadas com duas condições diferentes de acabamento: oxidação natural e jateamento. A velocidade dos cilindros foi modificada selecionando duas opções de rotação (27 ou $54 \mathrm{rpm}$ ). As temperaturas máxima e mínima medidas nas placas antes e depois da laminação foram de $1150{ }^{\circ} \mathrm{C}$ e $880{ }^{\circ} \mathrm{C}$, respectivamente. A placa tinha espessura, largura e comprimento de $19 \mathrm{~mm}, 92 \mathrm{~mm}$ e $280 \mathrm{~mm}$, respectivamente. As placas foram laminadas considerando-se uma redução de $10 \%$ ou $20 \%$ na espessura, isto é, reduções de $1,90 \mathrm{~mm}$ ou 
$3,80 \mathrm{~mm}$, respectivamente (conforme Tabela 1). A Figura 29 mostra um esquema que representa como foi planejado o experimento no laminador piloto do IPT.

Tabela 1. Experimento realizado no laminador piloto do IPT.

\begin{tabular}{|c|c|c|c|c|}
\hline $\mathbf{N}^{0}$ Teste & $\begin{array}{l}\text { Superfície do } \\
\text { Material }\end{array}$ & $\begin{array}{l}\text { Rotação dos } \\
\text { Cilindros - U } \\
\quad(\mathbf{r p m})\end{array}$ & $\begin{array}{c}\text { Temperatura do } \\
\text { Material - Tm } \\
\left({ }^{\circ} \mathbf{C}\right)\end{array}$ & $\begin{array}{l}\text { Redução de } \\
\text { Altura (\%) }\end{array}$ \\
\hline 1 & oxidado & 27 & 876 & 10 \\
\hline 2 & oxidado & 27 & 880 & 10 \\
\hline 3 & oxidado & 27 & 883 & 20 \\
\hline 4 & oxidado & 27 & 880 & 20 \\
\hline 5 & oxidado & 27 & 1120 & 10 \\
\hline 6 & oxidado & 27 & 1127 & 10 \\
\hline 7 & oxidado & 27 & 1141 & 20 \\
\hline 8 & oxidado & 27 & 1143 & 20 \\
\hline 9 & oxidado & 56 & 890 & 10 \\
\hline 10 & oxidado & 56 & 880 & 10 \\
\hline 11 & oxidado & 56 & 884 & 20 \\
\hline 12 & oxidado & 56 & 879 & 20 \\
\hline 13 & oxidado & 56 & 1123 & 10 \\
\hline 14 & oxidado & 56 & 1131 & 10 \\
\hline 15 & oxidado & 56 & 1132 & 20 \\
\hline 16 & oxidado & 56 & 1138 & 20 \\
\hline 17 & jateado & 27 & 892 & 10 \\
\hline 18 & jateado & 27 & 886 & 10 \\
\hline 19 & jateado & 27 & 892 & 20 \\
\hline 20 & jateado & 27 & 899 & 20 \\
\hline 21 & jateado & 27 & 1125 & 10 \\
\hline 22 & jateado & 27 & 1133 & 10 \\
\hline 23 & jateado & 27 & 1141 & 20 \\
\hline 24 & jateado & 27 & 1134 & 20 \\
\hline 25 & jateado & 56 & 897 & 10 \\
\hline 26 & jateado & 56 & 887 & 10 \\
\hline 27 & jateado & 56 & 893 & 20 \\
\hline 28 & jateado & 56 & 881 & 20 \\
\hline 29 & jateado & 56 & 1124 & 10 \\
\hline 30 & jateado & 56 & 1131 & 10 \\
\hline 31 & jateado & 56 & 1147 & 20 \\
\hline 32 & jateado & 56 & 1154 & 20 \\
\hline
\end{tabular}

Todas as condições do processo foram testadas no laminador piloto e foi possível obter a temperatura da superfície do cilindro utilizando-se os termopares instalados em sua superfície. A Figura 30 mostra o perfil de temperatura durante um ciclo térmico. É importante 
notar que neste experimento, a temperatura máxima medida na superfície do cilindro foi de aproximadamente $300{ }^{\circ} \mathrm{C}$.

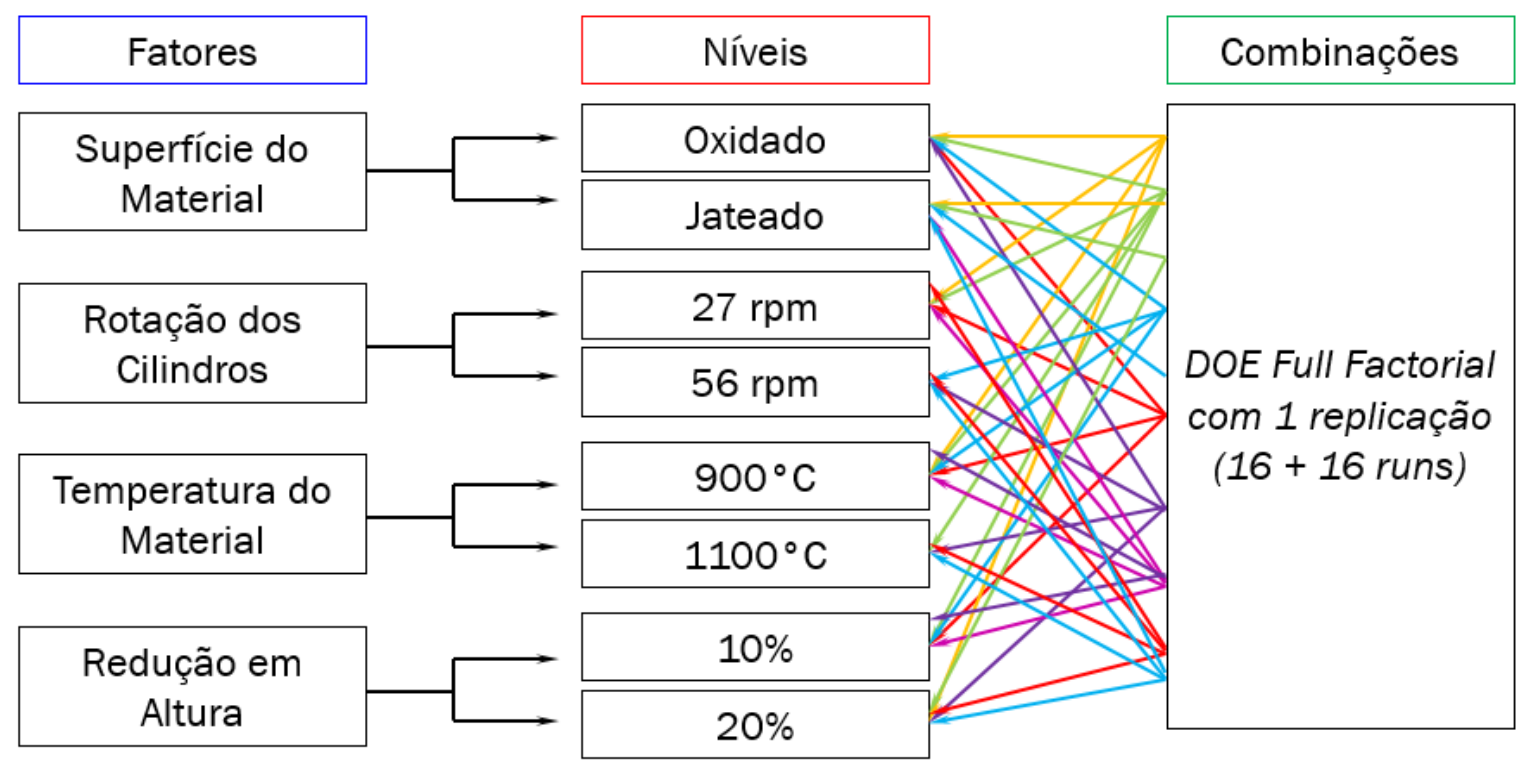

Figura 29. Planejamento do experimento Full Factorial

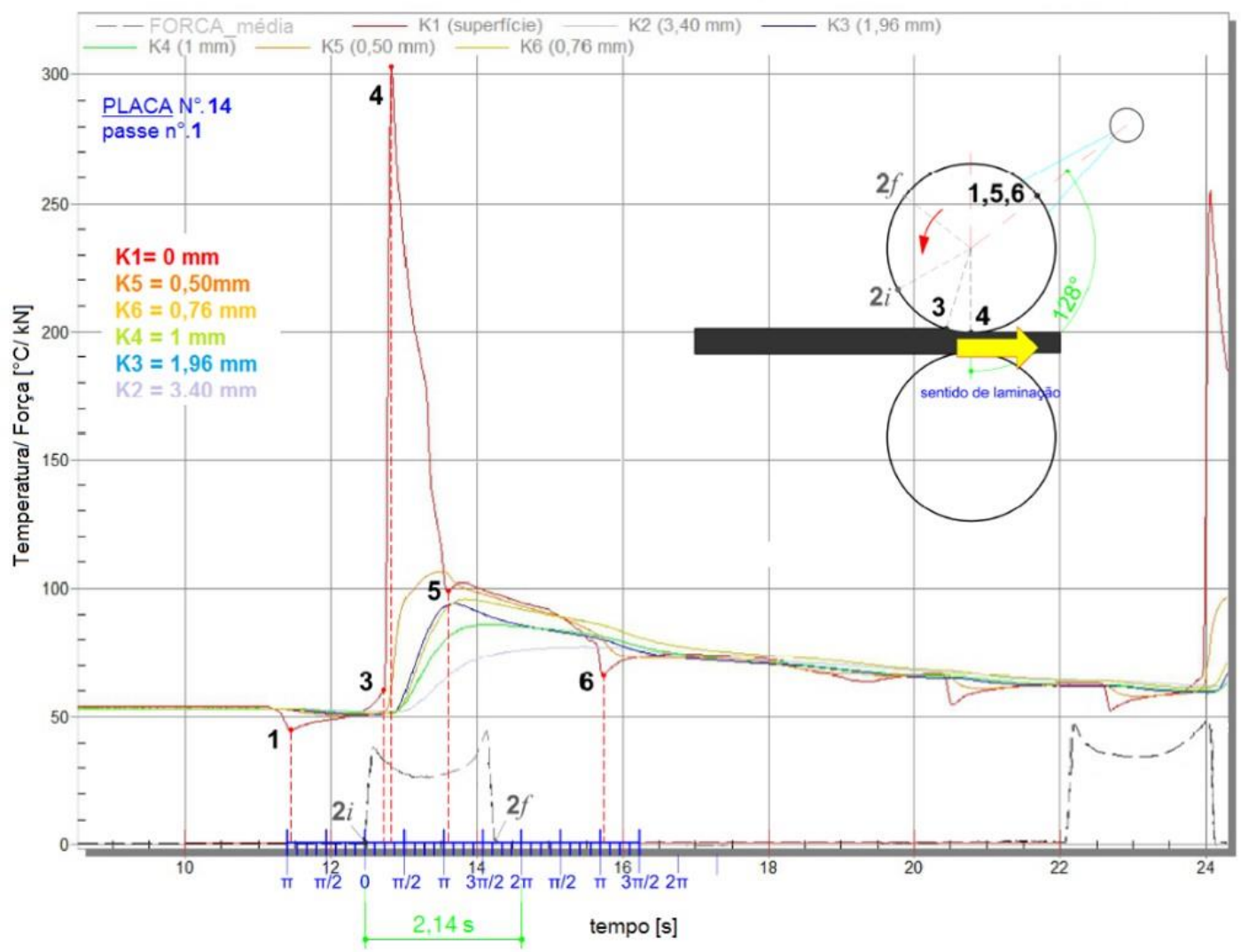

Figura 30. Perfil de temperatura durante o ciclo térmico [41]. 
Estudos semelhantes mostraram que a temperatura da superfície do cilindro em um laminador industrial é de cerca de $500{ }^{\circ} \mathrm{C}$. Stevens et al. [22] mediram uma temperatura de $535{ }^{\circ} \mathrm{C}$ na primeira gaiola de desbaste em seu estudo de laminação. Ye [28] mediu $455^{\circ} \mathrm{C}$ na segunda gaiola de laminação em seu trabalho. Wright [7] calculou um pico de $415{ }^{\circ} \mathrm{C}$ usando o método dos elementos finitos.

A diferença entre os dados medidos e os descritos na literatura pode estar associada à montagem do conjunto de termopares no cilindro usado no IPT. Contudo, mesmo que fosse possível medir temperaturas mais altas, os efeitos de cada parâmetro não se alteram, pois representam como é alterada a variável resposta quando se alteram parâmetros de entrada do experimento. Para comprovar esta afirmação, os Anexos E e F apresentam as rotinas usadas no planejamento de experimentos, considerando: (i) as temperaturas medidas e (ii) estas mesmas temperaturas medidas acrescidas de um valor constante de $300{ }^{\circ} \mathrm{C}$. Uma comparação dos resultados do Anexo F, com os das Figuras 36 a 38 indicam que os coeficientes da equação (43) seriam os mesmos. A explicação para esta semelhança se dá pelo fato de que, em um planejamento de experimentos full factorial onde os fatores possuem dois níveis, como é o caso dos quatro fatores analisados no experimento do IPT, o efeito principal estimado é a diferença entre as respostas médias nos dois níveis. Se ocorrer um incremento na variável resposta, de igual magnitude para todos os fatores, a diferença entre as respostas médias nos dois níveis ainda será a mesma.

\subsection{EXPERIMENTOS NOS LAMINADORES INDUSTRIAIS}

Para o estudo, utilizaram-se informações técnicas disponíveis de três laminadores industriais da Gerdau Aços Especiais, sendo dois deles laminadores de perfis leves e um laminador de perfis pesados. O laminador \#1 produz perfis leves (Figura 31) e é um equipamento composto por três laminadores distintos: um laminador de desbaste com uma gaiola TRIO, um laminador intermediário composto por quatro gaiolas TRIO e um laminador contínuo composto por 12 gaiolas DUO. Toda a análise deste trabalho é feita baseando-se apenas no laminador contínuo, o qual possui nos passes $n^{\circ} 2,4,9$ e 11 cilindros formadores de borda, ou canteadores, que não foram avaliados. Os demais passes são constituídos por cilindros "mesa lisa", ou seja, sem geometria de canal. 


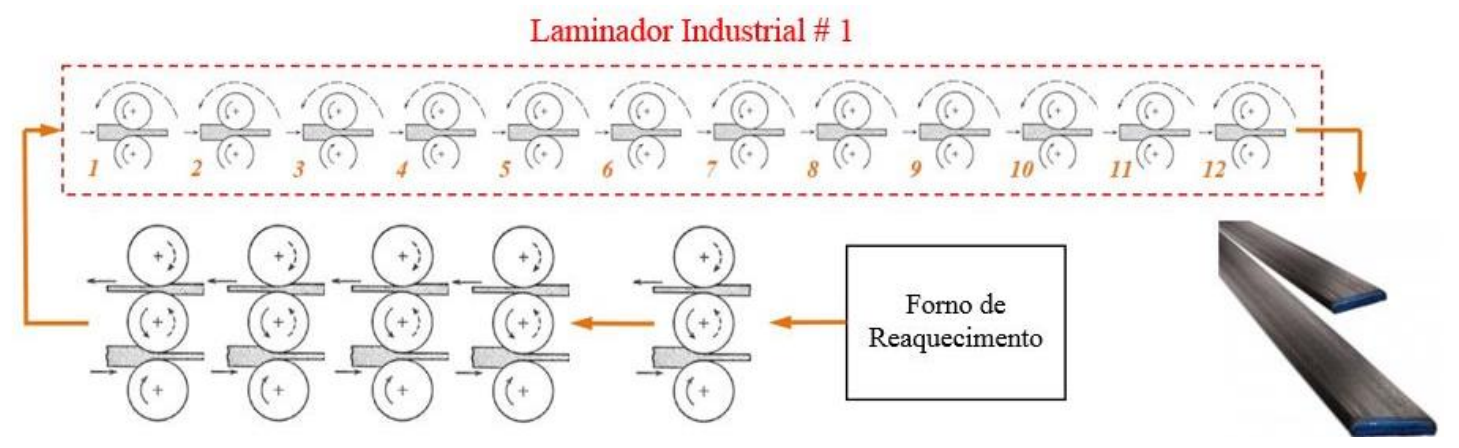

Figura 31. Layout do laminador industrial \#1.

Os cilindros "mesa lisa" montados em uma gaiola de laminação podem ser utilizados formando-se 5 ou 6 canais de laminação, dependendo da largura da barra. A Figura 32 mostra o que está sendo considerado como um canal de laminação de um cilindro "mesa lisa". Os cilindros avaliados neste laminador industrial são de ferro fundido centrifugado com posterior tratamento térmico para alívio de tensões (o Anexo B apresenta propriedades do material do cilindro).
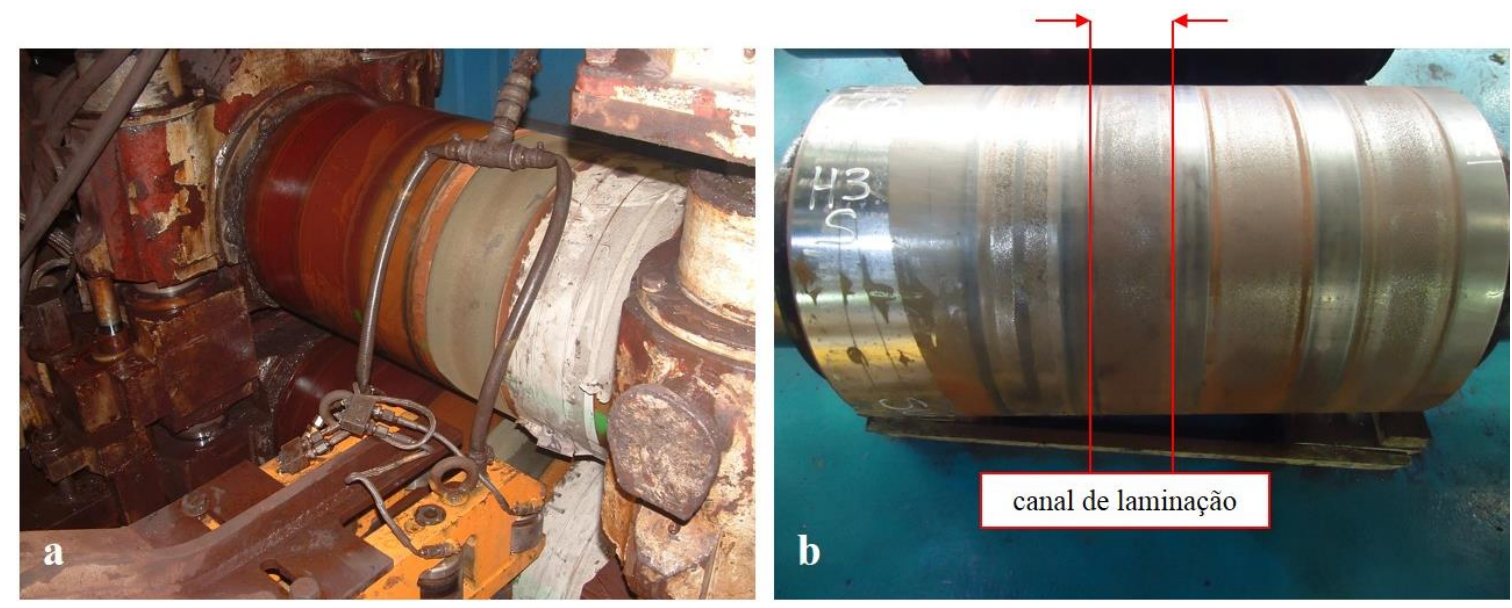

Figura 32. a) visão geral de uma gaiola de laminação do trem contínuo b) esquema que mostra o que é considerado como sendo o canal de laminação de um cilindro "mesa lisa"

O laminador \#2 também produz perfis leves (Figura 33) e é um equipamento composto por 18 gaiolas DUO posicionadas em linha, de forma contínua. Da mesma forma que o laminador \#1, os passes 7, 9, 11, 13, 15 e 17 possuem gaiolas verticais, montadas com cilindros canteadores, que não foram avaliados. As gaiolas anteriores ao passe 6 também não foram avaliadas, por não possuírem o canal de laminação mesa lisa. Os cilindros avaliados neste laminador industrial são de ferro fundido, obtidos pelo processo de fundição 
convencional com posterior tratamento térmico de austêmpera e revenimento (o Anexo C apresenta propriedades do material do cilindro).

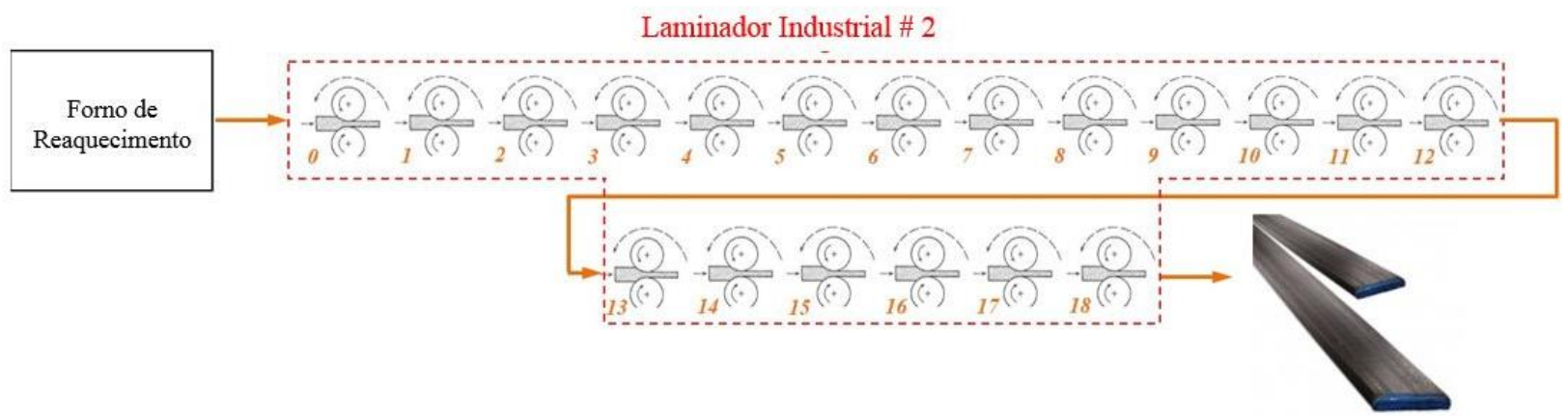

Figura 33. Layout do laminador industrial \#2.

O laminador \#3 produz perfis pesados (Figura 34) e é um equipamento composto por uma gaiola blooming, ou seja, uma gaiola DUO reversível de desbaste. Este laminador, diferentemente dos laminadores \#1 e \#2, recebe lingotes do forno de reaquecimento ao invés de tarugos. Foram avaliados três tipos de lingotes diferentes para a mesma gaiola de laminação, conforme Tabela 2. Os cilindros avaliados neste laminador industrial possuem material e fabricação idênticos aos utilizados no laminador \#2.

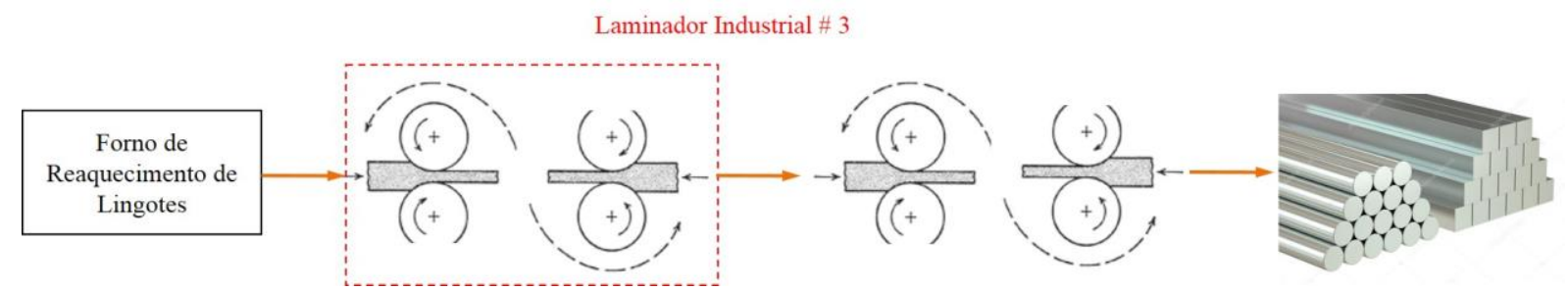

Figura 34. Layout do laminador industrial \# 3.

Para todos os experimentos industriais, o material laminado foi o SAE 5160 (o Anexo A apresenta propriedades do material laminado). A sequência de passes de laminação (reduções) é referida como sendo sua "calibração". Foram calculados os valores médios para os principais parâmetros da laminação do produto "perfil chato" para cada uma das gaiolas estudadas. Dentre eles, a redução em altura $\Delta \mathrm{h}$ e a rotação do cilindro U. As temperaturas dos materiais laminados foram medidas nas saídas dos fornos de reaquecimento, e em determinados pontos ao longo da linha de laminação, utilizando-se termômetros 
infravermelho específicos para o processo de laminação a quente (o Anexo D apresenta a especificação deste equipamento). Foram também utilizados os diâmetros nominais de cada cilindro de trabalho.

Foram calculadas as temperaturas superficiais dos cilindros e as profundidades de camada aquecida para cada gaiola estudada. Para estas determinações, foi utilizado o que Stevens et al. [22] definiram em seu trabalho, ou seja, um coeficiente de transferência de calor fixo $\left(41,9 \mathrm{~kW} / \mathrm{m}^{2} \mathrm{~K}\right.$ durante o agarre do material no comprimento projetado do arco de contato e $18 \mathrm{~kW} / \mathrm{m}^{2} \mathrm{~K}$ para o restante do perímetro do cilindro). A escolha destes parâmetros se dá devido à semelhança nas dimensões dos cilindros avaliados no presente trabalho e no estudo de Stevens et al. e por se tratar, igualmente, de laminadores industriais (com a mesma realidade operacional).

Tabela 2. Informações sobre os diferentes tipos de lingotes utilizados na avaliação da gaiola blooming.

\begin{tabular}{ccccc}
\hline Lingote & Peso $(\mathbf{k g})$ & Perfil & $\begin{array}{c}\text { Comprimento } \\
(\mathbf{m m})\end{array}$ & Largura $(\mathbf{m m})$ \\
\hline 134 & 3.230 & Quadrado & 1.637 & 513 \\
544 & 4.200 & Quadrado & 2.005 & 536 \\
574 & 4.620 & Retangular & 1.960 & 628 \\
\hline
\end{tabular}

Durante as campanhas de laminação foram feitas interrupções para inspeção e análise da superfície do cilindro com o objetivo identificar trincas térmicas. Ao final das campanhas, os cilindros foram submetidos a uma inspeção utilizando-se o ensaio por líquidos penetrantes. Foram correlacionados cada parâmetro de processo estudado (redução, rotação do cilindro e temperatura do material) com a temperatura superficial do cilindro (calculada) e com a profundidade da camada aquecida (calculada), equações (17) e (28), respectivamente.

A Tabela 3 especifica quais foram as gaiolas de laminação estudadas e contém informações de medições realizadas (diâmetro e temperatura do material) e de alguns parâmetros de laminação calculados: redução e rotação dos cilindros, utilizando-se as equações (5) e (12), respectivamente. 
Tabela 3. Laminadores e gaiolas estudadas com parâmetros de laminação calculados e temperatura do material medida pelo termômetro infravermelho.

\begin{tabular}{|c|c|c|c|c|c|}
\hline Laminador & Gaiola & $\begin{array}{c}\text { Diâmetro do } \\
\text { Cilindro (mm) }\end{array}$ & $\begin{array}{c}\text { Redução de } \\
\text { Altura }-\Delta \mathrm{h}(\mathrm{mm}) \\
- \text { Eq. } 5 \\
\end{array}$ & $\begin{array}{c}\text { Rotação dos } \\
\text { Cilindros - U (rpm) } \\
\text { - Eq. 12 } \\
\end{array}$ & $\begin{array}{l}\text { Temperatura do } \\
\text { Material - } \mathbf{T m}\left({ }^{\circ} \mathbf{C}\right)\end{array}$ \\
\hline \multirow{8}{*}{$\# 1$} & $\# 1$ & 472 & 21,1 & 35 & 1015 \\
\hline & $\# 3$ & 472 & 14,9 & 53 & 1010 \\
\hline & \# 5 & 472 & 10,6 & 78 & 1005 \\
\hline & \# 6 & 350 & 3,2 & 125 & 990 \\
\hline & \# 7 & 350 & 2,8 & 143 & 985 \\
\hline & $\# 8$ & 350 & 2,3 & 167 & 980 \\
\hline & \# 10 & 350 & 1,7 & 196 & 970 \\
\hline & $\# 12$ & 350 & 1,4 & 225 & 960 \\
\hline \multirow{7}{*}{$\# 2$} & $\# 6$ & 405 & 39,5 & 33 & 1150 \\
\hline & $\# 8$ & 405 & 18,7 & 44 & 1140 \\
\hline & \# 10 & 405 & 7,5 & 60 & 1130 \\
\hline & \# 12 & 350 & 4,6 & 99 & 1120 \\
\hline & \# 14 & 350 & 4,1 & 125 & 1110 \\
\hline & \# 16 & 350 & 3,5 & 156 & 1100 \\
\hline & \# 18 & 350 & 1,3 & 195 & 1090 \\
\hline \multirow{3}{*}{$\# 3$} & LG134 & 950 & 42,0 & 95 & 1250 \\
\hline & LG544 & 950 & 43,7 & 95 & 1250 \\
\hline & LG574 & 950 & 35,5 & 95 & 1250 \\
\hline IPT & $\# 1$ & 127 & 2,9 & 27 & 1271 \\
\hline
\end{tabular}

\subsection{MODELO NUMÉRICO}

Baseado nas configurações operacionais dos laminadores industriais, foram desenvolvidos modelos de elementos finitos termo-estruturais acoplados, utilizando o software comercial ABAQUS/Explicit. A Figura 35 mostra a descrição e detalhe da malha de elementos finitos utilizada no modelo bi-dimensional desenvolvido por Lima [40] para o laminador de Stevens et al. [21], e aplicado às condições operacionais dos laminadores industriais \#1, \#2 e \#3, com as seguintes considerações:

- Modelo elástico perfeitamente plástico;

- Coeficiente de transferência de calor fixo $\left(41,9 \mathrm{~kW} / \mathrm{m}^{2} \mathrm{~K}\right.$ durante o agarre do material no comprimento projetado do arco de contato e $18 \mathrm{~kW} / \mathrm{m}^{2} \mathrm{~K}$ para o restante do perímetro do cilindro); 
- As temperaturas na superfície dos cilindros não foram calculadas e sim informadas no modelo (baseando-se na utilização da Equação (17));

- O coeficiente de expansão térmica $\gamma_{c i l}$ e o Módulo de Elasticidade E foram considerados constantes em função da temperatura.

- Propriedades físicas e mecânicas do material laminado e dos cilindros de laminação conforme Anexos A, B e C.

Uma descrição mais detalhada das simulações pode ser obtida em Lima [40]. Os parâmetros de laminação usados em [40] não foram exatamente os mesmos, mas o procedimento numérico foi igual.

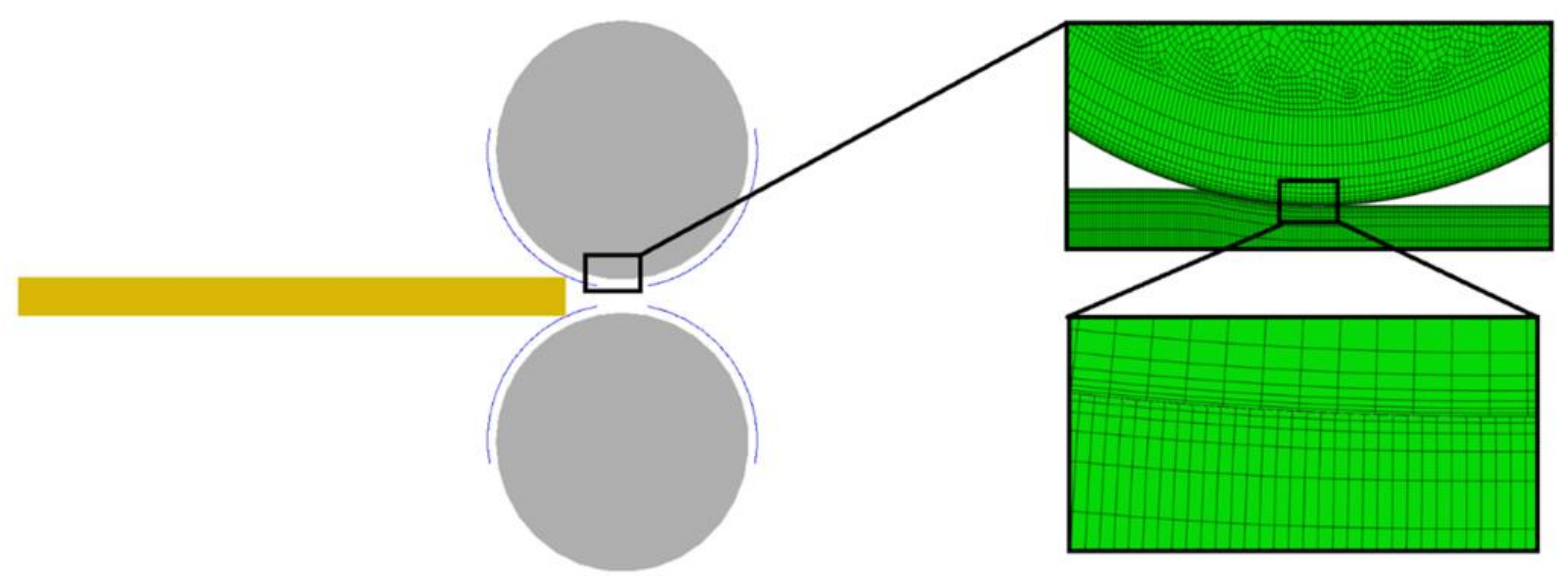

Figura 35. Descrição e detalhe da malha de elementos finitos dos modelos bidimensionais [40]. 


\section{RESULTADOS}

\subsection{DETERMINAÇÃO DO MODELO PARA O LAMINDOR DO IPT}

A técnica de planejamento de experimentos (designs of experiments- DOE) foi aplicada no laminador piloto para possibilitar a determinação dos efeitos dos parâmetros de entrada do modelo (condição superficial do material, temperatura do material, rotação dos cilindros e redução em altura) no parâmetro de saída (temperatura superficial dos cilindros). O planejamento pode ser visto na Tabela 4 , juntamente com as respostas para a temperatura superficial do cilindro.

As Figura 36 e 37 mostram os resultados da análise fatorial e indicam que o parâmetro mais significativo, ou o fator com efeito mais significativo sobre a temperatura da superfície, é a redução. Este fator é três vezes mais significativo que o segundo parâmetro mais importante, a rotação. O terceiro parâmetro significativo é a temperatura do material. A condição da superfície do material (oxidado e decapado) não foi significativa para a temperatura da superfície do cilindro.

Os resultados do experimento corroboram, em parte, com a literatura estudada. Zhou [6] já havia demonstrado através da Fig.17, que uma maior redução durante o passe de laminação, e consequentemente, uma maior pressão dos cilindros sobre o material conformado, geram maior coeficiente de transferência de calor e, desta forma, uma maior temperatura superificial dos cilindros. Li et al. [35] também apontam como muito significativa a influência da redução no coeficiente de transferência de calor (Figura 18). Serajdazeh [26] apresenta resultados de simulação numérica que, para uma determinada condição, mostram que uma redução de $15 \%$ no passe de laminação causa uma temperatura superficial dos cilindros de $380^{\circ} \mathrm{C}$, enquanto uma redução de $24 \%$ no passe de laminação acarreta uma temperatura de $450^{\circ} \mathrm{C}$ (Figura 10a).

A Figura $10 \mathrm{~b}$ apresenta a influência da velocidade de laminação na temperatura superficial dos cilindros e confirma a importância deste parâmetro na variável resposta analisada. Na primeira revolução dos cilindros, com uma redução de $15 \%$ no passe de laminação e com uma velocidade de $1,5 \mathrm{~m} / \mathrm{s}$, foi possível atingir uma temperatura na superfície dos cilindros de $320^{\circ} \mathrm{C}$, enquanto com uma velocidade de $1,1 \mathrm{~m} / \mathrm{s}$ a temperatura calculada foi de $350^{\circ} \mathrm{C}$. 
Tabela 4. Resultado do experimento realizado no laminador piloto do IPT.

\begin{tabular}{|c|c|c|c|c|c|}
\hline$N^{o}$ Teste & $\begin{array}{l}\text { Superfície do } \\
\text { Material }\end{array}$ & $\begin{array}{l}\text { Rotação dos } \\
\text { Cilindros - U } \\
\quad(\text { rpm) }\end{array}$ & $\begin{array}{c}\text { Temperatura do } \\
\text { Material - Tm } \\
\left({ }^{\circ} \mathbf{C}\right)\end{array}$ & $\begin{array}{l}\text { Redução de } \\
\text { Altura (\%) }\end{array}$ & $\begin{array}{c}\text { Temperatura } \\
\text { Superficial - Tcs } \\
\left({ }^{\circ} \mathbf{C}\right)\end{array}$ \\
\hline 1 & oxidado & 27 & 876 & 10 & 92,11 \\
\hline 2 & oxidado & 27 & 880 & 10 & 124,61 \\
\hline 3 & oxidado & 27 & 883 & 20 & 237,17 \\
\hline 4 & oxidado & 27 & 880 & 20 & 225,53 \\
\hline 5 & oxidado & 27 & 1120 & 10 & 139,13 \\
\hline 6 & oxidado & 27 & 1127 & 10 & 101,73 \\
\hline 7 & oxidado & 27 & 1141 & 20 & 289,40 \\
\hline 8 & oxidado & 27 & 1143 & 20 & 251,56 \\
\hline 9 & oxidado & 56 & 890 & 10 & 59,26 \\
\hline 10 & oxidado & 56 & 880 & 10 & 76,06 \\
\hline 11 & oxidado & 56 & 884 & 20 & 196,91 \\
\hline 12 & oxidado & 56 & 879 & 20 & 190,28 \\
\hline 13 & oxidado & 56 & 1123 & 10 & 120,31 \\
\hline 14 & oxidado & 56 & 1131 & 10 & 101,48 \\
\hline 15 & oxidado & 56 & 1132 & 20 & 217,79 \\
\hline 16 & oxidado & 56 & 1138 & 20 & 238,87 \\
\hline 17 & jateado & 27 & 892 & 10 & 117,11 \\
\hline 18 & jateado & 27 & 886 & 10 & 112,35 \\
\hline 19 & jateado & 27 & 892 & 20 & 243,09 \\
\hline 20 & jateado & 27 & 899 & 20 & 263,18 \\
\hline 21 & jateado & 27 & 1125 & 10 & 142,70 \\
\hline 22 & jateado & 27 & 1133 & 10 & 116,53 \\
\hline 23 & jateado & 27 & 1141 & 20 & 314,72 \\
\hline 24 & jateado & 27 & 1134 & 20 & 297,70 \\
\hline 25 & jateado & 56 & 897 & 10 & 57,98 \\
\hline 26 & jateado & 56 & 887 & 10 & 70,92 \\
\hline 27 & jateado & 56 & 893 & 20 & 203,17 \\
\hline 28 & jateado & 56 & 881 & 20 & 197,44 \\
\hline 29 & jateado & 56 & 1124 & 10 & 105,99 \\
\hline 30 & jateado & 56 & 1131 & 10 & 103,00 \\
\hline 31 & jateado & 56 & 1147 & 20 & 231,11 \\
\hline 32 & jateado & 56 & 1154 & 20 & 215,53 \\
\hline
\end{tabular}

A não significância do tratamento superficial do material não era esperada, pois a literatura confirma a influência deste parâmetro na dinâmica de troca de calor entre o material laminado e os cilindros $[35,41,51]$. A explicação para este resultado pode estar no fato de que as interações entre a camada de óxido e a superfície do cilindro ocorrem em uma escala microscópica, e, talvez, o laminador piloto do IPT, da forma como foi concebido conceitualmente, não possua a sensibilidade necessária para acusar estas alterações na variável resposta durante os experimentos. O ponto importante é que os parâmetros de 
laminação estão interligados de uma maneira complexa e não há evidências de uma relação linear entre eles.

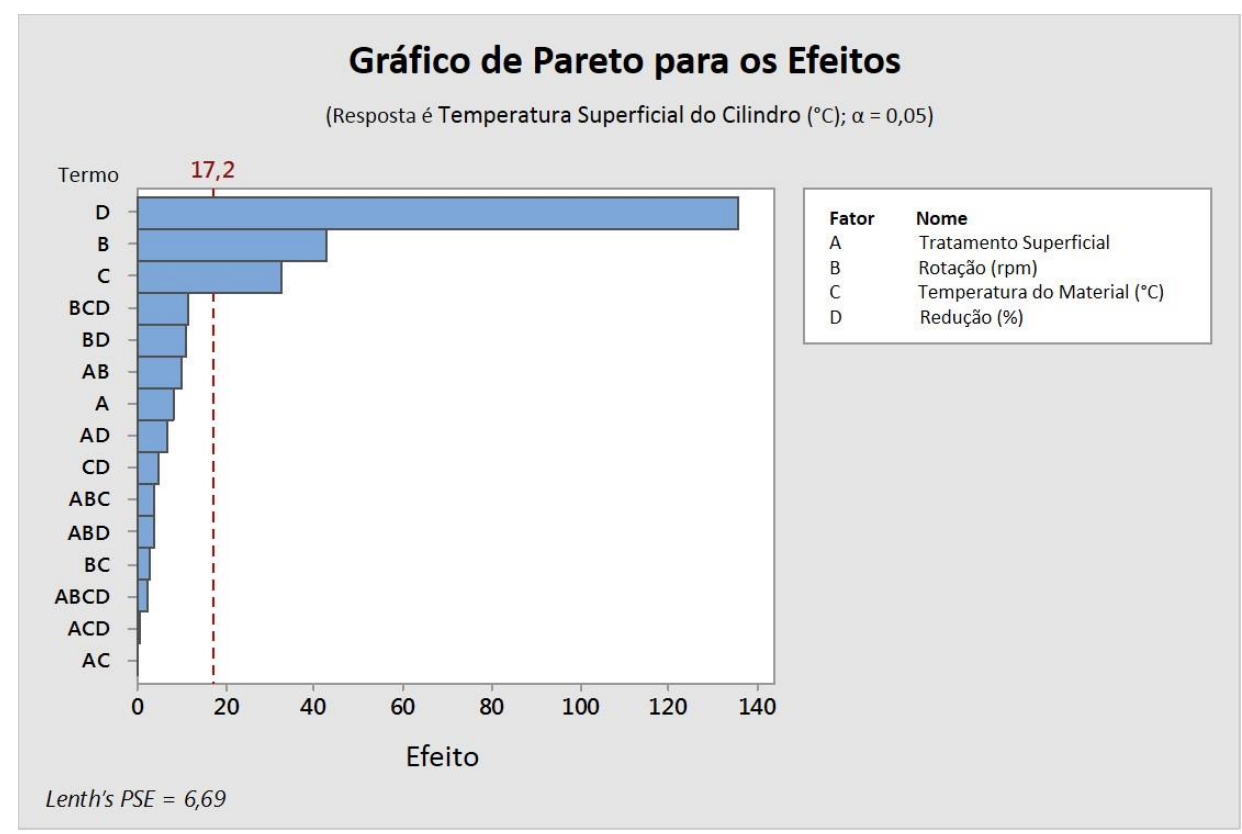

Figura 36. Gráfico de Pareto dos efeitos para a temperatura superficial do cilindro.

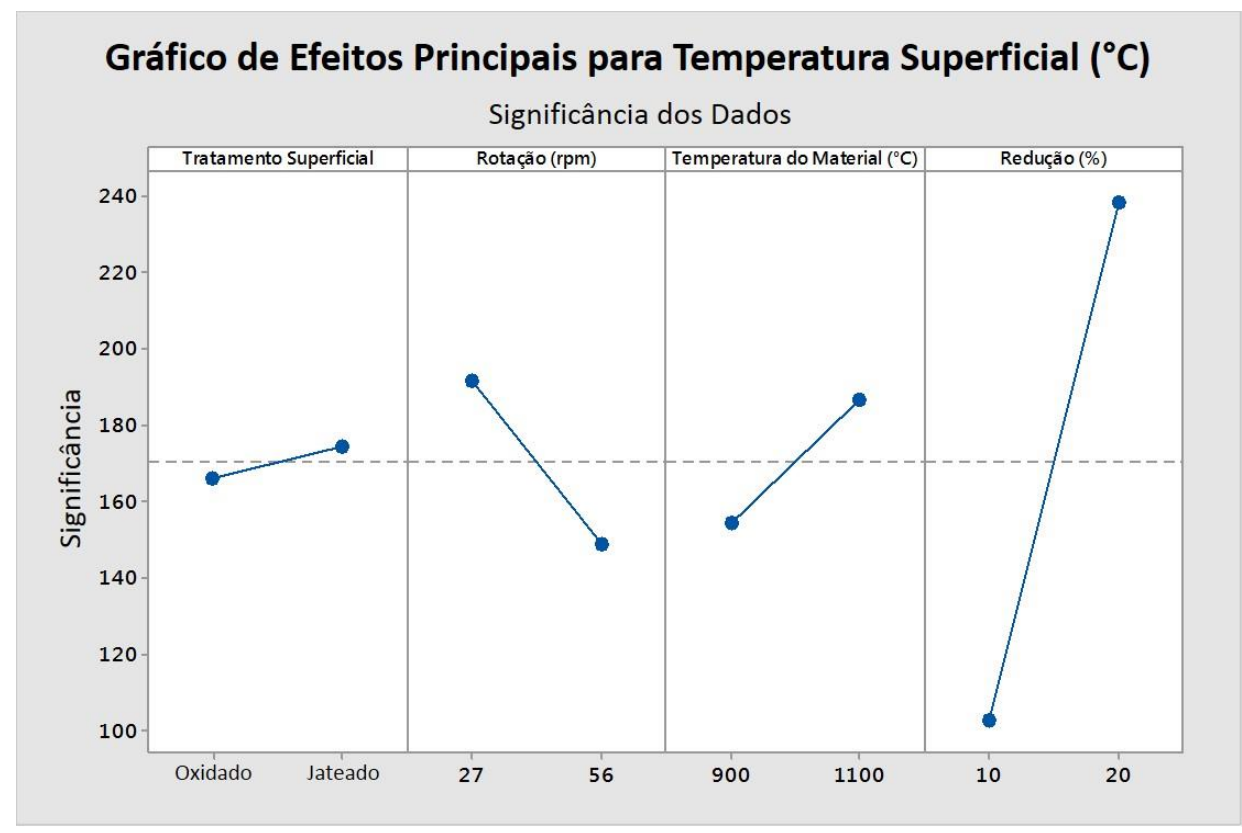

Figura 37. Gráfico de efeitos principais para a temperatura superficial do cilindro.

A Figura 38 apresenta todas as interações possíveis entre os parâmetros estudados. Verifica-se que não existem interações fortes, ou seja, nenhuma relação combinada entre os 
parâmetros torna-se mais significativa que cada um deles de forma individualizada, quando avalia-se a temperatura superficial do cilindro de laminação como resposta do experimento.

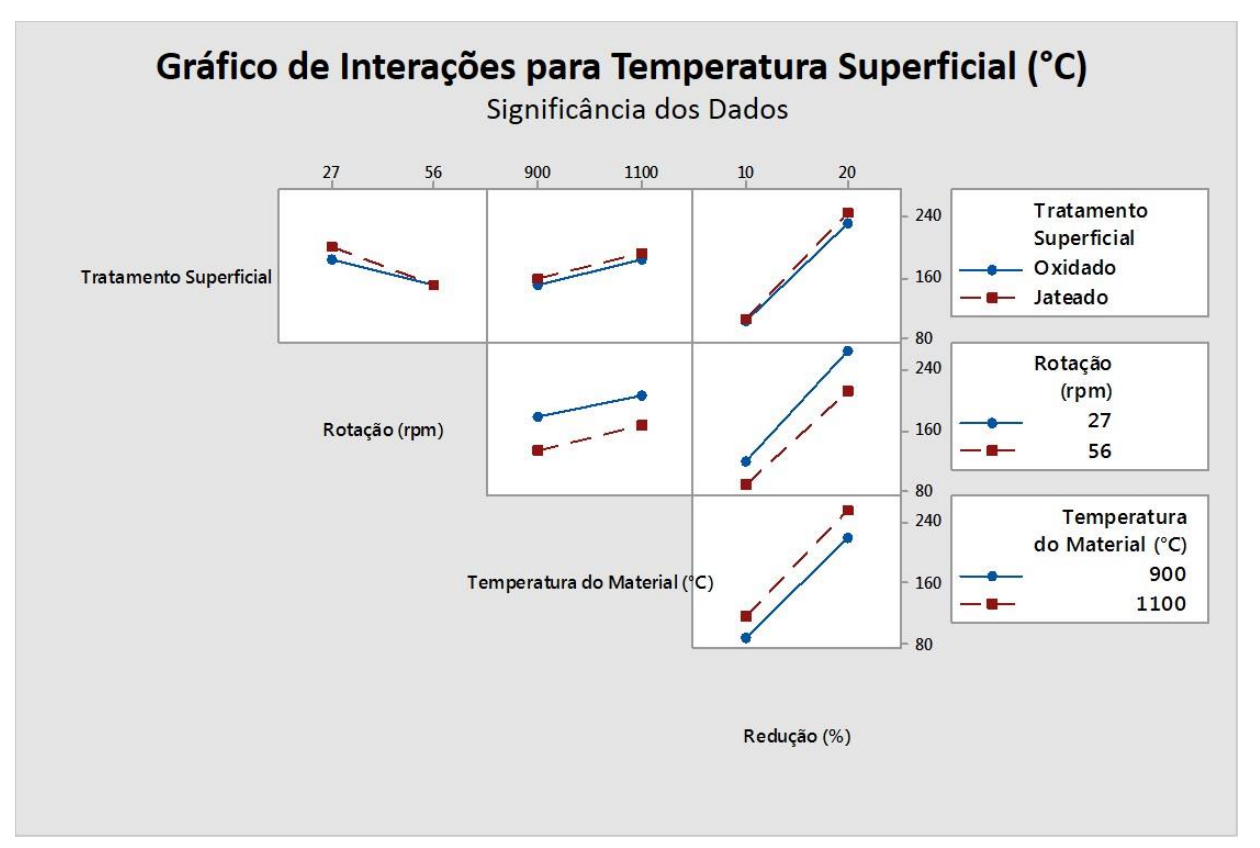

Figura 38. Gráfico de interações para a temperatura superficial do cilindro.

De posse dos resultados obtidos através do experimento fatorial completo, e aplicando-se técnicas estatísticas para o tratamento dos dados como análise de variância e análise de regressão, é possível a determinação de uma equação que prevê a temperatura superficial dos cilindros do laminador do IPT. A equação (42) apresentou um coeficiente de determinação $\left(\mathrm{R}^{2}\right)$ de $98,97 \%$ para os dados amostrados e possui aplicação apenas para o laminador do IPT. Importante salientar também que esta equação foi obtida considerando-se as medições de temperatura superficial do cilindro medidas pelo termopar. Conforme discutido anteriormente, considerando-se que as temperaturas são, na realidade maiores, é necessário modificar o primeiro termo da equação (42) adicionando-se o incremento de temperatura requerido.

$$
\begin{aligned}
& T c_{s}=361-11,67 U-0,373 T m-75,4 \Delta h \\
& +(0,01108 U . T m+3,19 U \cdot \Delta h+0,1610 T m . \Delta h) \\
& -(0,00352 U . T m . \Delta h)
\end{aligned}
$$




\subsection{COEFICIENTE DE DANO À SUPERFÍCIE DO CILINDRO ( $\kappa)$}

Em um planejamento de experimento fatorial completo (full factorial) é possível a determinação de todos os efeitos de primeira ordem, pois todas as condições possíveis são avaliadas. Os efeitos de primeira ordem para os três parâmetros de laminação testados no experimento podem ser vistos na Tabela 5.

\begin{tabular}{cc}
\hline $\begin{array}{c}\text { Tabela 5. Principais efeitos de primeira ordem } \\
\text { (Parâmetros }\end{array}$ & Efeito \\
\hline Redução & 135,76 \\
Rotação & $-42,66$ \\
$\begin{array}{c}\text { Temperatura do } \\
\text { Material }\end{array}$ & 32,52 \\
\hline
\end{tabular}

Esta informação é importante porque permite que seja feita uma boa estimativa do dano causado à superfície do cilindro de laminação, utilizando-se informações que estão disponíveis aos engenheiros de processo. O experimento (DOE) realizado no IPT permitiu a quantificação da relevância de cada parâmetro do processo de laminação a quente na temperatura superficial do cilindro, durante a conformação do material. Diante da necessidade de se possuir um indicador de severidade para o dano térmico do cilindro, que contemple os três principais parâmetros de processo e que seja de fácil utilização por técnicos e engenheiros, propõe-se a determinação de um coeficiente de dano à superfície do cilindro, definido como:

$$
\kappa=(1,3576 \Delta h-0,4266 U+0,3252 T m)
$$

Os valores dos efeitos principais obtidos na Tabela 5 foram divididos por 100 apenas para simplificação matemática, e foram utilizados na equação (43) de forma a quantificar a importância de cada parâmetro do processo de laminação. As unidades de medida de cada um dos parâmetros são milímetros, rotações por minuto e graus Celsius para redução em altura, rotação e temperatura do material, respectivamente. Os efeitos para cada parâmetro foram calculados considerando a temperatura superficial do cilindro, medida pelos termopares 
durante o experimento. Conforme já mencionado, as temperaturas medidas podem ser menores do que os valores reais devido a questões relacionadas com a montagem dos termopares no cilindro.

Uma explicação física que suporta os resultados do experimento e fundamentam o coeficiente de dano à superfície do cilindro $(\kappa)$ pode ser dada quando se considera o fato de que o tempo de contato entre o cilindro e o material, dado pela equação (12), é função do ângulo de contato do cilindro com o material, que por sua vez está diretamente ligado à redução em altura do passe de laminação e também é função da rotação dos cilindros. Maiores temperaturas de laminação acarretarão maior transferência de calor entre o material e os cilindros de trabalho. Menores velocidades e maiores reduções terão como consequência um maior tempo de contato do material com o cilindro, propiciando também, desta forma, uma maior transferência de calor entre o material e os cilindros.

É importante salientar que a composição da equação (43), onde somam-se os produtos de cada parâmetro de laminação com seu respectivo efeito, revela uma importância menor da temperatura do material. É preciso, entretanto, reconhecer que os valores de temperatura que serão inseridos na equação (43), para o processo de laminação a quente, variam entre $900{ }^{\circ} \mathrm{C} \mathrm{e}$ $1200^{\circ} \mathrm{C}$ para a grande maioria dos aços, enquanto os valores de redução, em milímetros, podem variar entre 0,1 e 100, dependendo do desenho do processo. Estas ordens de grandeza tornam, em muitos casos, a temperatura do material determinante para a redução do valor de kappa e consequentemente a redução da probabilidade de incidência de trincas térmicas na superfície do cilindro.

\subsection{EQUAÇÃO QUE DESCREVE A CURVA CARACTERÍSTICA PARA OS LAMINADORES INDUSTRIAIS}

Uma das primeiras constatações das análises dos parâmetros de laminação foi de que, assim como na análise de vibrações, no campo da manutenção preditiva de equipamentos, onde cada máquina possui uma assinatura única de vibração, cada laminador possuirá um plano de calibração e um arranjo de gaiolas de laminação específico. Esta constatação torna, por si só, muito difícil a determinação de uma solução universal para a análise de temperatura superficial dos cilindros. Entretanto, após a análise dos parâmetros e resultados obtidos por Stevens et al. [22] e Ye [28], e com as informações coletadas dos laminadores industriais \#1 e 
\#2, é possível estabelecer uma relação entre a temperatura superficial e o tempo de contato do material com o cilindro (Figura 39). Cabe salientar que os valores apresentados na Figura 39 para os laminadores estudados por Stevens et al. [22] e Ye [28], foram obtidos experimentalmente. Já para os laminadores industriais \#1 e \#2, os valores foram calculados utilizando-se a equação (17).

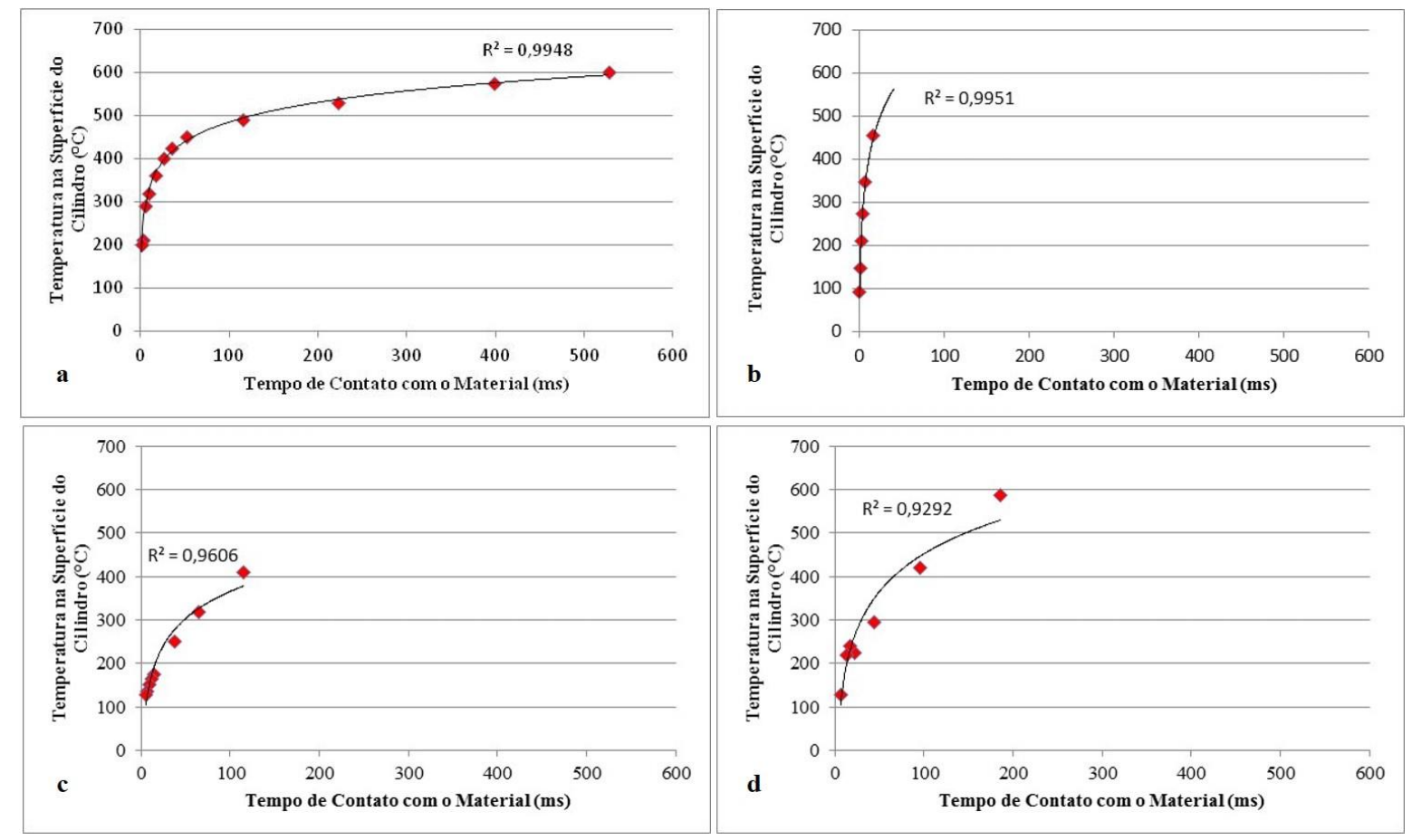

Figura 39. Comparação das curvas temperatura superficial do cilindro versus tempo de contato. a) Stevens et al. [21], b) Ye [25], c) Laminador \#1 e d) Lamiandor \#2.

Conhecendo-se os tempos de aplicação da deformação para cada passe de laminação para qualquer laminador e aplicando-se as equações similares às definidas na Tabela 6, tornase possível a estimativa das respectivas temperaturas superficiais. Foram mantidas as mesmas escalas nos gráficos da Figura 39, como forma de comparar os laminadores.

Para todos os laminadores avaliados neste trabalho, esta relação é logarítmica e recebe o nome de equação característica. Todos os laminadores contínuos possuem uma curva semelhante às apresentadas na Figura 39, porém apresentam equações características distintas, devido às particularidades de cada projeto de laminação do produto. A identificação da equação característica só é possível com o cálculo da temperatura superficial do cilindro em estudo. Uma vez determinada, pode ser utilizada para predizer o comportamento térmico em cada passe de laminação. 
Tabela 6. Equações das curvas características dos laminadores estudados.

\begin{tabular}{cc}
\hline Laminador & Equação \\
\hline Stevens et al. & $T c_{S}=65,648 \ln (t)+182,59$ \\
Ye [25] & $T c_{S}=130,22 \ln (t)+79,428$ \\
$\# 1$ & $T c_{S}=89,533 \ln (t)-46,333$ \\
$\# 2$ & $T c_{S}=125 \ln (t)-122,99$ \\
\hline
\end{tabular}

\subsection{RESULTADOS DA SIMULAÇÃO NUMÉRICA}

A simulação numérica utilizando o método de elementos finitos teve como objetivo reproduzir as condições de laminação das gaiolas \#1, \#6 e LG134 dos laminadores \#1, \#2 e \#3, respectivamente. A Figura 40 apresenta os resultados das simulações, onde foi possível a determinação de gráficos tensão-deformação que permitiram o conhecimento das amplitudes de deformação plástica para cada caso estudado. Os gráficos mostram a evolução das tensões e deformações ao longo do tempo, apresentando o acúmulo de deformação plástica por ciclo, semelhante ao exposto por Stevens et al [22], para uma quantidade reduzida de ciclos térmicos, por meio da Figura 21.

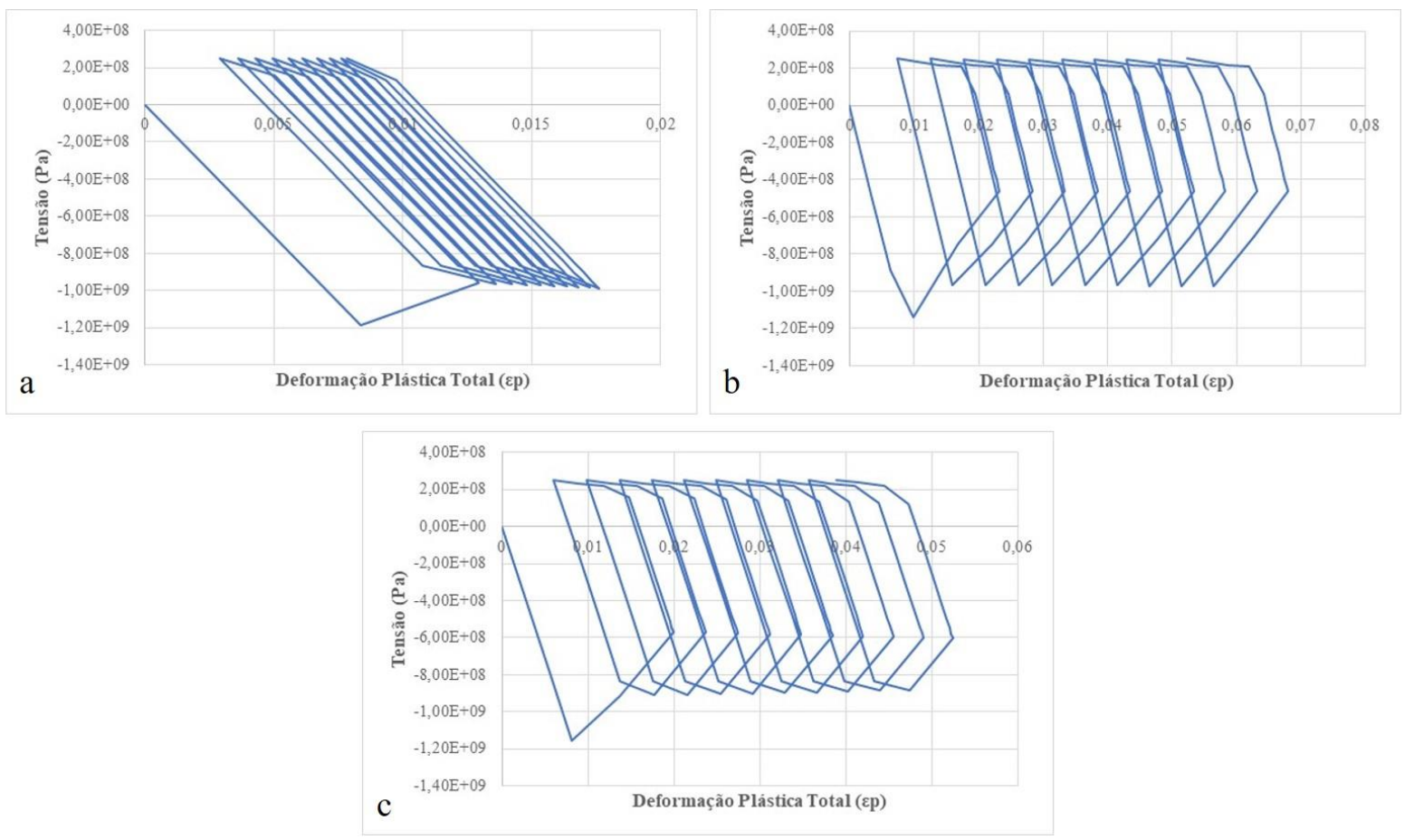

Figura 40. Gráficos tensão-deformação para os laminadores industriais a) \#1, b) \#2 e c) \#3. 


\subsection{APLICAÇÃO DO COEFICIENTE DE DANO À SUPERFÍCIE ( $\kappa)$}

A Tabela 7 mostra os valores calculados para a temperatura superficial do cilindro $\left(\mathrm{Tc}_{\mathrm{s}}\right)$, profundidade da camada aquecida $(\delta)$ e o coeficiente de dano à superfície $(\kappa)$ para todas as gaiolas de laminação estudadas e acompanhadas durante os experimentos industriais. A tabela ainda fornece a indicação de incidência ou não de trincas de fadiga térmica.

Foram alvo de análise e experimentação um total de 18 gaiolas de laminação distribuídas entre três laminadores industriais, conforme demonstrado na Tabela 7. Os valores calculados para a temperatura superficial do cilindro $\left(\mathrm{Tc}_{\mathrm{s}}\right)$ e profundidade da camada aquecida

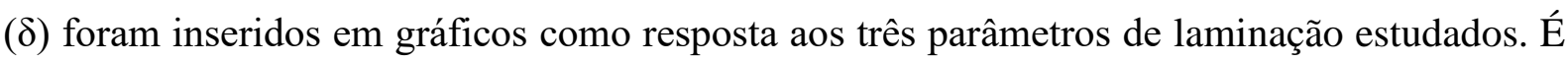
possível afirmar que uma maior temperatura de laminação acarretará uma maior transferência de calor entre o material e o cilindro de laminação.

Tabela 7. Resultados calculados para os laminadores estudados.

\begin{tabular}{|c|c|c|c|c|c|}
\hline Laminador & Gaiola & $\begin{array}{c}\text { Temperatura } \\
\text { Superficial - Tc } \\
\left({ }^{\circ} \mathbf{C}\right) \text { - Eq. } 17\end{array}$ & $\begin{array}{c}\text { Profundidade da } \\
\text { Camada } \\
\text { Aquecida - } \delta \\
(\mathrm{mm}) \text { - Eq. } 23 \\
\end{array}$ & $\begin{array}{l}\text { Coeficiente de Dano à } \\
\text { Superfície - к - Eq. } 39\end{array}$ & Fadiga Térmica \\
\hline \multirow{8}{*}{ \# 1} & $\# 1$ & 410 & 0,24 & 343 & NÃO \\
\hline & \# 3 & 317 & 0,22 & 326 & NÃO \\
\hline & \# 5 & 252 & 0,19 & 308 & NÃO \\
\hline & \# 6 & 176 & 0,13 & 273 & NÃO \\
\hline & \# 7 & 164 & 0,13 & 263 & NÃO \\
\hline & \# 8 & 151 & 0,12 & 250 & NÃO \\
\hline & \# 10 & 137 & 0,12 & 234 & NÃO \\
\hline & \# 12 & 127 & 0,11 & 218 & NÃO \\
\hline \multirow{7}{*}{ \# 2} & \# 6 & 588 & 0,19 & 413 & SIM \\
\hline & \# 8 & 420 & 0,17 & 377 & NÃO \\
\hline & \# 10 & 294 & 0,13 & 352 & NÃO \\
\hline & \# 12 & 225 & 0,17 & 328 & NÃO \\
\hline & \# 14 & 201 & 0,16 & 313 & NÃO \\
\hline & \# 16 & 180 & 0,16 & 296 & NÃO \\
\hline & \# 18 & 142 & 0,10 & 273 & $\mathrm{NÃO}$ \\
\hline \multirow{3}{*}{ \# 3} & LG134 & 525 & 0,33 & 422 & SIM \\
\hline & LG544 & 529 & 0,32 & 425 & SIM \\
\hline & LG574 & 513 & 0,30 & 414 & SIM \\
\hline IPT & $\# 1$ & 477 & 0,08 & 406 & SIM \\
\hline
\end{tabular}


A Figura 41 apresenta os resultados de $\mathrm{Tc}_{\mathrm{s}}$ e $\delta$ calculados para cada uma das temperaturas medidas no material nos passes de laminação equivalentes às gaiolas estudadas. Os pontos marcados com um círculo vermelho representam campanhas de laminação onde houve a ocorrência de trincas por fadiga térmica.
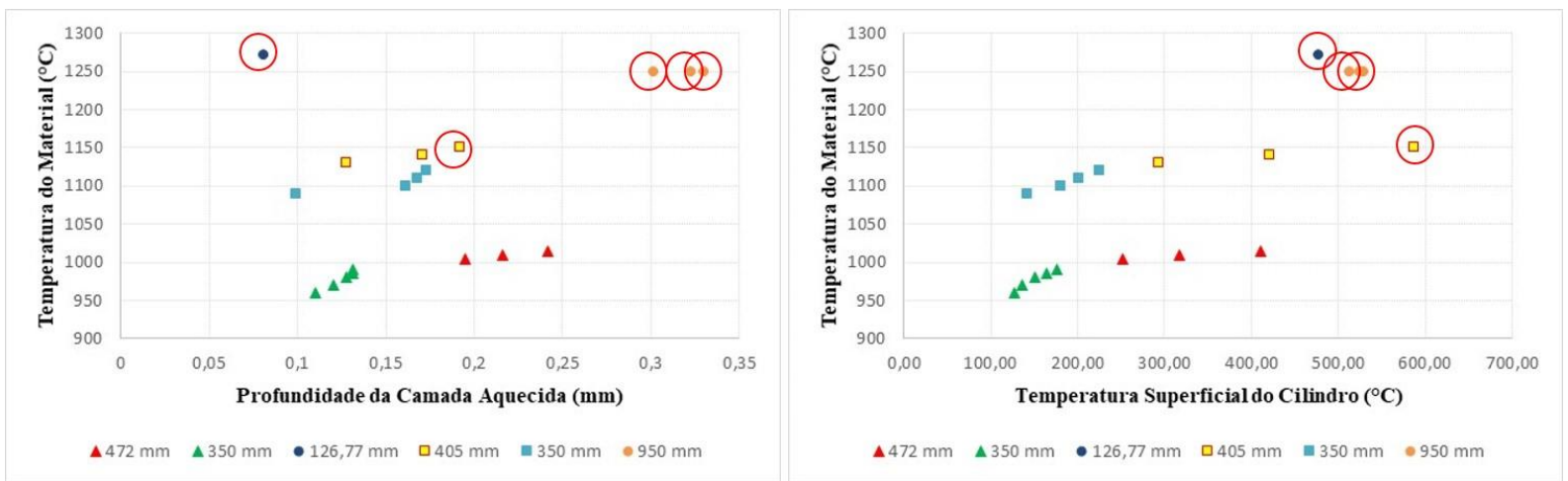

Figura 41. Relação entre a temperatura do material $(\mathrm{Tm})$ e as respectivas respostas $\left(\delta \mathrm{e} \mathrm{Tc}_{\mathrm{s}}\right)$.

Na Figura 42 é possível verificar os resultados da temperatura superficial do cilindro e profundidade da camada aquecida para diferentes velocidades de laminação, expressas aqui por meio da rotação dos cilindros. Menores rotações permitirão um maior tempo de contato entre o material e o cilindro, permitindo, consequentemente, uma maior transferência de calor na interface cilindro-material.
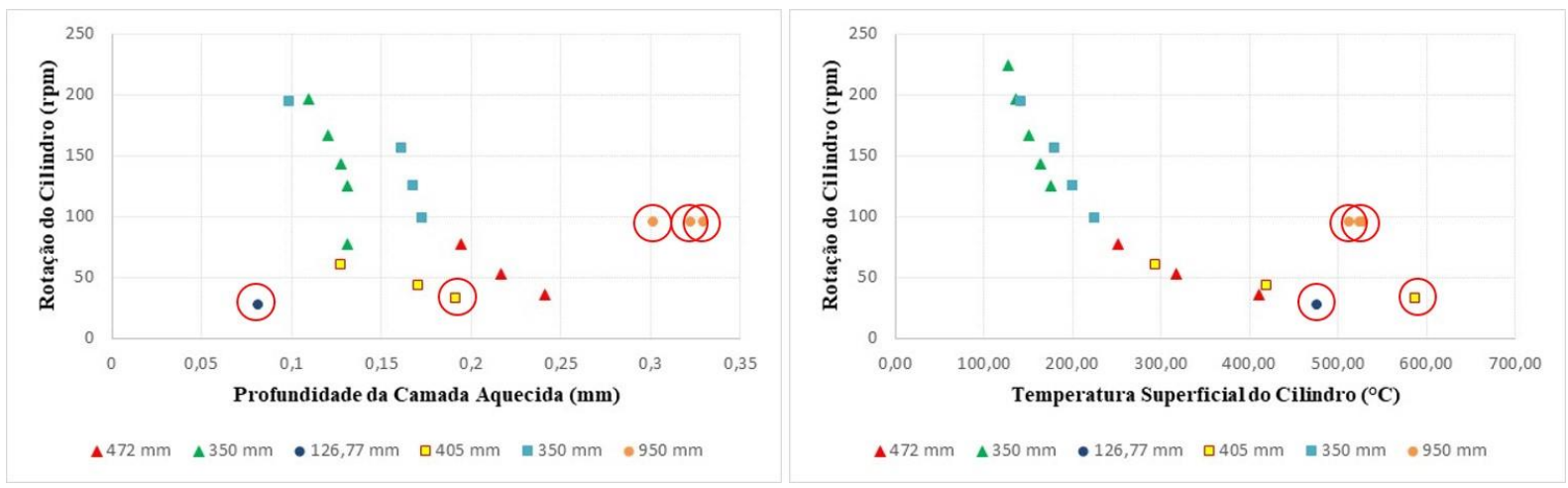

Figura 42. Relação entre a rotação dos cilindros de laminação (U) e as respectivas respostas ( $\delta$ e $\left.\mathrm{Tc}_{\mathrm{s}}\right)$.

A Figura 43 mostra como se comporta a temperatura superficial do cilindro e profundidade da camada aquecida para variações na redução do passe de laminação. Maiores reduções permitirão maiores arcos de contato do cilindro no momento do agarre do material, propiciando assim, maiores tempos de contato entre o material e o cilindro. 


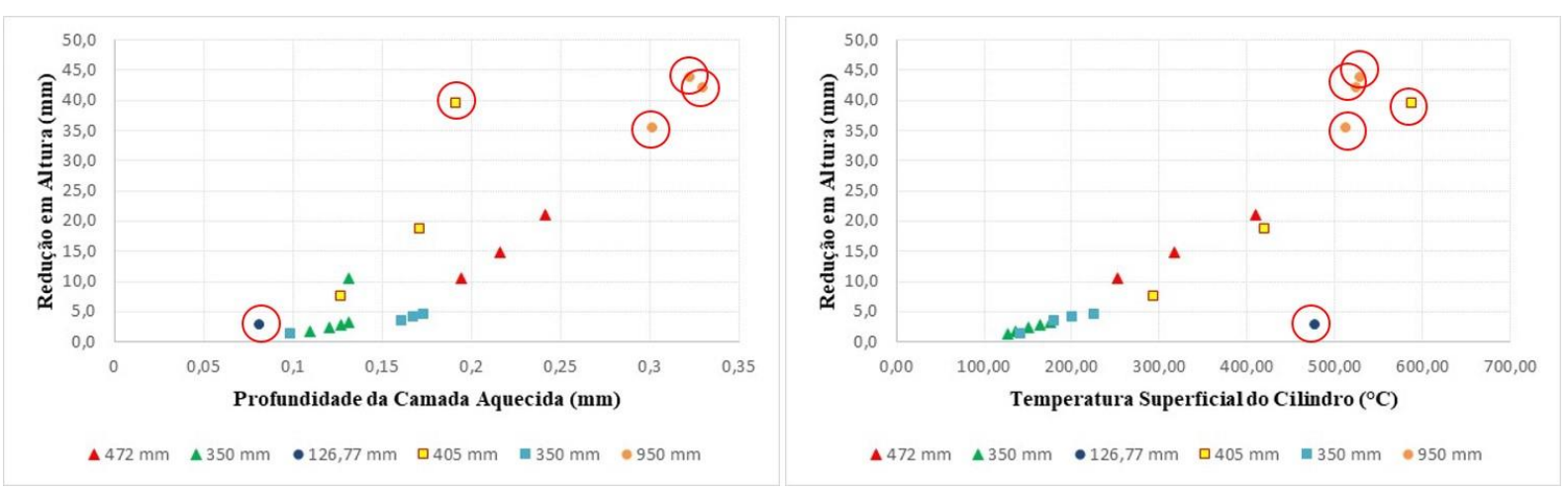

Figura 43. Relação entre a redução em altura $(\Delta \mathrm{h})$ e as respectivas respostas $\left(\delta\right.$ e $\left.\mathrm{Tc}_{\mathrm{s}}\right)$.

Quando analisados individualmente, os resultados apresentados nas Figuras 41, 42 e 43 sugerem a possibilidade de determinação de um valor limite para a temperatura superficial do cilindro, na ordem de $450{ }^{\circ} \mathrm{C}$. Os resultados sugerem também uma relação importante quando combinados estes parâmetros em um único coeficiente representativo - coeficiente de dano à superfície do cilindro $(\kappa)$.

A Tabela 7 apresenta valores para o coeficiente de dano à superfície $(\kappa)$ calculado através da equação (43) e também indica quais foram as gaiolas que apresentaram trincas de fadiga térmica ao longo das campanhas de laminação. Os resultados sugerem a existência de um limite entre 375 e 400 para que $\kappa$ torne-se severo, confirmando, desta forma, que os parâmetros de processo levarão a superfície do cilindro a temperaturas suficientemente elevadas, que por sua vez poderão gerar deformações plásticas para a nucleação de trincas por fadiga térmica. A Figura 44 apresenta a relação entre a profundidade da camada aquecida e kappa para todos os experimentos realizados nos três laminadores industriais e para o laminador piloto do IPT. Os pontos marcados com um círculo vermelho representam campanhas de laminação onde houve a ocorrência de trincas por fadiga térmica. As faixas verde, amarela e vermelha são apenas uma sugestão do autor para caracterizar regiões de transição para a determinação de severidade do coeficiente de dano à superfície do cilindro.

A condição que gerou fadiga térmica com menor valor calculado para a profundidade da camada aquecida foi a do laminador piloto do IPT $(0,08 \mathrm{~mm})$. A severidade pode ser explicada devido à baixa velocidade de laminação e ao pequeno diâmetro do cilindro de trabalho. Adicionalmente a temperatura de laminação foi de $1271{ }^{\circ} \mathrm{C}$ (maior entre todos os experimentos). Esta constatação comprova a importância de kappa como um indicador que 
combina todos os fatores críticos para a determinação da severidade da campanha de laminação.

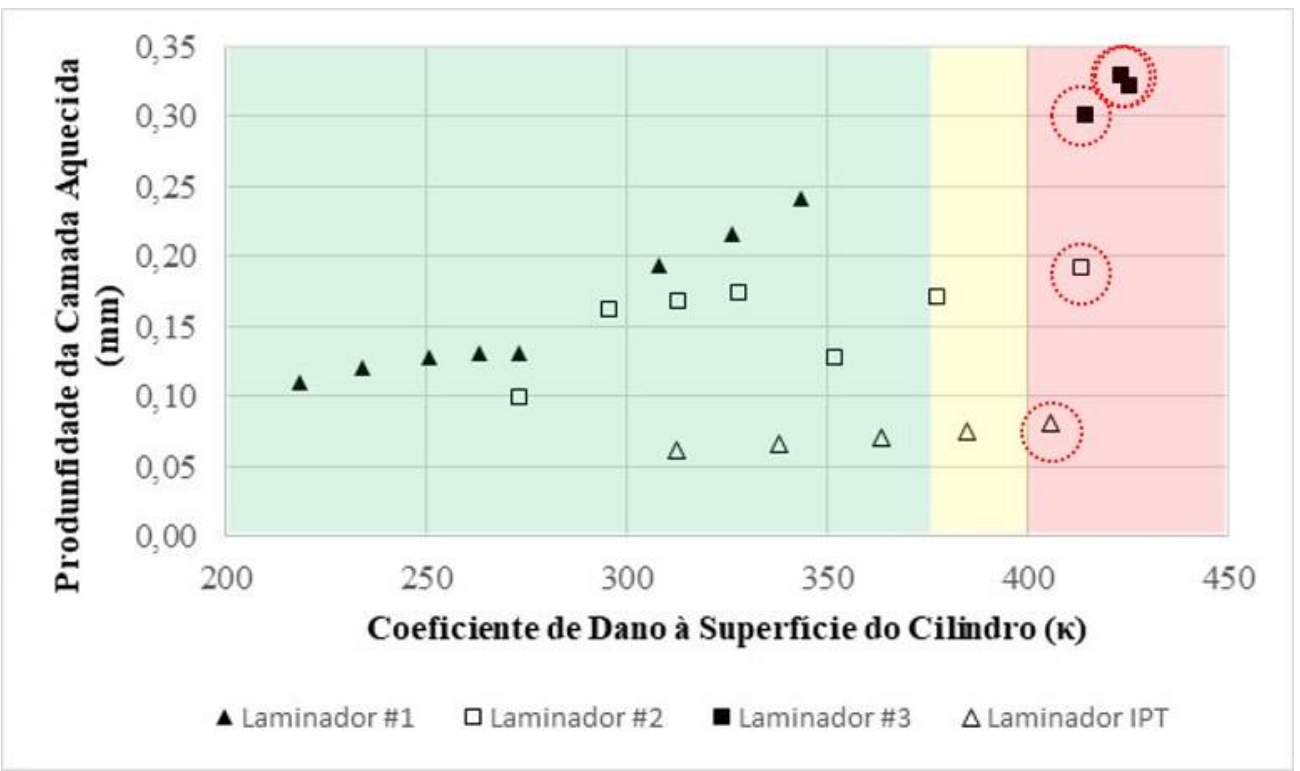

Figura 44. Relação do coefíciente de dano à superfície do cilindro $(\kappa)$ e a profundidade da camada aquecida $(\delta)$.

$\mathrm{Na}$ equação (28), desenvolvida por Tseng [29], pode-se verificar que quanto maior for a velocidade de laminação (ou velocidade dos cilindros) menor será a profundidade da camada aquecida. Da mesma forma, esta equação mostra que quanto maior for a difusividade térmica do material do cilindro, maior será a espessura da camada aquecida. Ambas constatações fazem sentido e são bastante coerentes, porém a Figura 44 não apresenta uma boa correlação para o coeficiente de dano à superfície do cilindro $(\kappa)$ e a profundidade da camada aquecida $(\delta)$. Isto pode ser explicado pelo fato do coeficiente de transferência de calor $\left(h_{d}\right)$ estar relacionado de forma indireta através da equação (30) para a determinação do Número de Biot. O coeficiente de transferência de calor é uma variável importante e pequenas modificações deste deveriam modificar consideravelmente as relações térmicas na interface cilindro-material, conforme apresentado por Serajzadeh et al. [34].

Os resultados para a relação de kappa e temperatura superficial do cilindro podem ser vistos na Figura 45. Neste caso é possível identificar uma boa correlação entre os dados calculados. Os resultados confirmam também o efeito da temperatura máxima do ciclo térmico na incidência de trincas de fadiga térmica, corroborando com o que foi proposto por outros autores [43, 45]. A Figura 45 valida o modelo proposto por Stevens et al. [22] como uma estimativa para o dano térmico na superfície do cilindro. Há, entretanto, que considerar 
sua complexidade matemática e a necessidade de determinação de várias propriedades físicas do cilindro de laminação e do material laminado. O coeficiente de dano à superfície do cilindro $(\kappa)$ revela grande simplicidade matemática e considera que o sistema de refrigeração dos cilindros tem a capacidade de extrair calor da superfície do cilindro a cada ciclo térmico, sem a necessidade da determinação do coeficiente de transferência de calor $\left(h_{d}\right)$, o que muitas vezes pode ser extremante complexo, devido à natureza das interações térmicas na interface cilindro-material.

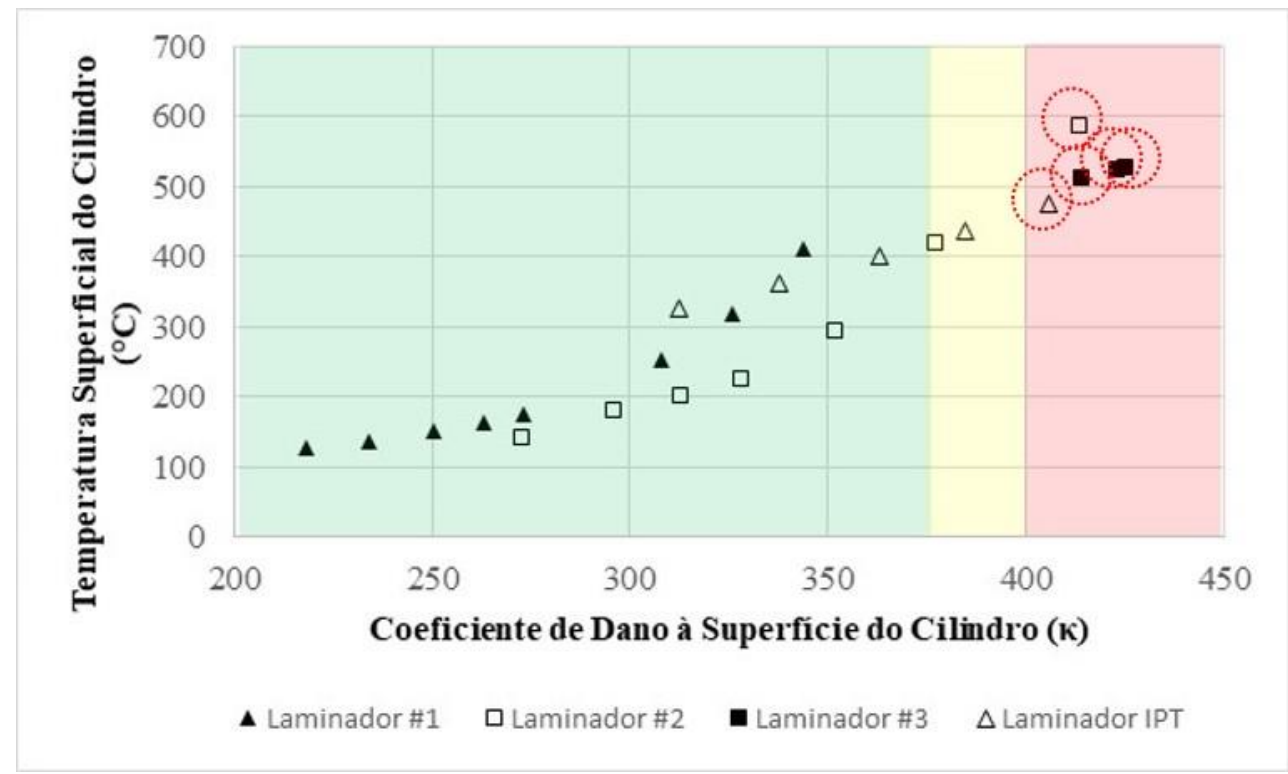

Figura 45. Relação do coeficiente de dano à superfície do cilindro ( $\kappa)$ e a temperatura superficial do cilindro $\left(\mathrm{Tc}_{\mathrm{s}}\right)$.

A Tabela 8 apresenta algumas informações das campanhas de laminação que foram diariamente monitoradas afim de identificar o momento do surgimento das malhas de trinca térmica. A cada dia foi possível obter uma produção média de 700 toneladas, nos laminadores \#1 e \#2, fazendo com que fosse possível aproximadamente 8 avaliações até o final da campanha. Para o laminador \#3 a produção média foi de 500 toneladas por dia, permitindo pelo menos 5 avaliações até a identificação da malha de trinca térmica.

A Figura 46 mostra a condição superficial dos canais de laminação do laminador \#1 para as gaiolas \#1, \#3 e \#5. Pode-se verificar a ausência de trincas após uma quantidade significativa de ciclos térmicos (>50.000 ciclos). Além das campanhas destacadas na Tabela 8 , estas gaiolas foram novamente analisadas ao final de campanhas similares, onde novamente não foram observadas trincas térmicas. 
Tabela 8. Informações das campanhas de laminação avaliadas.

\begin{tabular}{|c|c|c|c|}
\hline Laminador & Gaiola & $\begin{array}{c}\text { Tamanho da } \\
\text { Campanha (ton) }\end{array}$ & $\begin{array}{l}\text { Quantidade de } \\
\text { Ciclos }\left(\mathbf{N}^{\circ}\right)\end{array}$ \\
\hline \multirow{3}{*}{ \# 1} & $\# 1$ & 5.294 & 57.540 \\
\hline & \# 3 & 5.698 & 61.346 \\
\hline & \# 5 & 5.667 & 62.188 \\
\hline \multirow{2}{*}{$\# 2$} & \# 6 & 6.012 & 59.405 \\
\hline & \# 8 & 5.772 & 58.159 \\
\hline \multirow{3}{*}{ \# 3} & LG134 & 6.156 & 26.929 \\
\hline & LG544 & 6.240 & 33.406 \\
\hline & LG574 & 5.987 & 30.227 \\
\hline
\end{tabular}

Para possibilitar o entendimento da ordem de grandeza dos canais de laminação avaliados, pode-se considerar que todas as imagens dos canais dos cilindros das Figuras 46, 50 e 51, possuem aproximadamente $100 \mathrm{~mm}$ de largura. Os canais de laminação do laminador \#3 da Figura 49 possuem aproximadamente $500 \mathrm{~mm}$ de largura.
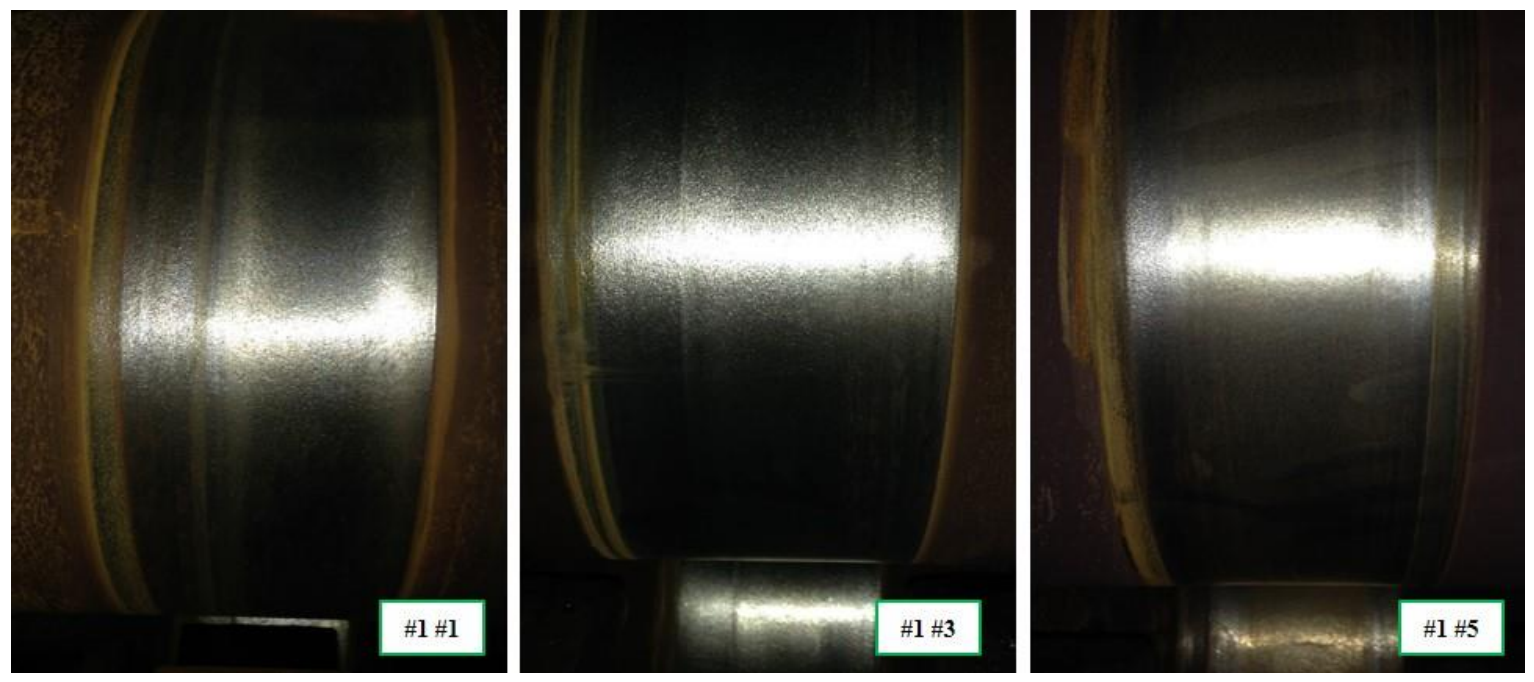

Figura 46. Condição superficial dos canais de laminação das gaiolas \#1, \#3 e \#5 do laminador \#1.

A Figura 47 mostra a condição superficial do canal de laminação da gaiola \#8, onde cada etapa representa aproximadamente 1.000 toneladas laminadas ( 10.000 ciclos).

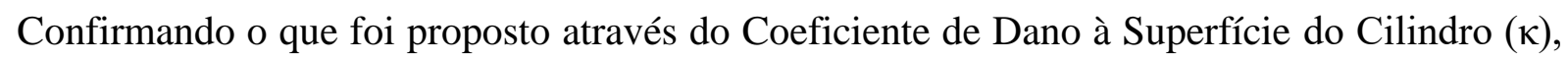
este canal de laminação não apresentou trincas térmicas ao final da campanha de laminação. Existia, entretanto, a suspeita de que a gaiola \#8 representava uma condição limite para a operação dos cilindros no que tange ao mecanismo de degradação por fadiga térmica. Desta forma, optou-se por realizar o mesmo acompanhamento com a gaiola anterior do trem de 
laminação (gaiola \#6), pois o valor calculado de $\kappa$ para atingiu 413, sendo bastante superior aos 377 encontrado para a gaiola \#8.

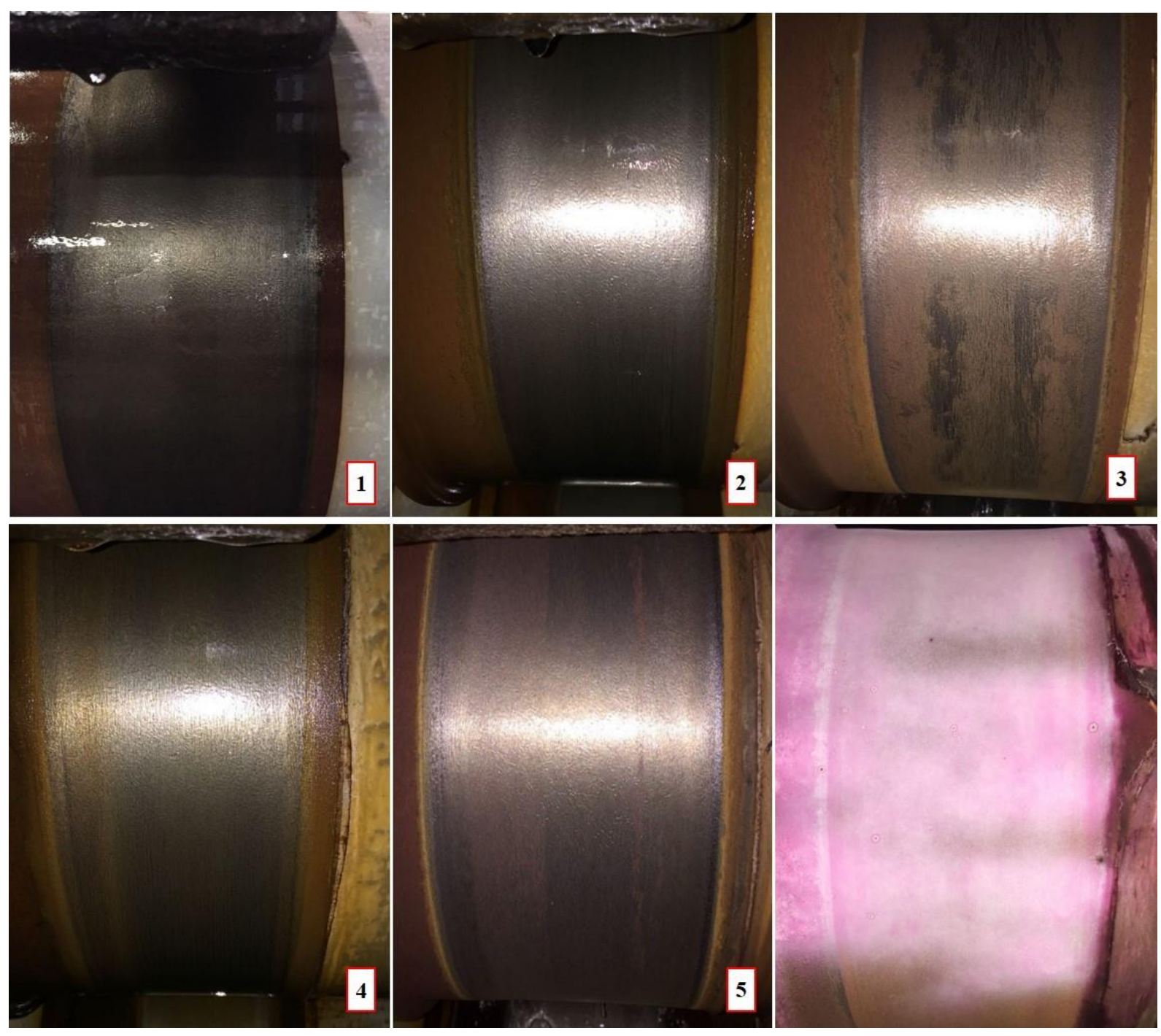

Figura 47. Evolução da superfície do cilindro da gaiola \#8 após a campanha de laminação do laminador \#2.

$\mathrm{Na}$ avaliação da gaiola \#6 foi possível identificar as trincas térmicas no meio e bordas do canal de laminação (Figura 48). 


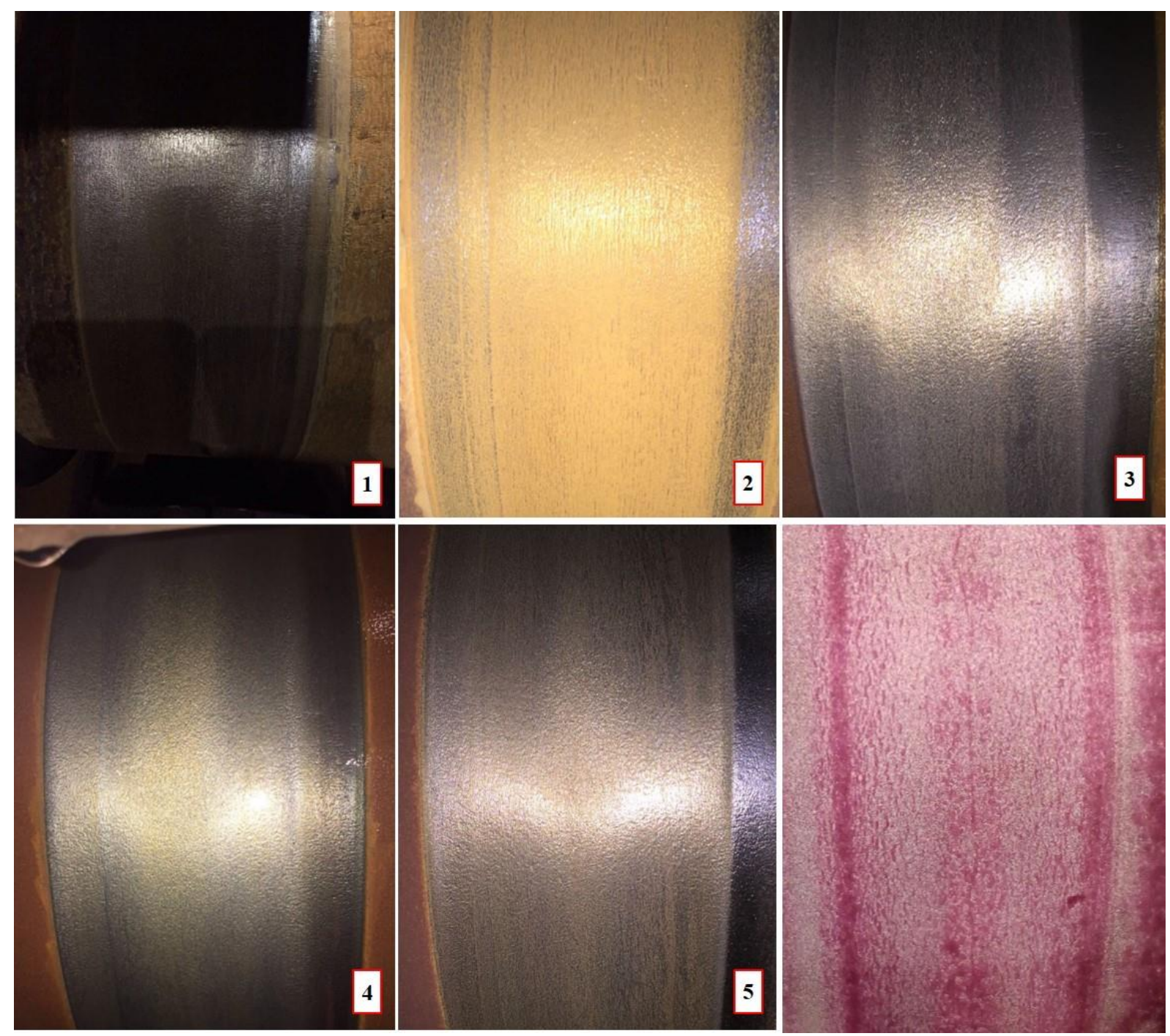

Figura 48. Evolução da superfície do cilindro da gaiola \#6 após a campanha de laminação do laminador \#2.

Com o objetivo de confirmar a existência de um valor limite para $\kappa$ próximo de 400 , foram avaliados três jogos de cilindros em diferentes campanhas de laminação, os quais tiveram valores calculados, para o coeficiente de dano à superfície do cilindro, entre $414 \mathrm{e}$ 422. Nestes experimentos, conduzidos no laminador \#3, em todos os casos foi constatado o surgimento de malhas de trinca térmica. A Figura 49 mostra os cilindros que foram utilizados para a laminação dos lingotes 134, 544 e 574, respectivamente. Após as campanhas de laminação, é possível verificar malhas de trinca térmica bastante profundas. Estas foram as condições mais severas apontada pelo kappa e foi também a pior condição superficial encontrada nos cilindros alvo dos experimentos industriais, comprovando assim, coerência entre a teoria proposta e os resultados experimentais. 

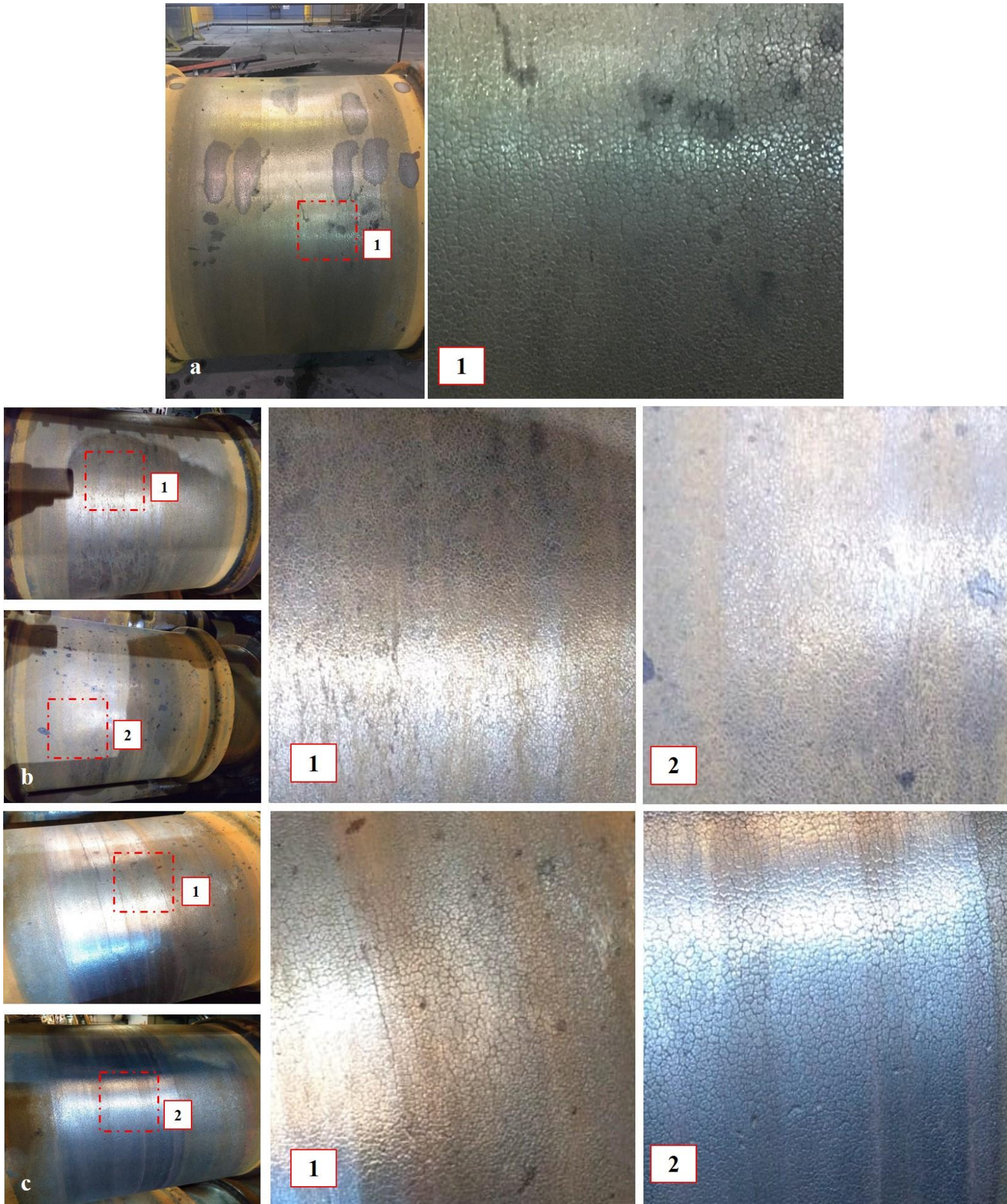

Figura 49. Superfície dos cilindros após as campanhas de laminação utilizando-se lingotes 134, 544 e 574 no laminador \#3.

Durante os ensaios realizados no laminador piloto do Instituto de Pesquisas Tecnológicas de São Paulo (IPT), para outros estudos [40 e 49], verificou-se o surgimento de malhas de trinca térmica após a laminação de 829 peças (aproximadamente 4500 ciclos 
térmicos), conforme visto na Figura 50. O equipamento foi automatizado para executar 5 passes de laminação por chapa, sendo a rotação do cilindro e dos rolos transportadores do material laminado invertida a cada passe, permitindo que a mesma chapa seja laminada 5 vezes pelo mesmo par de cilindros.
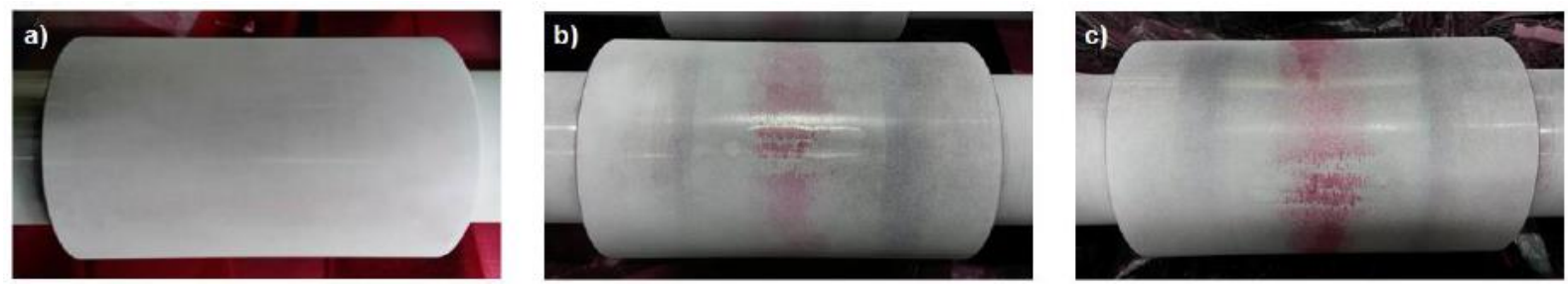

Figura 50. Superfície do cilindro após as campanhas de laminação no laminador piloto do IPT. a) cilindro antes da laminação, b) após 4544 ciclos térmicos e c) após 6754 ciclos térmicos.

A Tabela 9 mostra o Coeficiente de Dano à Superfície calculado para cada um dos 5 passes deste laminador, no regime de operação descrito acima.

Tabela 9. Kappa calculado para os 5 passes de laminação do estudo de Lima [40].

\begin{tabular}{cc}
\hline $\begin{array}{c}\text { Passe de } \\
\text { Laminação }\end{array}$ & $\begin{array}{c}\text { Coeficiente de Dano à } \\
\text { Superfície - }\end{array}$ \\
\hline 1 & 406 \\
2 & 385 \\
3 & 363 \\
4 & 337 \\
5 & 312 \\
\hline
\end{tabular}

Lima [40] demonstrou, através de simulação pelo método de elementos finitos, que a temperatura da superfície do cilindro atinge um valor de aproximadamente $590{ }^{\circ} \mathrm{C}$, contrariando, desta forma, o valor de $477{ }^{\circ} \mathrm{C}$ calculado através da equação (17), para um mesmo kappa calculado de 406. É importante salientar que a utilização do método analítico pressupõe simplificações que podem explicar esta diferença. Observando-se a Figura 45, existe, para ambas as hipóteses, a confirmação de que um valor de kappa igual à 406 é suficientemente severo para indicar o possível surgimento de trincas características da fadiga térmica.

Os resultados observados permitem sugerir a existência de limites para o Coeficiente

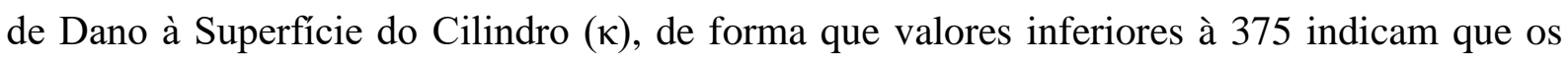
parâmetros de laminação não provocarão fadiga térmica nos cilindros. Valores entre 375 e 
400 representam uma faixa de transição onde poderá ocorrer o dano por fadiga e valores superiores à 400 indicam que os cilindros estarão sujeitos à tensões e deformações tais que o dano por fadiga térmica ocorrerá.

Usando as equações (41) e (43), é possível identificar uma forte correlação entre a deformação plástica total e o coeficiente de dano à superfície do cilindro. Esta relação foi estabelecida utilizando-se valores calculados para todos os laminadores industriais, e os resultados são mostrados na Figura 51. O ponto verde é a deformação plástica total apresentada por Lima [40] através de método de elementos finitos para o caso do IPT. Assim como para o caso da temperatura, a deformação plástica total também foi apresentada com um valor maior do que o proposto pelo método analítico, sugerindo a hipótese de que os valores sejam ligeiramente maiores aos apresentados neste trabalho.

O ponto azul refere-se aos valores calculados para o laminador apresentado por Stevens et al. [21]. Para este caso em particular, o material do cilindro também é ferro fundido, mas o trabalho não especifica qual sua composição química e classificação.

Os pontos em vermelho são os resultados dos modelos numéricos simulados conforme descrito em 4.3. Estes pontos estão ligados por meio de uma linha de tendência com seus equivalentes calculados, conforme descrito em 5.5. No modelo numérico foram assumidas algumas simplificações de forma a permitir uma rápida comparação com os valores calculados através dos experimentos industriais. Como mencionado anteriormente, o coeficiente de expansão térmica e o módulo de elasticidade do material dos cilindros de laminação foram considerados constantes em função da temperatura.

Com o aumento da temperatura do cilindro, o valor para o módulo de elasticidade tende a diminuir, enquanto o valor para o coeficiente de expansão térmica tende a aumentar. Com isso, se fosse considerado o valor real para o módulo de elasticidade, seria possível observar uma pequena redução no valor de deformação plástica total (podendo chegar em até $2 \%$ para os valores marcados pelos pontos em vermelho). Considerando-se o valor real para o coeficiente de expansão térmica, este incremento poderia ser de até $5 \%$ no valor de deformação plástica total. Estas constatações foram possíveis simulando valores através da equação (43). Os valores podem ser considerados próximos e corroboram com a teoria apresentada até o momento. 


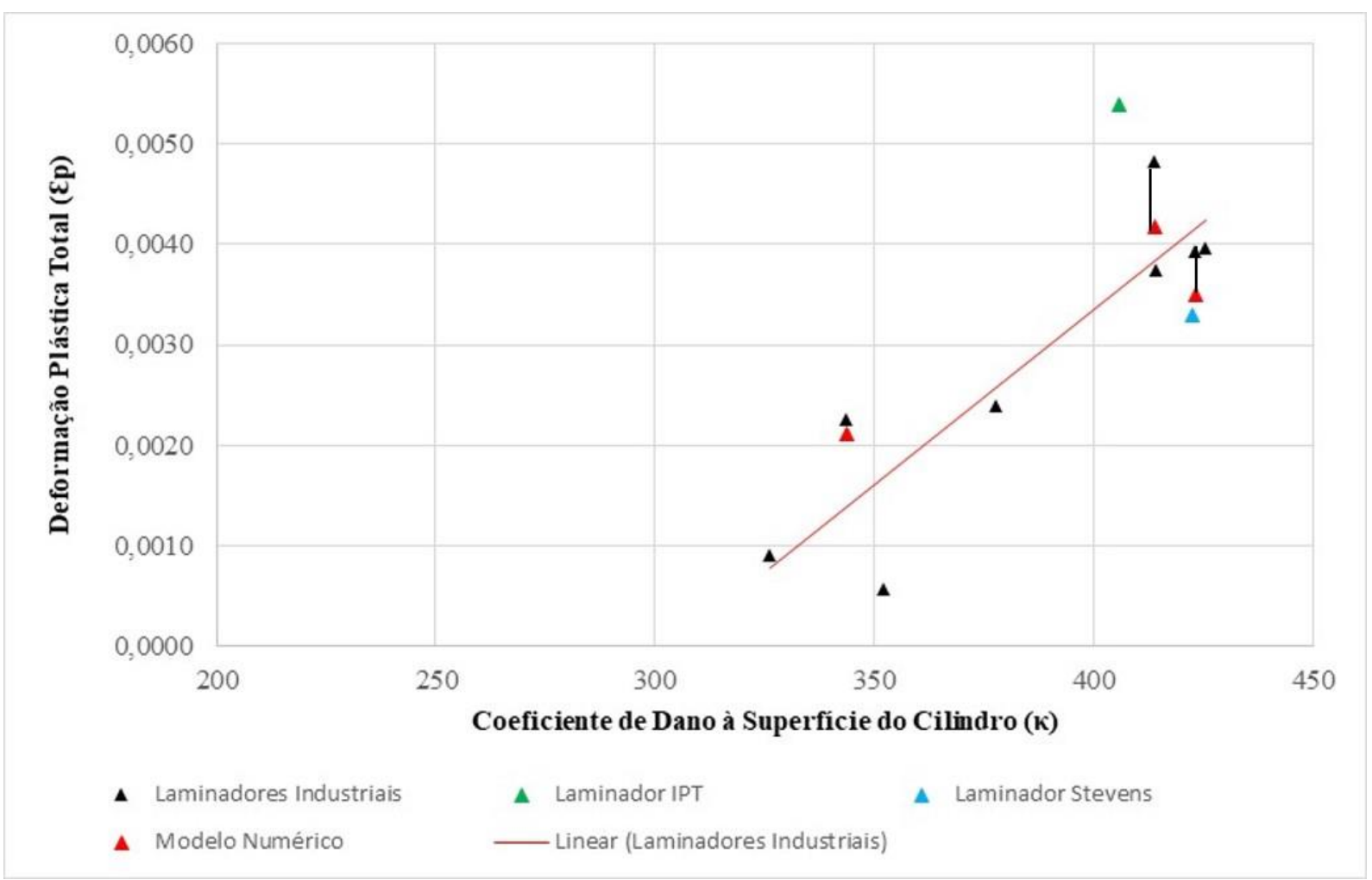

Figura 51. Relação entre a deformação plástica total e o coeficiente de dano à superfície do cilindro.

O coeficiente de dano à superfície do cilindro $(\kappa)$ pode ser considerado um indicador para a severidade da fadiga térmica, uma vez que pode ser relacionado à deformação plástica total e, consequentemente, à fadiga de baixo ciclo. Esta relação entre kappa e a deformação plástica total pode ser utilizada para a obtenção de modelos de previsão de vida de cilindros de laminação.

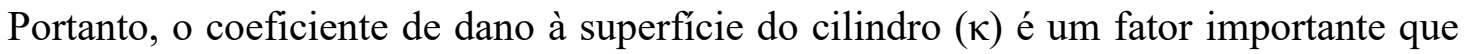
permite previsões sobre duas questões consideradas críticas em laminação: a) se a gaiola de laminação ou laminador em estudo está sujeito à fadiga térmica e, no caso afirmativo, b) a gravidade da campanha para aquela gaiola ou cilindro analisado. Essas previsões são fundamentais para o engenheiro de processo porque permitem um melhor planejamento de desligamento, otimização do consumo de cilindro e, consequentemente, expressivas reduções de custo.

É possível afirmar que maiores temperaturas de laminação acarretarão maior transferência de calor entre o material e os cilindros de trabalho, menores velocidades e maiores reduções terão como consequência um maior tempo de contato do material com o 
cilindro, propiciando também, desta forma, uma maior transferência de calor entre o material e os cilindros.

Entretanto, os laminadores industriais são equipamentos projetados para atender demandas específicas de produtos e possuem sequências de passes e reduções únicos. Possuem, também, sistemas de refrigeração e características que influenciarão no coeficiente de transferência de calor e que poderão mudar muito o comportamento térmico dos cilindros. O modelo apresentado fornece uma alternativa para o engenheiro de laminação para que seja possível estimar o dano térmico nos cilindros, causado pelo desenho e sequência dos passes de laminação, podendo, desta forma, sugerir modificações nos parâmetros de processo afim de minimizar o dano causado por fadiga térmica.

A utilização de velocidades maiores nos trens de laminação industriais requer a especificação de equipamentos mais robustos e consequentemente de maior valor agregado. Estas especificações terão inicialmente um custo maior, mas garantirão maior produtividade e menor custo de operação futuro, visto que, em relação à degradação por fadiga térmica, os cilindros terão uma durabilidade maior em serviço.

As proposições de menores reduções por passe de laminação tornam-se muito complexas, pois existem limitações importantes para garantir o atrito no momento do agarre do material. Adicionalmente, alguns materiais não podem ser laminados com elevadas taxas de deformação devido a limites de plasticidade e existem limitações técnicas e financeiras para a especificação de equipamentos com potência maior. Por exemplo, um engenheiro pode projetar um laminador com 10 passes de laminação (10 reduções em área) para produzir determinado material com um custo inicial estimado de máquinas e equipamentos. Se, por acaso, este mesmo material puder ser laminado com apenas 7 passes de laminação, o investimento inicial será bem menor e atrativo para o investidor, mesmo assumindo um custo operacional maior (custo com cilindros) no decorrer dos anos.

Conceitos metalúrgicos também limitam modificações na temperatura do material, visto que as transformações termomecânicas durante a laminação do material garantirão a ele suas principais propriedades mecânicas.

A escolha do tipo de material para a fabricação dos cilindros de laminação a quente depende, fundamentalmente, do tipo de mecanismo de desgaste associado, ou seja, cilindros para desbaste, por estarem sujeitos a fadiga térmica, deverão possuir microestrutura diferente de cilindros acabadores, onde o mecanismo de desgaste predominante é a abrasão. $\mathrm{O}$ 
Coeficiente de Dano à Superfície $(\kappa)$ pode ser utilizado para identificar a suscetibilidade à fadiga térmica, determinando em última forma, a composição química e microestrutura necessária para cada um dos cilindros de laminação do trem contínuo. Isto é, a partir de qual passe de laminação a fadiga térmica não é mais o mecanismo de desgaste predominante. Adicionalmente, kappa pode também atestar a eficiência do sistema de refrigeração pois se houver a incidência de trincas térmicas em cilindros com valores de kappa abaixo do limite teórico, é provável que existam deficiência neste sistema de refrigeração.

Com o conhecimento e utilização do Coeficiente de Dano à Superfície ( $\kappa)$ é possível modificação no sistema de refrigeração dos cilindros, novos estudos considerando outras variáveis de laminação (como por exemplo, o tempo de laminação entre peças) e questionamento do status quo no que se refere a teorias de calibração e desenho de processo de laminação. 


\section{CONCLUSÕES}

Neste trabalho foram apresentados dois métodos para o cálculo e avaliação do dano térmico em cilindros de laminação a quente (temperatura da superfície do cilindro e profundidade da camada aquecida). Estes dois métodos foram confrontados com parâmetros de laminação a quente (temperatura do material, velocidade de laminação e redução em altura) e foram analisados individualmente, mostrando que a temperatura superficial do cilindro é um método mais assertivo quando comparado com a profundidade da camada aquecida.

O experimento fatorial completo conduzido no laminador piloto do IPT permitiu a determinação dos efeitos principais de cada um dos parâmetros avaliados para a temperatura superficial do cilindro. Esta informação foi então utilizada para a determinação de um coeficiente que combina os três parâmetros de laminação e que é capaz de indicar o grau de severidade destes no processo de degradação da superfície do cilindro por fadiga térmica. Foi então proposto o Coeficiente de Dano à Superfície $(\kappa)$.

O Coeficiente de Dano à Superfície $(\kappa)$ foi então correlacionado com a temperatura da superfície do cilindro e profundidade da camada aquecida. Os resultados mostram uma melhor correlação com a temperatura superficial do cilindro do que com a profundidade da camada aquecida. Foi possível então correlacionar kappa com a deformação plástica calculada para os casos onde as tensões térmicas ultrapassaram o regime elástico. A relação entre $\kappa$ e $\Delta \varepsilon_{\mathrm{p}}$ mostrou-se satisfatória, com tendência linear. Os resultados permitem afirmar que é possível, com apenas três parâmetros do processo de laminação a quente, estimar o dano térmico ao qual a superfície do cilindro estará submetida, bem como estimar a deformação plástica total do ciclo térmico, permitindo, desta forma, o cálculo de vida em fadiga.

O Coeficiente de Dano à Superfície $(\kappa)$ foi aplicado nos laminadores industriais e possibilitou a identificação das gaiolas de laminação que podem estar sujeitas à fadiga térmica. Mostrou-se uma ferramenta bastante assertiva no universo ao qual foi aplicado, permitindo a modificação da estratégia de utilização dos cilindros, resultado em ganhos financeiros importantes. Existe, entretanto, a necessidade de aplica-lo em outros laminadores afim de atestar sua confiabilidade e assertividade. 


\section{BIBLIOGAFIA}

[1] INSTITUTO AÇO BRASIL. Dados do Setor Siderúrgico. 2017. Disponível em <http://www.acobrasil.org.br/site2015/dados.asp >. Acesso em: 07 jan. 2016.

[2] ABM - ASSOCIAÇÃO BRASILEIRA DE METALURGIA, MATERIAIS E MINERAÇÃO. Estudo Prospectivo do Setor Siderúrgico - Panorama do Setor Siderúrgico. $\quad 2008 . \quad$ Disponível em <http://www.abmbrasil.com.br/epss/arquivos/documentos/2011_4_18_16_42_43_32042.pdf> . Acesso em: 12 mai. 2016.

[3] ABM - ASSOCIAÇÃO BRASILEIRA DE METALURGIA, MATERIAIS E MINERAÇÃO. Estudo Prospectivo do Setor Siderúrgico - Panorama do Setor Siderúrgico. $2008 . \quad$ Disponível em <http://www.abmbrasil.com.br/epss/arquivos/documentos/2011_4_19_9_51_22_10820.pdf >. Acesso em: 09 abr. 2016.

[4] Benasciutti, D.; BRUSA, E.; BAZZARO, G. Finite Elements Prediction of Thermal Stresses in Work Roll of Hot Rolling Mills. Procedia Engineering. Vol 2, 2010 (707-716).

[5] PHANIRAJ, M. P.; GEHERA, B. B.; LAHIRI, A.K. Thermo-mechanical Modeling of Two Phase Rolling and Microstructure Evolution in the Hot Strip Mill Part I. Prediction of Rolling Loads and Finish Rolling Temperatures. Journal of Materials Processing Technology, Vol. 170, 2005 (323-335).

[6] ZHOU, S. X. An Integrated Model for Hot Rolling of Steel Strips. Journal os Materials Processing Technology 134, 2003 (338-351).

[7] WRIGHT, B. Thermal Behavior of Work Rolls in the Hot Mill Rolling Process. Doctorate Thesis, The University of Swansea, United Kingdom, 2012.

[8] BAGHERIPOOR, M.; BISADI, H. An Investigation on the Roll Force and Torque Fluctuations During Hot Strip Rolling Process. Production \& Manufacturing Research: An Open Acess Journal, 2:1, 2014 (128-141).

[9] CORRAL, R. L.; COLÁS, R.; PÉREZ, A. Modeling the Thermal and Thermoelastic Responses of Work Rolls Used for Hot Rolling Steel Strip. Journal of Materials Processing Technology 153-154, 2004 (886-893). 
[10] BRESCIANI, E.; SILVA, I. B.; BATALHA, G.F.; BUTTON, S. T. Conformação Plástica dos Metais. Quinta Edição. Editora da Unicamp, 1997.

[11] DIETER, G. E. Mechanical Metallurgy. Third Edition. McGraw-Hill, 1986.

[12] HITCHCOCK, J. H. Roll Neck Bearings. ASME, New York, 1935.

[13] EKELUND, S. The Analysis of Factors Influencing Rolling Pressure and Power Consumption in the Hot Rolling of Steel. Steel, Vol. 93, 1933.

[14] OROWAN, E.; PASCOE, K.J. A Simple Method of Calculating Roll Pressure and Power Consumption in Flat Hot Rolling. Iron and Steel Institute (London), No.34, 1946 (124-126).

[15] SIMS, R. B. The Calculation of Roll Force and Torque in Hot Rolling Mills. Proceedings of the Institution of Mechanical Engineers. Vol. 168, No. 1, 1954 (191-214).

[16] GORNI, A. A.; SILVA, M. R. S. Comparação entre Modelos de Carga para o Cálculo de Carga de Laminação a Quente Industrial. Tecnologia em Metalurgia, Materiais e Mineração, São Paulo, Vol. 9, No. 3, 2012 (197-203).

[17] MACCAGNO, T.M.; JONAS, J.J.; YUE, S.; MCCRADY, B.J.; SLOBODIAN, R; DEEKS, D. Determination of Recrystallization Stop Temperature from Rolling Mill Logs and Comparison with Laboratory Simulation Results. ISIJ International - The Iron and Steel Institute of Japan, Vol. 34, 1996 (917-922).

[18] ROBERTS, L. W. Hot Rolling of Steel. Manufacturing Engineering and Materials Processing. Vol. 10, New York, 1983.

[19] GIACOMIN, C. N.; SANTOS, A. A. Desenvolvimento de Modelos Matemáticos de Previsão da Temperatura Durante a Laminação a Quente de Aços. Tecnologia em Metalurgia, Materiais e Mineração, São Paulo, v.12, n. 4, (2105) p. 318-324.

[20] SEREDYNSKI, F. Prediction of Plate Cooling During Rolling Mill Operation. Journal of Iron and Steel Institute, 1973 (197-203).

[21] GINZBURG, V. B. Steel Rolling Technology. Manufacturing Engineering and Materials Processing. Vol. 30, New York, 1989.

[22] STEVENS, P.G.; IVENS, K. P.; HARPER, P. Increasing Work-Roll Life by Improved Roll-Cooling Practice. Journal of the Iron and Steel Institute. January, 1971.

[23] HENSEL, A.; SPITTEL, T. Rationeller Energieeinsatz bei Umformprozessen. Leipzig: VEB Deutscher Verlarg für Grundstoffindustrie, 1981. 
[24] GELEJI, A.: Forge Equipment Rolling Mills and Accessories. Budabest: Akadémiai Kiadó, 1967.

[25] WILlians, R. V.; BOXAL, G. M. Roll Surface Deterioration in Hot-Strip Mills. Journal of Iron and Steel Institute, 1973 (197-203).

[26] SERAJZADEH, S. Effects of Rolling Parameters on Work-Roll Temperature Distribution in the Hot Rolling of Steels. The International Journal of Advanced Manufacturing Technology, Vol. 35, 2008 (859-866).

[27] DEVADAS, C. The Prediction of the Evolution of Microstructure During Hot Rolling of Steel Strip. Ph.D Thesis. The University of British Columbia, Vancouverm Canadá, 1989.

[28] YE, X. Thermal Crown Development in Hot Strip Mill Work Rolls and the Role of Spray Cooling. Master Dissertation. The University of British Columbia, Vancouverm Canadá, 1990.

[29] TSENG, A. A. A Numerical Heat Transfer Analysis of Strip Rolling. Journal of Heat Transfer 106, 1984 (512-517).

[30] RYU, J. H.; KWON, O.; LEE, P. J.; KIM, Y. M. Evaluation of the Finishing Roll Surface Deterioration at Hot Strip Mill. ISIJ International, Vol. 32 (11), 1992 (1221-1223).

[31] DEVADAS, C.; SAMARASKERA, I. V. Heat Transfer During Hot Rolling of Steel Strip. Iron and Steelmaking. April, 1965 (369-377).

[32] JIN, D. Q.; SAMARASEKERA I. V.; BRIMACOMBE, J. K. Modeling Inhomogeneous Deformation During Hot Rolling of Plain Carbon Steel. 38th MWSP Conference Proceedings, ISS 34, 1997 (329-337).

[33] HADLY, C. O.; BRIMACOMBE, J. K.; SAMARASEKARA, I. V.; HAWBOLT, E. B. Heat Transfer in the Hot Rolling of Metals. Metallurgical and Materials Transactions B 26, 1995 (1019-1027).

[34] SERAJZADEH, S.; MUCCIARDI, F. Modeling the Work-Roll Temperature Variation at Unsteady State Condition. Modeling and Simulation in Materials Science and Engineering, Vol. 11, 2003 (179).

[35] LI, Y.H.; SELLARS, C.M. Modeling Deformation Behavior of Oxide Scales and Their Effects on Interfacial Heat Transfer and Friction During Hot Steel Rolling. 2nd Int. Conf. On Modelling of Metal Rolling Processes, Proceedings, J. H. Beynon, P. Ingham, H. Teichert and K. Waterson, Eds., (London, UK), The Institute of Materials, 1996, p 192-206 
[36] KRZYANOWSKI, M.; BEYNON, J.H. Interfacial Heat Transfer During Hot Metal Forming Operations Assuming Scale Failure Effects. Materials Science and Technology, Volume 32, 2016.

[37] GARCIA, A.; SPIM, J. A.; SANTOS, C. A. Ensaios dos Materiais. Segunda Edição. Litros Técnicos Científicos - LTC, 2012

[38] SCHÖN, |C. G. Mecânica dos Materiais. Editora Elsevier, 2013.

[39] SPUZIC, S.; STRAFFORD, C.; SUBRAMANIAN, G.; SAVAGE, G. Wear of Hot Rolling Mills: an Overview. Wear, n. 176, 1994 (261-271).

[40] COLÁS, R.; RAMÍREZ, J.; SANDOVAL, I.; MORALES, J. C.; LEDUC, L. A. Damage in Hot Rolling Work Rolls. Wear, n. 230, 1999 (56-60).

[41] LIMA, L. G. D. B. S. Análise Experimental e Modelagem Numérica da Influência da Oxidação na Fadiga Térmica de Cilindros de Laminação a Quente. Dissertação de Mestrado. Universidade de São Paulo, São Paulo, 2018.

[42] WILliaMS, T. R. G.; LOWCOCK, M. T. Blueing of Steel During Fatigue Cycling. Iron Steel. Vol. 35, 1962 (554-557)

[43] MIQUEL, B.; JEAN, S.; ROUX, S. LE.; LAMESLE, P.; RÉZAÏ-ARIA, F. HeatChecking of Hot Tool Steels. Temperature-Fatigue Interaction. Elsevier Science, 2002.

[44] LE ROUX, S.; MEDJEDOUB, F.; DOUR, G.; RÉZAÏ-ARIA, F. Role of Heat-Flux Density and Mechanical Loading on the Microscopic Heat-Checking of High Temperature Tool Steel Under Thermal Fatigue Experiments. International Journal of Fatigue 51 (2013) 15-25.

[45] PERSSON, A.; HOGMARK, S.; BERGSTRÖM, J. Simulation and Evaluation of Thermal Fatigue Cracking of Hot Work Tool Steels. International Journal of Fatigue 26 (2004) 1095-1107.

[46] NORTHCOTT, L.; BARON, H. G. J. Iron Steel Institute, 1956, 182, 385.

[47] MALM, S.; NORSTRÖN, L. A. Material-related Model for Thermal Fatigue Applied to Toll Steels in Hot-work Applications. Metal Science, p. 544-550, 1979.

[48] DÜNCKEMEYER, M.; KREMPASKY, C.; WERNER, E.; HEIN, G.; SCHÖRKHUBER, K. Analytical Modeling of Thermo-mechanically Induced Residual 
Stresses of Work Rolls During Hot Rolling. Proceedings of the $13^{\text {th }}$ International Conference on Metal Forming, Toyoashi, Japão, 2010.

[49] JURAN, J. M.; GRYNA, F. M. Juran's Quality Control Handbook. Fourth Edition. McGraw-Hill Book Company, 1951.

[50] LIMA, L.G.D.B.S, GONÇALVES, A., BRAGA, A.P.V., BOCCALINI JR, M., SOUZA, R.M. Coupled experimental-numerical analysis of wear in hot-rolling rolls. Proceedings of the 10th Tooling Conference. Bratislava, Eslováquia, 2016.

[51] WESTER, H.; BEHRENS, B. A.; KAWALLA, R.; AWISZUS, B.; BOUGUECHA, M.; ULLMANN, M.; GRAF, M.; BONK, C.; CHUGREEV, A. Numerical Investigation of the Oxide Scale Deformation Behaviour with Consideration of Carbon Content During Hot Forging. Proceedings of the International Conference on the Technology of Plasticity. Cambridge, United Kingdom, 2017. 


\section{ANEXOS}

ANEXO A - Informações sobre a ductilidade do aço SAE 5160 produzido pela Gerdau Aços Especiais.

- Composição química (unidade de medida em \%):

\begin{tabular}{|c|c|c|c|c|c|c|c|c|c|c|}
\hline \multicolumn{10}{|c|}{ SAE 5160 } \\
\hline C & Si & Mn & P & S & Cr & Ni & Mo & Ti & Al & Cu \\
\hline 0,63 & 0,20 & 0,85 & 0,021 & 0,008 & 0,76 & 0,05 & 0,02 & 0,0027 & 0,016 & 0,16 \\
\hline
\end{tabular}

- Redução em área

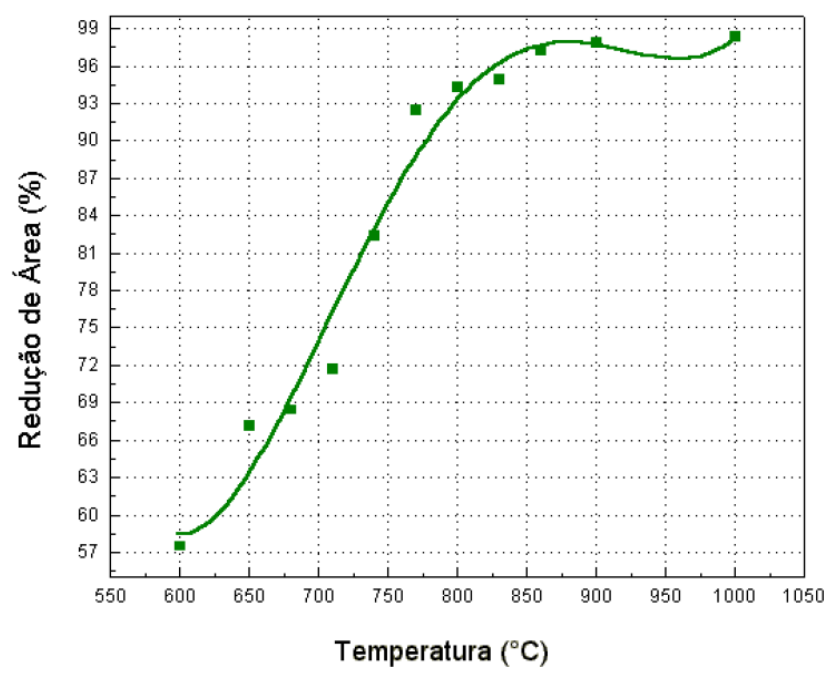

- Tensão máxima vs. temperatura

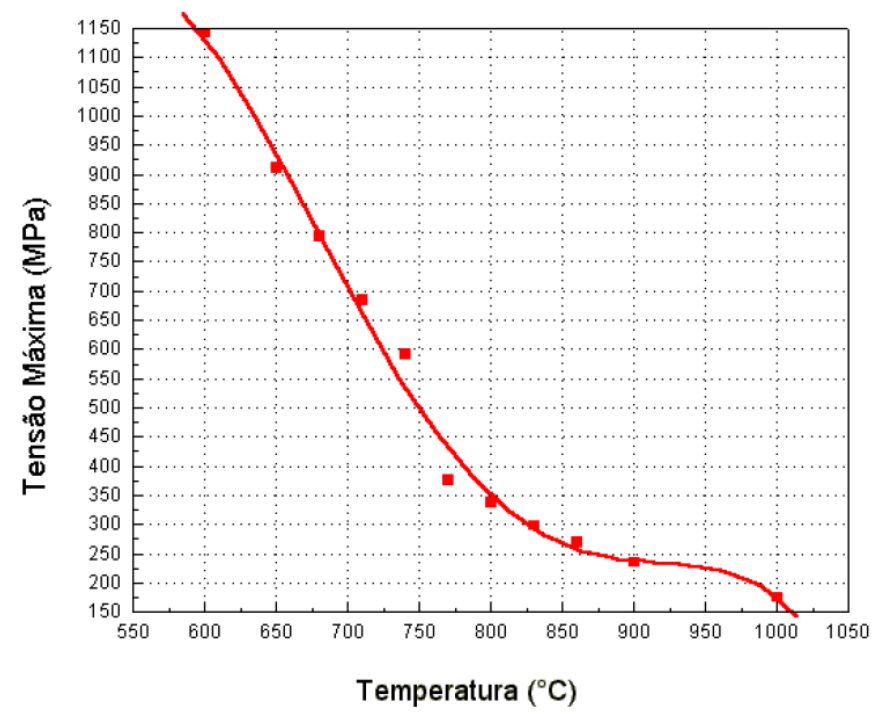


- Alongamento

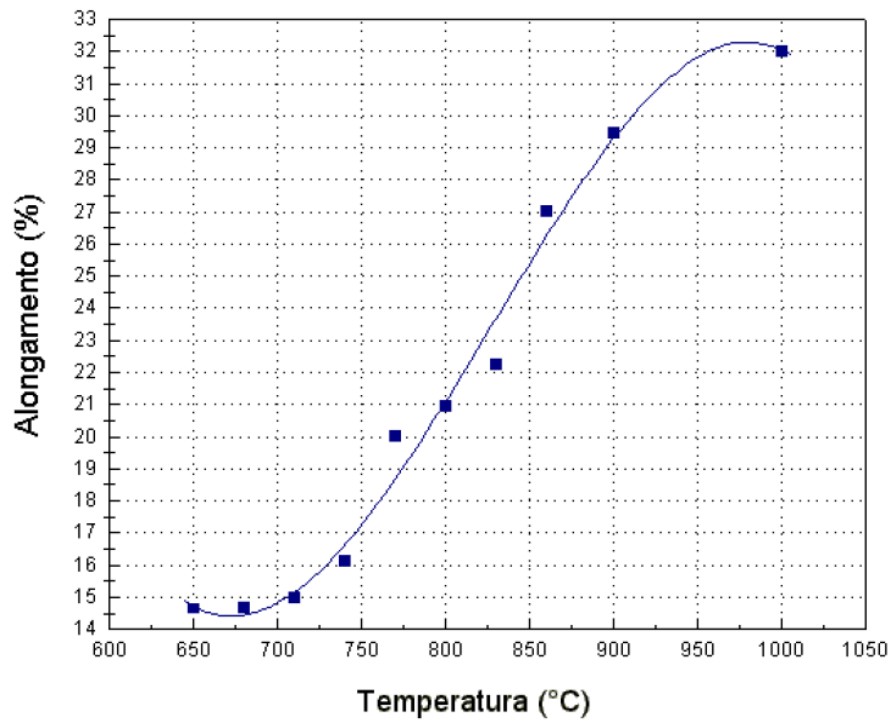

- Tensão vs. deformação

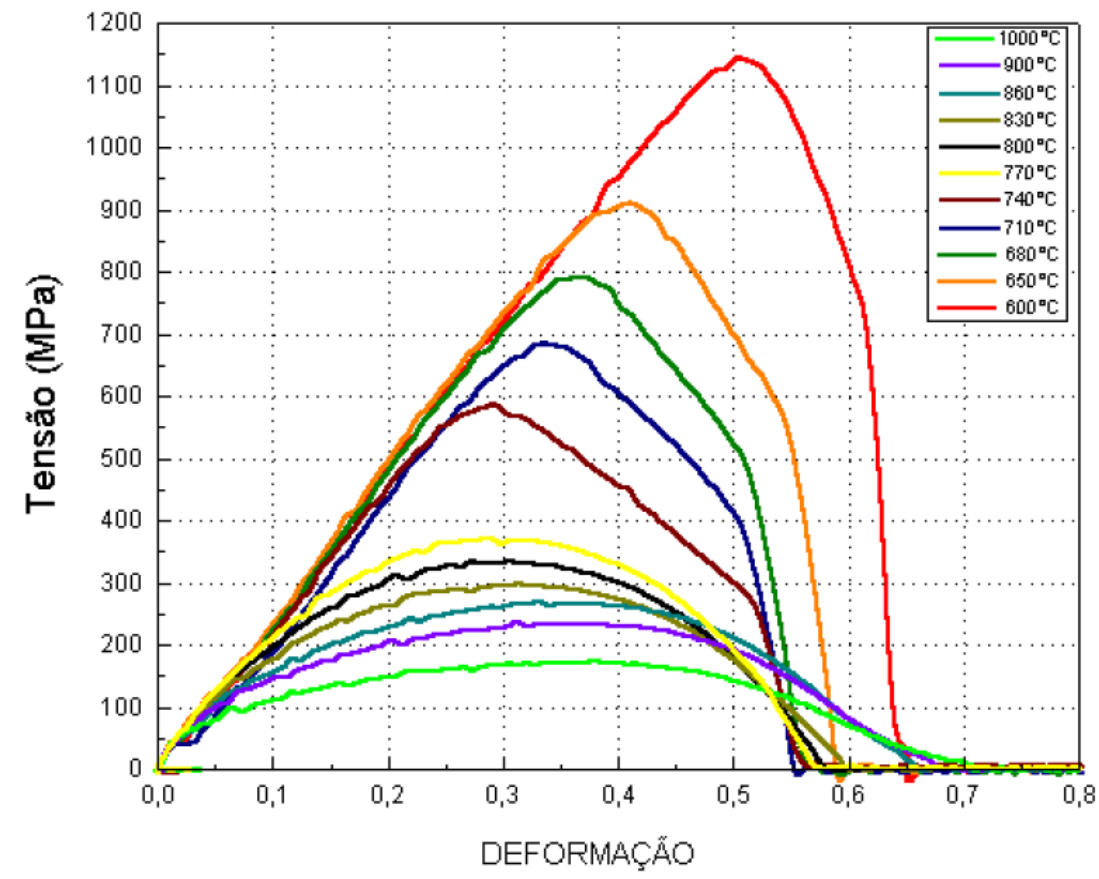

- Propriedades

$\rho_{\text {mat }}($ densidade do material $)=7850 \mathrm{~kg} / \mathrm{m}^{3}$

$\lambda_{\text {mat }}($ condutividade térmica do material $)=52,9 \mathrm{~W} / \mathrm{mK}$ 
$C p_{\text {mat }}$ (calor específico do material à $\left.25^{\circ} \mathrm{C}\right)=465 \mathrm{~J} / \mathrm{kgK}$

$\xi_{\text {mat }}($ difusividade térmica do material $)=0,0000144 \mathrm{~m}^{2} / \mathrm{s}$

$v_{\text {mat }}($ coeficiente de Poisson do material $)=0,32$

ANEXO B - Propriedades mecânicas do cilindro de trabalho do Laminador \#1.

- Material: ferro fundido com conquilhamento indefinido e núcleo nodular (Indefinite Chill Double Poured)

- Processo de Fundição: centrifugado bimetálico

- Tratamento Térmico: Alívio de tensões

- Composição química (unidade de medida em \%):

\begin{tabular}{|l|c|c|c|c|c|c|c|c|}
\cline { 2 - 8 } \multicolumn{1}{c|}{} & C & Si & Mn & Ni & Cr & Mo & P & S \\
\hline Mín & 3,200 & 0,650 & 0,430 & 3,390 & 1,600 & 0,100 & - & - \\
\hline Máx & 3,500 & 1,050 & 0,720 & 4,200 & 2,000 & 0,450 & 0,100 & 0,05 \\
\hline
\end{tabular}

- Propriedades:

Dureza Rockwell C $=60$

$\sigma_{r}$ (limite de resistência $)=425 \mathrm{MPa}$

$\sigma_{r c}($ limite de resistência a compressão $)=2200 \mathrm{MPa}$

$\sigma_{r f}$ (limite de resistência a flexão) $=600 \mathrm{MPa}$

$E_{\text {cil }}($ módulo de elasticidade do cilindro $)=180 \mathrm{GPa}$

$\rho_{\text {cil }}($ densidade do cilindro $)=7450 \mathrm{~kg} / \mathrm{m}^{3}$

$\lambda_{\text {cil }}$ (condutividade térmica do cilindro) $=23,5 \mathrm{~W} / \mathrm{mK}$

$C p_{c i l}$ (calor específico do cilindro à $\left.25^{\circ} \mathrm{C}\right)=470 \mathrm{~J} / \mathrm{kgK}$

$\xi_{c i l}\left(\right.$ difusividade térmica do cilindro) $=0,0000067 \mathrm{~m}^{2} / \mathrm{s}$

$\gamma_{\text {cil }}($ coeficiente de expansão térmica do cilindro $)=0,00001451 / \mathrm{K}$

$v_{\text {cil }}($ coeficiente de Poisson do cilindro $)=0,27$ 
ANEXO C - Propriedades mecânicas do cilindro de trabalho dos Laminadores \#2 e \#3.

- Material: ferro fundido baianítico

- Processo de Fundição: convencional estático monometálico

- Tratamento Térmico: Austêmpera e revenimento

- Composição química (unidade de medida em \%):

\begin{tabular}{|l|c|c|c|c|c|c|c|c|}
\cline { 2 - 8 } \multicolumn{1}{c|}{} & C & Si & Mn & Ni & Cr & Mo & P & S \\
\hline Mín & 3,100 & 1,600 & 0,400 & 1,900 & - & 0,200 & - & - \\
\hline Máx & 3,500 & 2,200 & 0,900 & 2,500 & 0,200 & 1,000 & 0,090 & 0,025 \\
\hline
\end{tabular}

- Propriedades:

Dureza Rockwell C $=48$

$\sigma_{r}$ (limite de resistência) $=725 \mathrm{MPa}$

$E_{\text {cil }}$ (módulo de elasticidade do cilindro) $=165 \mathrm{GPa}$

$\lambda_{\text {cil }}$ (condutividade térmica do cilindro) $=21 \mathrm{~W} / \mathrm{mK}$

$C p_{\text {cil }}$ (calor específico do cilindro à $\left.25^{\circ} \mathrm{C}\right)=460 \mathrm{~J} / \mathrm{kgK}$

$\gamma_{\text {cil }}$ (coeficiente de expansão térmica do cilindro) $=0,00001041 / \mathrm{K}$

ANEXO D - Especificação do termômetro infravermelho utilizado nas medições de temperatura do material durante o processo de laminação:

Faixa de medição: $250^{\circ} \mathrm{C}$ a $1600^{\circ} \mathrm{C}$

Campo de Visão: 200:1

Tipo de detector: comprimento de onda curto $1.6 \mu \mathrm{m}$

Display: local com transmissão de imagem

Configuração: local ou remota através de navegador WEB

Visualização de Imagem: local ou remota através de navegador WEB

Faixa do foco: $300 \mathrm{~mm}$ a infinito com ajuste local ou remoto

Mira LED: verde de alta intensidade intermitente 
Incerteza de medição: $0,25 \% \mathrm{~K}$ ou $2 \mathrm{~K}^{*}$

Repetibilidade: $<1^{\circ} \mathrm{C}$

Resolução: $0,1^{\circ} \mathrm{C}$

Ruído: $<0,5^{\circ} \mathrm{C}$ RMS (5\% a 95\% da faixa de medição)

Proteção: IP65

Tempo de resposta: ajustável de $1 \mathrm{~ms}$ a $10 \mathrm{~s}$

Interfaces Analógicas: 0 ... $20 \mathrm{~mA}$ ou 4 ... $20 \mathrm{~mA}$

Interfaces Digitais: comando entrada, comando saída

Comunicação: Ethernet (TCP-IP, Modbus TCP, http, udp e TCMP)

Funções de Processamento: pico, vale, média, "modemaster"

Alimentação: 24Vcc incluindo PoE (Power Over Ethernet)

Temperatura Ambiente: $0^{\circ} \mathrm{C}$ a $70^{\circ} \mathrm{C}$ (especificado $5^{\circ} \mathrm{C}$ a $60^{\circ} \mathrm{C}$ )

ANEXO E - Resultados estatísticos do experimento realizado no IPT utilizando-se o software estatístico Minitab versão 17.0.

\section{$15 / 12 / 2016$ 20:00:00}

Welcome to Minitab, press F1 for help.

\section{Full Factorial Design}

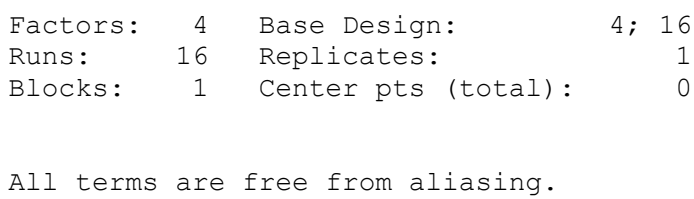

Factorial Regression: Temperatura versus Tratamento S; Rotação (rpm; Temperatura ; ...

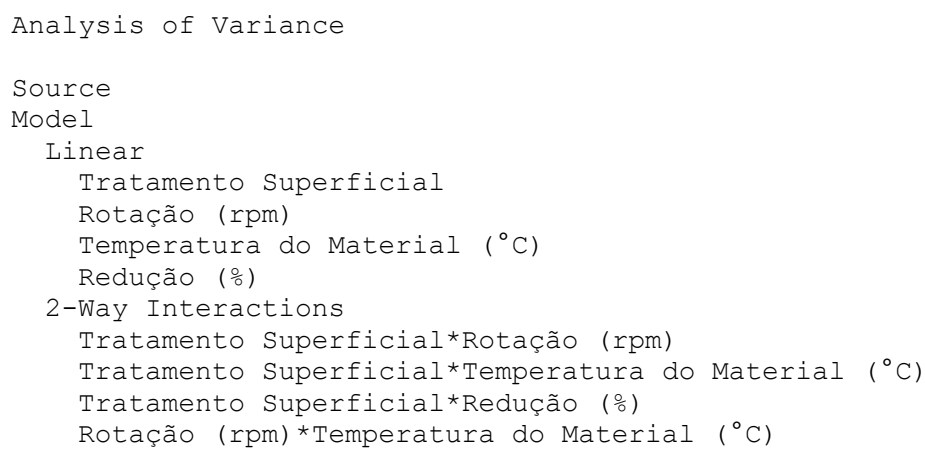




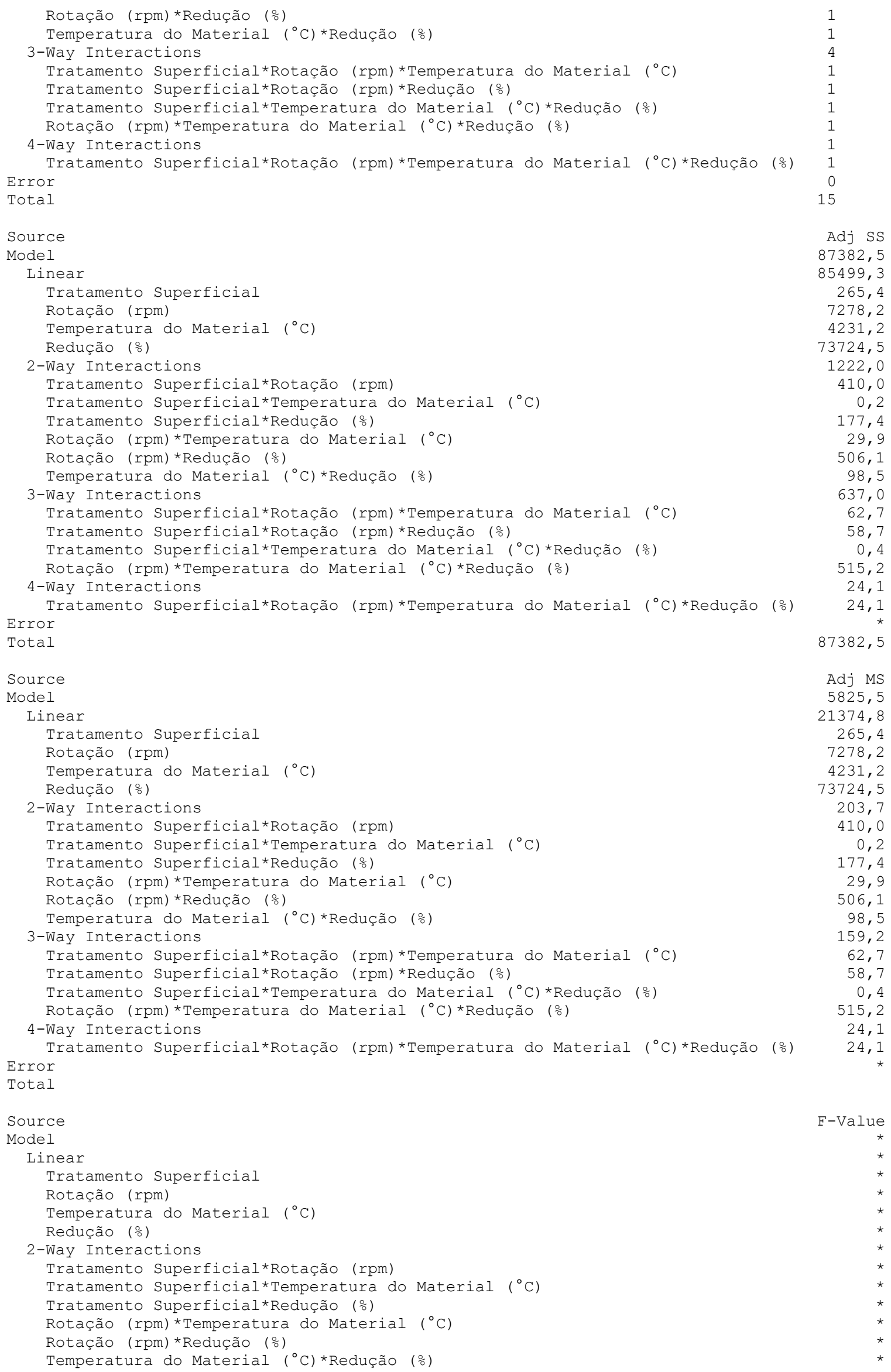


3-Way Interactions

Tratamento Superficial*Rotação (rpm)*Temperatura do Material $\left({ }^{\circ} \mathrm{C}\right)$

Tratamento Superficial*Rotação (rpm)*Redução (

Tratamento Superficial*Temperatura do Material $\left({ }^{\circ} \mathrm{C}\right){ }^{*}$ Redução (\%)

Rotação (rpm)*Temperatura do Material $\left({ }^{\circ} \mathrm{C}\right){ }^{*}$ Redução (\%)

4-Way Interactions

Tratamento Superficial*Rotação (rpm)*Temperatura do Material ( $\left.{ }^{\circ} \mathrm{C}\right){ }^{*}$ Redução (응 Error

Total

Source

Model

Linear

Tratamento Superficial

Rotação (rpm)

Temperatura do Material $\left({ }^{\circ} \mathrm{C}\right)$

Redução (\%)

2-Way Interactions

Tratamento Superficial*Rotação (rpm)

Tratamento Superficial*Temperatura do Material $\left({ }^{\circ} \mathrm{C}\right)$

Tratamento Superficial*Redução (

Rotação (rpm)*Temperatura do Material $\left({ }^{\circ} \mathrm{C}\right)$

Rotação (rpm)*Redução (\%)

Temperatura do Material $\left({ }^{\circ} \mathrm{C}\right)$ * Redução (\%)

3-Way Interactions

Tratamento Superficial*Rotação (rpm)*Temperatura do Material $\left({ }^{\circ} \mathrm{C}\right)$

Tratamento Superficial*Rotação ( $r \mathrm{pm})$ *Redução (

Tratamento Superficial*Temperatura do Material $\left({ }^{\circ} \mathrm{C}\right){ }^{*}$ Redução (\%)

Rotação (rpm) *Temperatura do Material $\left({ }^{\circ} \mathrm{C}\right)$ *Redução (\%)

4-Way Interactions

Tratamento Superficial*Rotação (rpm)*Temperatura do Material ( $\left.{ }^{\circ} \mathrm{C}\right)$ *Redução ( ${ }^{\circ}$ ) Error

Total

Model Summary

S R-sq R-sq(adj) R-sq(pred)

* $100,00 \%$

Coded Coefficients

Term

Effect

Constant

Tratamento Superficial

8,146

Rotação (rpm)

Temperatura do Material $\left({ }^{\circ} \mathrm{C}\right) \quad 32,52$

Redução (\%) 135,76

Tratamento Superficial*Rotação (rpm) -10,124

Tratamento Superficial*Temperatura do Material ( $\left.{ }^{\circ} \mathrm{C}\right) \quad 0,2312$

Tratamento Superficial*Redução (\%) 6,659

Rotação (rpm) *Temperatura do Material ( $\left.{ }^{\circ} \mathrm{C}\right) \quad 2,734$

Rotação (rpm)*Redução (\%) -11, 249

Temperatura do Material $\left({ }^{\circ} \mathrm{C}\right) *$ Redução (응 4,961

Tratamento Superficial*Rotação (rpm)*Temperatura do Material ( $\left.{ }^{\circ} \mathrm{C}\right) \quad-3,959$

Tratamento Superficial*Rotação (rpm)*Redução (\%) -3,831

Tratamento Superficial*Temperatura do Material ( $\left.{ }^{\circ} \mathrm{C}\right){ }^{*}$ Redução ( $\left.{ }^{\circ}\right) \quad 0,3238$

Rotação (rpm)*Temperatura do Material $\left({ }^{\circ} \mathrm{C}\right){ }^{*}$ Redução (\%) -11, 349

Tratamento Superficial*Rotação (rpm)*Temperatura do Material ( $\left.{ }^{\circ} \mathrm{C}\right) *$ Redução ( $\%$ ) -2, 456

Term

Constant

Tratamento Superficial

Rotação (rpm)

Temperatura do Material $\left({ }^{\circ} \mathrm{C}\right)$

Redução (\%)

Tratamento Superficial*Rotação (rpm)

Tratamento Superficial*Temperatura do Material $\left({ }^{\circ} \mathrm{C}\right)$

Tratamento Superficial*Redução (\%)

Rotação (rpm)*Temperatura do Material $\left({ }^{\circ} \mathrm{C}\right)$

Rotação (rpm)*Redução (\%) 
Temperatura do Material $\left({ }^{\circ} \mathrm{C}\right){ }^{*}$ Redução ( $\left.\%\right)$

Tratamento Superficial*Rotação (rpm)*Temperatura do Material $\left({ }^{\circ} \mathrm{C}\right) \quad-1,979$

Tratamento Superficial*Rotação (rpm)*Redução (\%)

Tratamento Superficial*Temperatura do Material $\left({ }^{\circ} \mathrm{C}\right){ }^{*}$ Redução ( $\left.\frac{\circ}{0}\right)$

Rotação (rpm)*Temperatura do Material $\left({ }^{\circ} \mathrm{C}\right) *$ Redução (\%)

0,1619

$-5,674$

Tratamento Superficial*Rotação (rpm)*Temperatura do

terial $\left({ }^{\circ} \mathrm{C}\right) *$ Redução $\left({ }^{\circ}\right)$

Term

Constant

Tratamento Superficial

Rotação (rpm)

Temperatura do Material $\left({ }^{\circ} \mathrm{C}\right)$

Redução (\%)

Tratamento Superficial*Rotação (rpm)

Tratamento Superficial*Temperatura do Material $\left({ }^{\circ} \mathrm{C}\right)$

Tratamento Superficial*Redução (\%)

Rotação (rpm)*Temperatura do Material $\left({ }^{\circ} \mathrm{C}\right)$

Rotação (rpm)*Redução (\%)

Temperatura do Material $\left({ }^{\circ} \mathrm{C}\right)$ *Redução (\%)

Tratamento Superficial*Rotação (rpm)*Temperatura do Material $\left({ }^{\circ} \mathrm{C}\right)$

Tratamento Superficial*Rotação (rpm)*Redução (\%)

Tratamento Superficial*Temperatura do Material ( $\left.{ }^{\circ} \mathrm{C}\right){ }^{*}$ Redução (\%)

Rotação (rpm)*Temperatura do Material $\left({ }^{\circ} \mathrm{C}\right){ }^{*}$ Redução (

Tratamento Superficial*Rotação ( $\mathrm{rpm}) *$ Temperatura do Material $\left({ }^{\circ} \mathrm{C}\right) *$ Redução

Term

Constant

Tratamento Superficial

Rotação (rpm)

Temperatura do Material $\left({ }^{\circ} \mathrm{C}\right)$

Redução (\%)

Tratamento Superficial*Rotação (rpm)

Tratamento Superficial*Temperatura do Material $\left({ }^{\circ} \mathrm{C}\right)$

Tratamento Superficial*Redução (\%)

Rotação (rpm)*Temperatura do Material $\left({ }^{\circ} \mathrm{C}\right)$

Rotação (rpm)*Redução (\%)

Temperatura do Material ( $\left.{ }^{\circ} \mathrm{C}\right) *$ Redução (\%)

Tratamento Superficial*Rotação ( $\mathrm{rpm}) *$ Temperatura do Material $\left({ }^{\circ} \mathrm{C}\right)$

Tratamento Superficial*Rotação (rpm)*Redução (\%)

Tratamento Superficial*Temperatura do Material ( $\left.{ }^{\circ} \mathrm{C}\right){ }^{*}$ Redução (\%)

Rotação (rpm)*Temperatura do Material $\left({ }^{\circ} \mathrm{C}\right){ }^{*}$ Redução $\left(\frac{\circ}{0}\right)$

Tratamento Superficial*Rotação (rpm) *Temperatura do Material ( $\left.{ }^{\circ} \mathrm{C}\right)$ *Redução ( $\left.{ }^{\circ}\right)$

T-Value

*

Regression Equation in Uncoded Units

Temperatura Superficial $\left({ }^{\circ} \mathrm{C}\right)=417,7+44,62$ Tratamento Superficial - 12,99 Rotação (rpm)

- 0,4381 Temperatura do Material ( $\left.{ }^{\circ} \mathrm{C}\right)$ - 20,65 Redução (\%)

- 1,129 Tratamento Superficial*Rotação (rpm)

- 0,05250 Tratamento Superficial*Temperatura do Material $\left({ }^{\circ} \mathrm{C}\right)$

- 5,591 Tratamento Superficial*Redução (\%)

$+0,01268$ Rotação (rpm)*Temperatura do Material $\left({ }^{\circ} \mathrm{C}\right)$

$+0,7051$ Rotação (rpm) *Redução (\%)

$+0,03744$ Temperatura do Material $\left({ }^{\circ} \mathrm{C}\right) *$ Redução (\%)

+ 0,001176 Tratamento Superficial*Rotação (rpm)

* Temperatura do Material $\left({ }^{\circ} \mathrm{C}\right)$

+ 0,1430 Tratamento Superficial*Rotação (rpm)*Redução (\%)

$+0,007354$ Tratamento Superficial*Temperatura do Material $\left({ }^{\circ} \mathrm{C}\right)$

*Redução (\%) - 0,000783 Rotação (rpm)

*Temperatura do Material $\left({ }^{\circ} \mathrm{C}\right){ }^{*}$ Redução (\%)

- 0,000169 Tratamento Superficial*Rotação (rpm)

*Temperatura do Material $\left({ }^{\circ} \mathrm{C}\right){ }^{*}$ Redução ( $\left.{ }^{\circ}\right)$

Alias Structure

Factor Name

A Tratamento Superficial

B Rotação (rpm)

C Temperatura do Material $\left({ }^{\circ} \mathrm{C}\right)$

D Redução (\%) 
ANEXO F - Resultados estatísticos utilizando-se a hipótese de um incremento de $300{ }^{\circ} \mathrm{C}$ na temperatura medida pelos termopares durante o experimento do IPT, utilizando-se o software estatístico Minitab versão 17.0.

\section{5/08/2018 09:05:42}

Welcome to Minitab, press Fl for help.

Retrieving project from file: ' \\lanmczp03\groups \LAM LAMINAÇÃO LB. TRIO E

LF \CONFIDENCIAL \Doutorado Engenharia Mecânica\Desenvolvimento do

Trabalho\Informações IPT \Experimento DOE IPT \DOE IPT Oficial.MPJ

\section{Factorial Regression: Temperatura versus Tratamento S; Rotação (rpm; Temperatura ;} $\cdots$

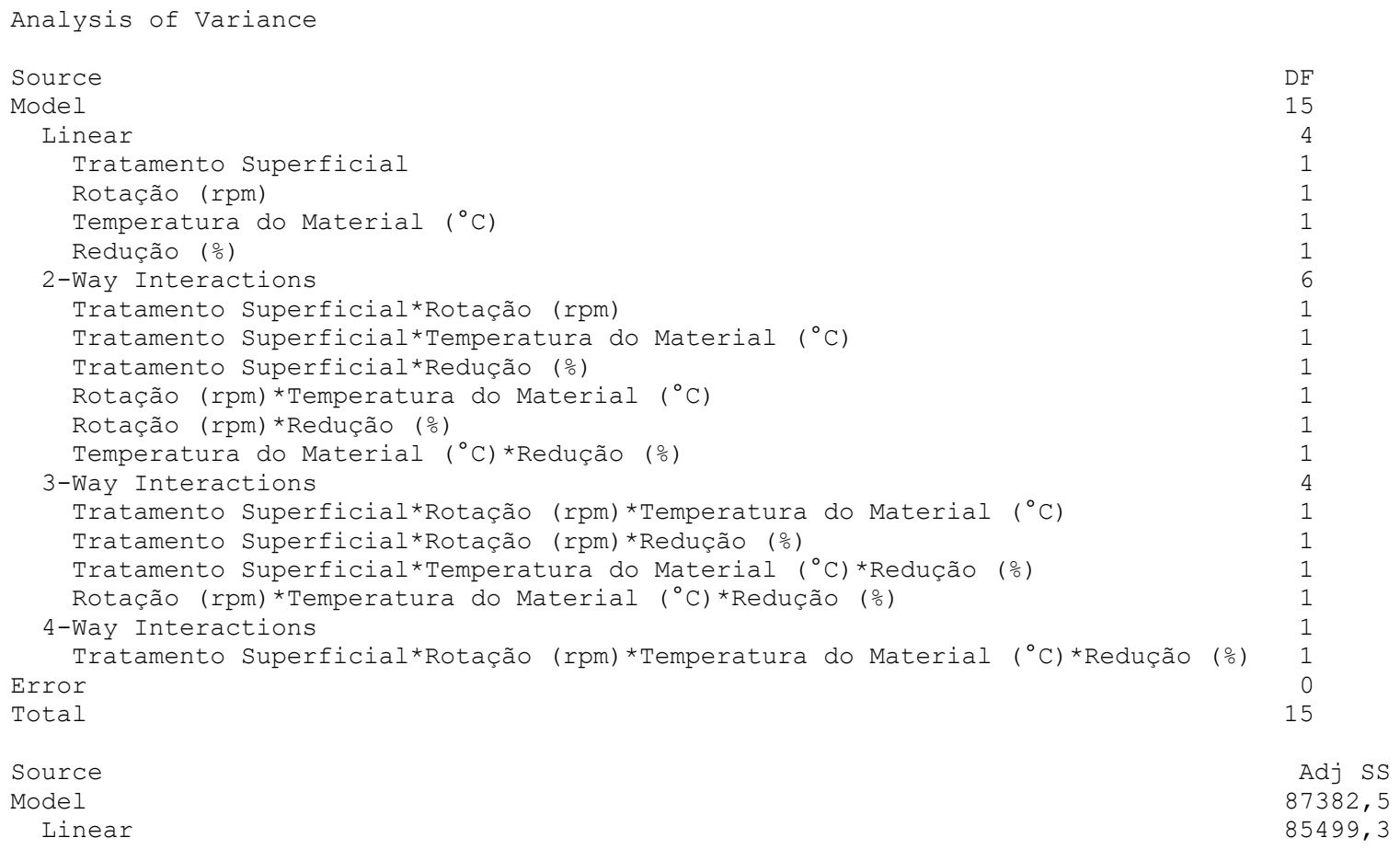




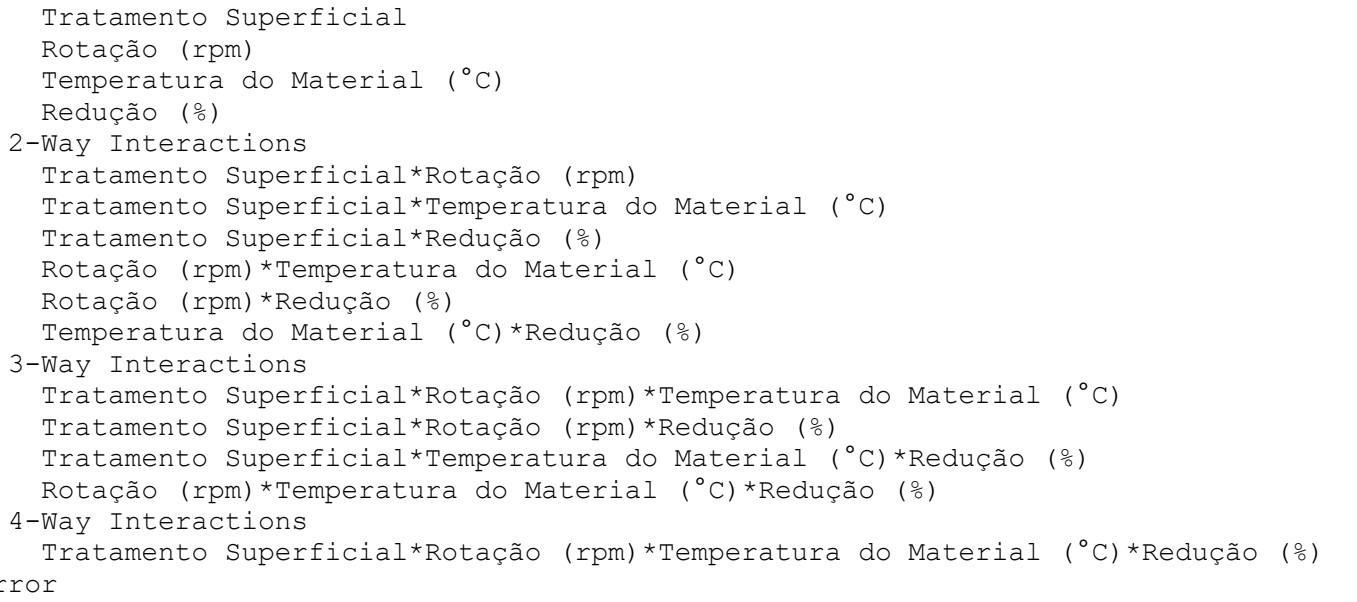


Temperatura do Material $\left({ }^{\circ} \mathrm{C}\right)$

Redução (\%)

2-Way Interactions

Tratamento Superficial*Rotação (rpm)

Tratamento Superficial*Temperatura do Material $\left({ }^{\circ} \mathrm{C}\right)$

Tratamento Superficial*Redução (\%)

Rotação (rpm)*Temperatura do Material $\left({ }^{\circ} \mathrm{C}\right)$

Rotação (rpm) *Redução (\%)

Temperatura do Material $\left({ }^{\circ} \mathrm{C}\right)$ *Redução (\%)

3-Way Interactions

Tratamento Superficial*Rotação (rpm)*Temperatura do Material $\left({ }^{\circ} \mathrm{C}\right)$

Tratamento Superficial*Rotação (rpm)*Redução (\%)

Tratamento Superficial*Temperatura do Material ( $\left.{ }^{\circ} \mathrm{C}\right){ }^{*}$ Redução (\%)

Rotação (rpm)*Temperatura do Material $\left({ }^{\circ} \mathrm{C}\right) *$ Redução (\%)

4-Way Interactions Error

Tratamento Superficial*Rotação (rpm)*Temperatura do Material ( $\left.{ }^{\circ} \mathrm{C}\right){ }^{*}$ Redução (응

Total

Model Summary

$\begin{array}{lrrr}\mathrm{S} & \mathrm{R}-\mathrm{sq} & \mathrm{R}-\mathrm{sq}(\mathrm{adj}) & \mathrm{R}-\mathrm{sq} \text { (pred) }\end{array}$

Coded Coefficients

Term

Effect

Constant

Tratamento Superficial

8,146

Rotação (rpm)

$-42,66$

Temperatura do Material $\left({ }^{\circ} \mathrm{C}\right)$

32,52

Redução (\%)

135,76

Tratamento Superficial*Rotação (rpm)

$-10,124$

Tratamento Superficial*Temperatura do Material $\left({ }^{\circ} \mathrm{C}\right)$

0,2313

Tratamento Superficial*Redução (\%)

6,659

Rotação (rpm)*Temperatura do Material $\left({ }^{\circ} \mathrm{C}\right)$

2,734

Rotação (rpm)*Redução (\%)

Temperatura do Material $\left({ }^{\circ} \mathrm{C}\right)$ *Redução (\%)

$-11,249$

4,961

$\begin{array}{llllll}\text { Tratamento Superficial*Rotação } & (\mathrm{rpm}) * \text { Temperatura do Material }\left({ }^{\circ} \mathrm{C}\right) & -3,959 \\ \text { Tratamento Superficial*Rotação } & \text { (rpm)*Redução (\%) } & -3,831\end{array}$

Tratamento Superficial*Temperatura do Material ( $\left.{ }^{\circ} \mathrm{C}\right) *$ Redução (\%) 0,3237

Rotação (rpm)*Temperatura do Material $\left({ }^{\circ} \mathrm{C}\right){ }^{*}$ Redução ( $\left.\%\right)$

Tratamento Superficial*Rotação (rpm)*Temperatura do Material ( $\left.{ }^{\circ} \mathrm{C}\right)$ *Redução ( $\left.{ }^{\circ}\right) \quad-2,456$

Term

Constant

Coef Coef

Tratamento Superficial

470,5

4,073

Rotação (rpm)

Temperatura do Material $\left({ }^{\circ} \mathrm{C}\right)$

$-21,33$

16,26

67,88

Redução (\%)

Tratamento Superficial*Rotação (rpm)

Tratamento Superficial*Temperatura do Material $\left({ }^{\circ} \mathrm{C}\right)$

$-5,062$

0,1156

3,329

1,367

Rotação (rpm)*Temperatura do Material $\left({ }^{\circ} \mathrm{C}\right.$

$-5,624$

2,481

Temperatura do Material $\left({ }^{\circ} \mathrm{C}\right){ }^{*}$ Redução (\%)

Tratamento Superficial*Rotação (rpm)*Temperatura do Material $\left({ }^{\circ} \mathrm{C}\right)$

$-1,979$

Tratamento Superficial*Rotação (rpm)*Redução (\%)

$-1,916$

0,1619

$-5,674$

Rotação (rpm)*Temperatura do Material $\left({ }^{\circ} \mathrm{C}\right){ }^{*}$ Redução (\%)

$-1,228$

Term

T-Value

Constant

Tratamento Superficial

Rotação (rpm)

Temperatura do Material $\left({ }^{\circ} \mathrm{C}\right)$

Redução (\%)

Tratamento Superficial*Rotação (rpm) 
Tratamento Superficial*Temperatura do Material $\left({ }^{\circ} \mathrm{C}\right)$

Tratamento Superficial*Redução (\%)

Rotação (rpm)*Temperatura do Material $\left({ }^{\circ} \mathrm{C}\right)$

Rotação (rpm)*Redução (\%)

Temperatura do Material $\left({ }^{\circ} \mathrm{C}\right)$ *Redução (\%)

Tratamento Superficial*Rotação (rpm)*Temperatura do Material ( ${ }^{\circ} \mathrm{C}$ )

Tratamento Superficial*Rotação (rpm)*Redução (\%)

Tratamento Superficial*Temperatura do Material ( $\left.{ }^{\circ} \mathrm{C}\right){ }^{\star}$ Redução ( $\left.{ }^{\circ}\right)$

Rotação (rpm)*Temperatura do Material $\left({ }^{\circ} \mathrm{C}\right){ }^{*}$ Redução (\%)

Tratamento Superficial*Rotação (rpm)*Temperatura do Material ( $\left.{ }^{\circ} \mathrm{C}\right){ }^{*}$ Redução (\%)

Term

Constant

Tratamento Superficial

Rotação (rpm)

Temperatura do Material $\left({ }^{\circ} \mathrm{C}\right)$

Redução (\%)

Tratamento Superficial*Rotação (rpm)

Tratamento Superficial*Temperatura do Material $\left({ }^{\circ} \mathrm{C}\right)$

Tratamento Superficial*Redução (\%)

Rotação (rpm)*Temperatura do Material $\left({ }^{\circ} \mathrm{C}\right)$

Rotação (rpm)*Redução (\%)

Temperatura do Material $\left({ }^{\circ} \mathrm{C}\right) *$ Redução (\%)

Tratamento Superficial*Rotação (rpm)*Temperatura do Material $\left({ }^{\circ} \mathrm{C}\right)$

Tratamento Superficial*Rotação (rpm)*Redução (\%)

Tratamento Superficial*Temperatura do Material ( $\left.{ }^{\circ} \mathrm{C}\right){ }^{*}$ Redução ( $\left.{ }^{\circ}\right)$

Rotação (rpm)*Temperatura do Material $\left({ }^{\circ} \mathrm{C}\right){ }^{*}$ Redução (\%)

Tratamento Superficial*Rotação (rpm)*Temperatura do Material $\left({ }^{\circ} \mathrm{C}\right){ }^{*}$ Reducáo $\left({ }^{\circ}\right)$

P-Value VIF

* 1,00

* 1,00

$\star \quad 1,00$

* 1,00

* 1,00

* 1,00

* 1,00

* 1,00

* 1,00

* 1,00

$\star \quad 1,00$

* 1,00

* 1,00

* 1,00

( Redução (\%)

* 1,00

Regression Equation in Uncoded Units

Temperatura Superficial $\left({ }^{\circ} \mathrm{C}\right)=717,7+44,62$ Tratamento Superficial - 12,99 Rotação (rpm)

- 0,4381 Temperatura do Material $\left({ }^{\circ} \mathrm{C}\right)$ - 20,65 Redução (\%)

- 1,129 Tratamento Superficial*Rotação (rpm)

- 0,05250 Tratamento Superficial*Temperatura do Material $\left({ }^{\circ} \mathrm{C}\right)$

- 5,591 Tratamento Superficial*Redução (\%)

$+0,01268$ Rotação (rpm) * Temperatura do Material $\left({ }^{\circ} \mathrm{C}\right)$

$+0,7051$ Rotação (rpm)*Redução (\%)

$+0,03744$ Temperatura do Material $\left({ }^{\circ} \mathrm{C}\right)$ *Redução (\%)

+ 0,001176 Tratamento Superficial*Rotação (rpm)

* Temperatura do Material $\left({ }^{\circ} \mathrm{C}\right)$

+ 0,1430 Tratamento Superficial*Rotação (rpm)*Redução (\%)

$+0,007354$ Tratamento Superficial*Temperatura do Material ( $\left.{ }^{\circ} \mathrm{C}\right)$

*Redução (\%) - 0,000783 Rotação (rpm)

*Temperatura do Material $\left({ }^{\circ} \mathrm{C}\right)$ *Redução (\%)

- 0,000169 Tratamento Superficial*Rotação (rpm)

*Temperatura do Material ( $\left.{ }^{\circ} \mathrm{C}\right){ }^{*}$ Redução (\%)

Alias structure

Factor Name

A Tratamento Superficial

B Rotação (rpm)

C Temperatura do Material $\left({ }^{\circ} \mathrm{C}\right)$

D Redução (\%) 
- Gráfico de Pareto dos efeitos para a temperatura superficial do cilindro considerando-se $\mathrm{X}+300{ }^{\circ} \mathrm{C}$

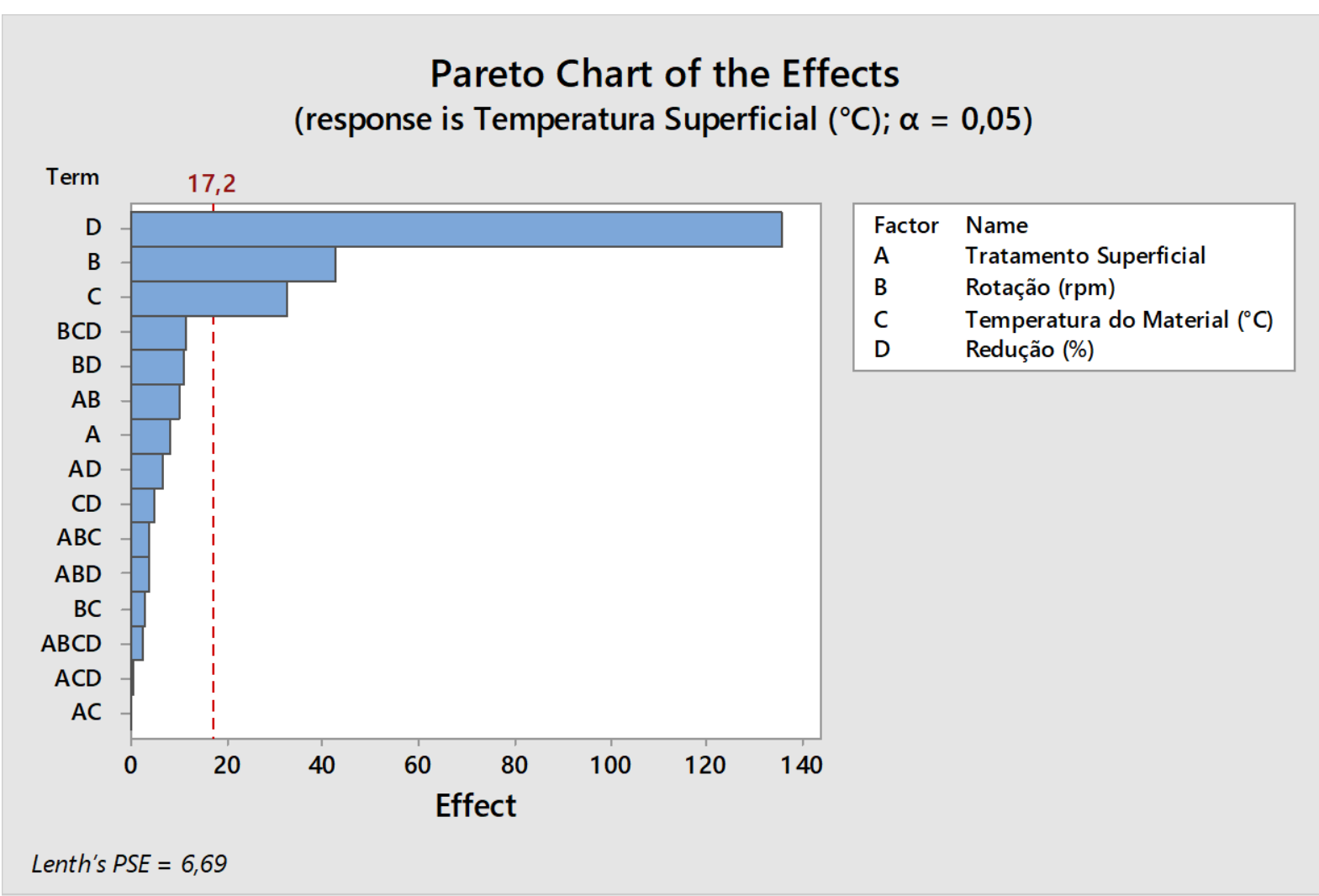

- Gráfico dos efeitos principais para a temperatura superficial do cilindro considerando-se $\mathrm{X}+300{ }^{\circ} \mathrm{C}$ 


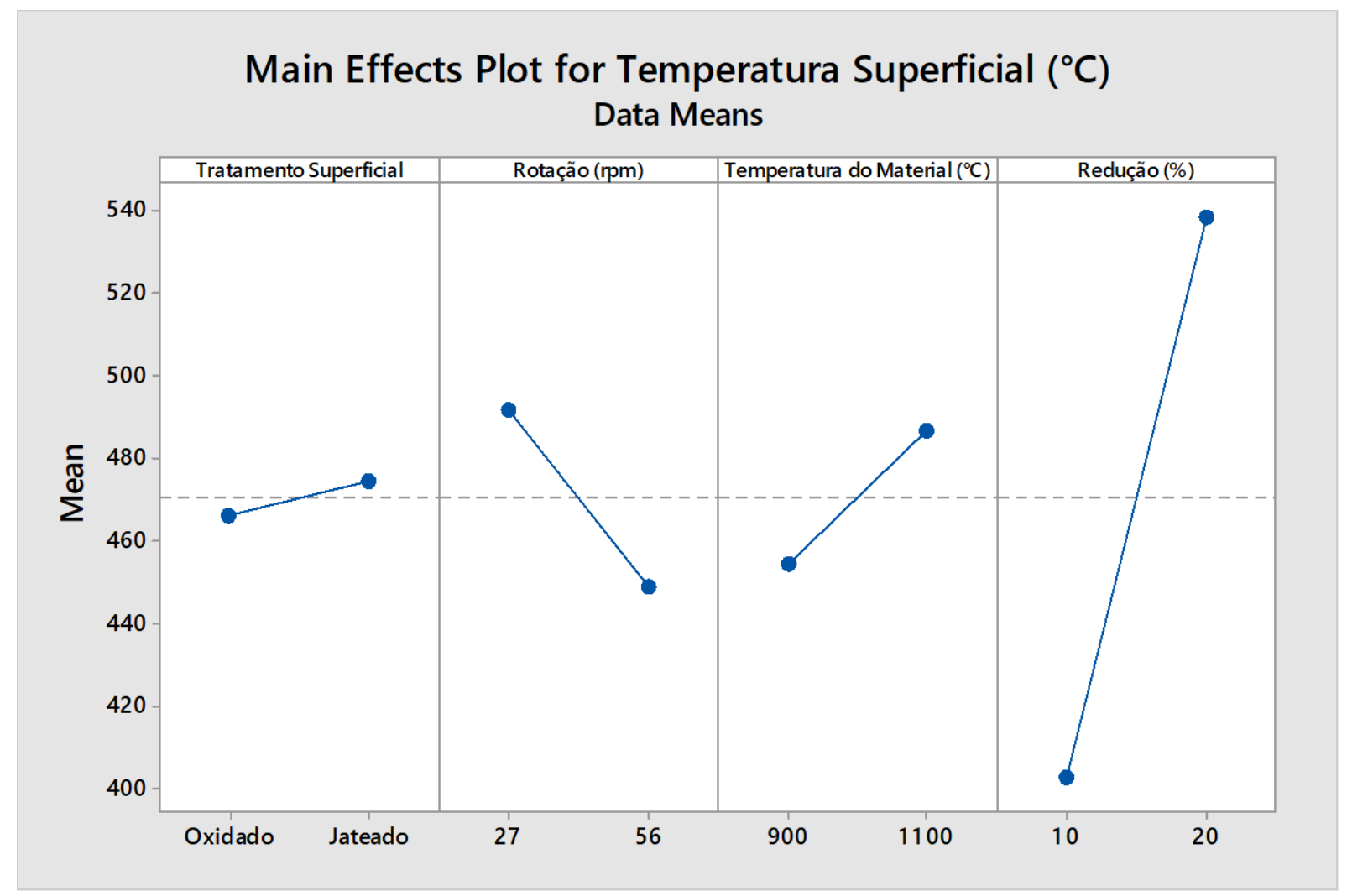

- Gráfico de interações para a temperatura superficial do cilindro considerando-se $\mathrm{X}+300{ }^{\circ} \mathrm{C}$

\section{Interaction Plot for Temperatura Superficial $\left({ }^{\circ} \mathrm{C}\right)$ \\ Data Means}

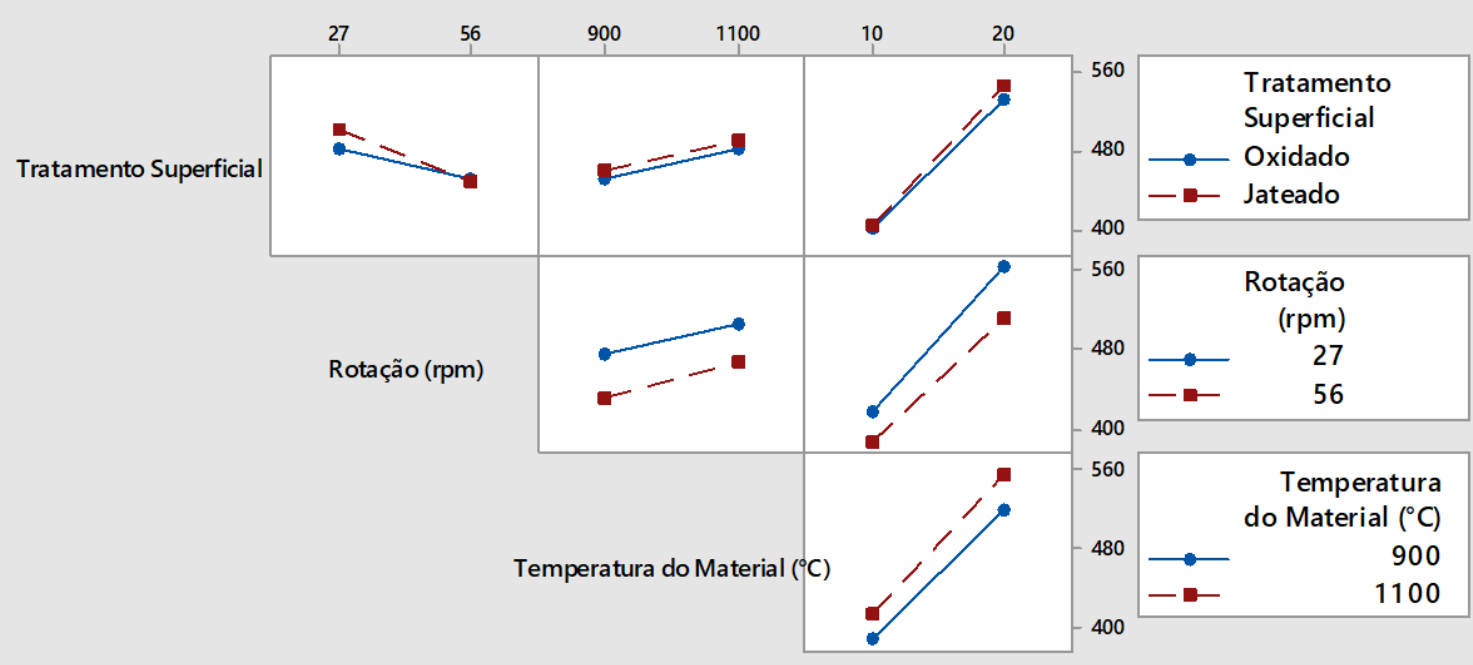

Redução (\%) 